\title{
A associação de abelhas silvestres de um biótopo urbano de Curitiba (Brasil), com comparações espaço-temporais: abundância relativa, fenologia, diversidade e explotação de recursos (Hymenoptera, Apoidea) ${ }^{1}$

\author{
The assemblage of wild bees \\ of an urban biotope of Curitiba (Brazil), \\ with spatio-temporal comparations: relative abundance, \\ diversity, phenology and exploitation of resources \\ (Hymenoptera, Apoidea) ${ }^{1}$
}

\section{Hilda Massako Taura ${ }^{2}$ \\ Sebastião Laroca ${ }^{3}$}

As abelhas (Hymenoptera, Apoidea) estão representadas por aproximadamente 20.000 espécies descritas, dispostas sociologicamente segundo um contínuo, que vai desde solitárias até as altamente sociais (ver Michener, 1969, 1974). A alta diversidade específica de Halictidae e a dominância de Apidae em indivíduos é uma característica disseminada nas várias melissocenoses do mundo. Na região holártica, em grande parte das associações locais de abelhas, verifica-se também elevada diversidade de Andrenidae, enquanto que de Colletidae nas melissocenoses australianas (ver MichenER, 1965, 1979; SAKAGAMI, LAROCA \& Moure, 1967; Laroca, 1972, 1983; SaKagami, FuKuda, 1973).

Os estudos quantitativos envolvendo comunidades de abelhas visando obter informações sobre a abundância relativa, composição faunística, fenologia e relações tróficas em um dado local, foram iniciados por Sakagami e Laroca, que desenvolveram um método de amostragem es-

\footnotetext{
${ }^{1}$ Contribuição ${ }^{\circ} \quad$ do Departamento de Zoologia, SCB, Universidade Federal do Paraná Caixa Postal 19020 - 81531-990 Curitiba, Paraná, Brasil. ${ }^{2}$ Estudante do Curso de PósGraduação (Doutorado), ${ }^{3}$.Professor Sênior da UFPR e Pesquisador do CNPQ (Proc. 300178/ 88-3), Email: slaroca@ netpar.com.br.
} 
pecífico para tal fim (LAROCA, 1972). Estes estudos foram continuados, especialmente, no norte do Japão por Sakagami e colaboradores e, no estado do Paraná, por Laroca e seus alunos. Com o acúmulo de informações quantitativas e qualitativas, torna-se possível estruturar o conhecimento sobre as associações de abelhas, relações com as flores, riqueza de espécies, abundância relativa e distribuição geográfica.

No Paraná, os censos foram realizados nas seguintes regiões: em uma área restrita nas proximidades do aeroporto Afonso Pena (São José dos Pinhais); em Alexandra (Paranaguá), em Boa Vista (um subúrbio de Curitiba); no Passeio Público (Curitiba); no Parque da Cidade (Curitiba); em São José dos Pinhais, com análise comparativa entre os levantamentos de 1962/63 e 1981/82; na Ilha do Mel, em Morretes (litoral); na Reserva Passa Dois (Lapa); na Ilha das Cobras; no Parque Estadual de Cerrado e na fazenda Cachoeira (Jaguariaíva), em área restrita de floresta de araucária em Guará (Guarapuava); em Pato Branco. Os resultados parciais de tais censos encontram-se nas seguintes contribuições: Sakagami, Laroca \& Moure, 1967; Laroca, 1972; Laroca, Cure \& Bortoli, 1982; Cure, 1983; Bortoli \& Laroca, 1990; Taura, 1990; Zanella, 1991; Barbola, 1993; Schwartz, 1993; Laroca \& Almeida, 1994; BAZILIO, 1997 e JAMOHUR, 1998.

Diversos estudos também têm sido efetuados em outras localidades do País, como: em Caçador (Orth, 1983) e Lages (Santa Catarina) (Ortolan \& Laroca, 1996); em Ribeirão Preto (São Paulo) (CAmargo \& Mazucato, 1984); no Campus da Universidade de São Paulo (São Paulo) (KNoll, 1985); na reserva de Corumbataí (São Paulo) (CAmpos, 1989); na Estação de Paraopeba (Minas Gerais) (SILVeIRA, 1989); no cerrado de Cajuru (São Paulo) (Pedro \& Camargo, 1991); em Viçosa (Minas Gerais) (Cure et al., 1992); em Ponte Nova (Minas Gerais) (Silveira et al., 1993); Corumbataí (São Paulo) e Paraopeba (MG) (comparativo) (SIlveira \& CAmpos, 1995) e na Reserva Ecológica Panga (Uberlândia, Minas Gerais) (CARVAlHo \& Bego, 1996), além de outros.

As informações fornecidas pelos estudos citados anteriormente, referem-se de modo geral, à diversidade e abundância relativa de espécies de Apoidea, frequiência de visitas às flores, com indicações de possíveis preferências e fenologia de abelhas e plantas.

Entre os estudos biocenóticos realizados no Japão, merecem destaque os de Sakagami \& Fukuda (1973); Matsuda, Sakagami \& Fukuda (1974); Usui et al. (1976); Yamauchi, Okumura \& Sakagami (1976) e Uehira, AkahiRa \& Sakagami (1979). 
Nos demais países, levantamentos visando o conhecimento da composição faunística de abelhas também têm sido desenvolvidos, embora alguns sejam restritos a apresentação de listagens de abelhas e flores visitadas. Assim, citam-se os de: OsYChNyuK (1959), na Ucrânia; HAESELER (1972), Dorn (1977) e TsCHARnTKe (1984), na Alemanha; Constantinescu (1976), na Romênia; Pesenko (1978), na Rússia; Heithaus (1979 a, b, c), na Costa Rica; Mackay \& KNERER (1979), MACKENZIE \& Winston (1984) e SAKAGAMI \& Toda (1986), no Canadá; ORRes , GAYUbo \& AsEnsio (1989), na Espanha; Celary (1988, 1991), na polônia; Armbruster \& Guinn (1989), no Alasca; Marchal \& LeclercQ (1979) e Jacob-Remacle \& JaCoB (1990), na Bélgica.

Nos Estados Unidos, destacam-se os trabalhos de Pearson (1933) na região de Chicago; MoldenKe (1976), que realiza comparações entre a região da Califórnia e Chile; GinsBERG $(1981,1983)$, que analisa tendências de visita às flores por algumas espécies de Apoidea, de áreas localizadas em Nova York e LAROCA (1983), que aborda aspectos biocenóticos de três localidades de Lawrence, Kansas, comparando-os com dados obtidos no leste do Paraná, Brasil.

Investigações envolvendo uma família de Apoidea em especial, também têm sido realizadas. Assim, Sakagami \& Matsumura (1967), Matsumura \& Munakata (1969) e Munakata (1971) efetuaram estudos biocenóticos de Andrenidae; SAKAgami \& Laroca (1971 a) e Knoll (1990) de Apidae; SaKagami \& Laroca (1971 b) de Xylocopinae (Anthophoridae) e Pyke (1982) de Bombinae, Apidae.

As interações recentes entre as plantas com flores (Angiospermae) e seus polinizadores são freqüentemente interpretadas como sendo o resultado de uma longa e íntima relação coevolucionária (BAKER \& HURD, 1968; Price, 1975; Crepet, 1983). Os primeiros registros fósseis de angiospermas indicam o seu surgimento no Cretáceo Inferior, há cerca de 110 milhões de anos. Durante o Terciário, estas diversificaram-se e passaram a dominar a maioria das florestas do planeta, mantendo a sua dominância ecológica desde então (BAKER \& HURD, 1968). Conforme estes mesmos autores, a diversificação das angiospermas coincide com um aumento pronunciado na diversidade dos grupos de insetos (especialmente Coleoptera, Lepidoptera, Hymenoptera e Diptera), cuja ecologia está intimamente relacionada à dessas plantas. VAN DER PIJL $(1960,1961)$ acredita que as primeiras angiospermas eram polinizadas por insetos, mais do que pela ação do vento.

Atualmente, existem aproximadamente 250.000 espécies de angiospermas e uma grande parcela das espécies destas plantas, depen- 
de de insetos para polinização e reprodução (WILSON, 1994). Os Apoidea são considerados o grupo mais importante de insetos polinizadores (BAKER \& HuRd, 1968; FAEGRI \& VAN DER PIJL, 1979). Michener (1979), argumenta que não se observa uma estreita correlação entre o número de espécies de abelhas em uma área e o número de espécies de angiospermas, embora floras e faunas de abelhas não sejam independentes umas das outras.

As abelhas dependem de flores, principalmente como recursos de néctar e pólen, para a sua alimentação e também como provisão para a sua cria. São variáveis no que se refere ao grau de especialização para o forrageamento (Laroca, Michener \& Hofmeister, 1989). Por exemplo, determinadas abelhas (espécies poliléticas) buscam o pólen, em uma ampla variedade de plantas, enquanto outras (espécies oligoléticas) obtêm o pólen de apenas uma espécie ou então de um grupo de plantas morfologicamente similares ou botanicamente relacionadas (LINSLEY, 1958).

MichenER (1979), detalha a classificação das abelhas quanto ao hábito de coleta de pólen. Assim, distingue as amplamente poliléticas (aquelas que visitam variadas espécies de plantas) e que as espécies estreitamente poliléticas (obtêm pólen de algumas espécies de plantas não necessariamente da mesma família ou gênero), e as oligoléticas ou monoléticas (restringem a coleta de pólen a poucas espécies vegetais, geralmente do mesmo gênero mesmo de uma única espécie).

As espécies de abelhas oligoléticas, segundo MichenER (1979), apresentam a distribuição limitada de acordo com a das plantas das quais se alimentam. Porém, a distribuição das espécies de plantas nem sempre são restritas pela ocorrência de abelhas polinizadoras oligoléticas, podendo ser na ausência destas, polinizadas pelas espécies poliléticas. Ainda, algumas espécies oligoléticas são consideradas como agentes polinizadores não significativos, exercendo na realidade, o papel de meros coletores de pólen.

Algumas espécies como a Lestrimelitta limao, L. ehrhardti e $L$. cubiceps, invadem e roubam ninhos de outras espécies de Apidae, apresentando assim um modo de vida cleptobiótico (SAKAGAMI \& LAROCA, 1963; MiCHENER, 1974).

LAROCA \& WINSTON (1978) descrevem um comportamento diferenciado de Apis mellifera, em que operárias coletam grãos de pólen do corpo de machos de Bombus pennsylvanicus, enquanto estes visitam flores de Cirsium altissimum (Compositae) para a obtenção de néctar. Fenômeno observado posteriormente, também, por THORP \& BRIGGS (1980), que cunham o termo cleptoléctico para designar esta interessante interação. 
Por outro lado, algumas abelhas solitárias apresentam atividade de vôo por um breve período a cada ano, durante o qual obtêm néctar e pólen de uma ou de poucas espécies vegetais, sendo que muitas destas abelhas são completamente especializadas (FEINSINGER, 1983).

Estudos com enfoque qualitativo e quantitativo são, portanto, necessários para melhor conhecimento do hábito de forrageamento de abelhas; isto é, quais espécies são efetivamente especialistas ou generalistas na exploração de recursos florais, e em que gráu.

Observam-se nas abelhas, diversas adaptações para a aquisição, manipulação e transporte do pólen para o seu ninho, as quais podem ser etológicas, fisiológicas ou estruturais (THORP, 1979).

Comunidades de abelhas e plantas com flores são consideradas sistemas dinâmicos onde ocorrem interações do tipo mutualismo e competição (PRICE, 1975). As espécies que participam de interações mutualísticas altamente específicas freqüentemente possuem adaptações estreitamente relacionadas umas com as outras. Por exemplo, isto pode ser observado através da interação entre machos de Euglossinae e orquídeas, sendo que cada uma destas espécies é considerada altamente específica, atraindo uma ou poucas espécies de abelhas (DresSLER, 1967); o comportamento de Scaura latitarsis para coleta de pólen de Amaranthus spinosus (Amaranthaceae) e Piper gaudichaudianum (Piperaceae) (Laroca \& LAUER, 1973); da adaptação dos palpos labiais de Niltonia virgili (Apoidea, Colletidae) para coleta de néctar em flores de Jacaranda puberula (Bignoniaceae) (LAROCA \& Almeida, 1985), ou das pernas anteriores de fêmeas de Rediviva (Apoidea, Melittidae) para a extração de óleo do esporão floral de Diascia (Scrophulariaceae) (Vogel \& Michener, 1985; Steiner \& WhiteheAd, 1990).

A competição pode ser de plantas por polinizadores bem como de polinizadores pelos recursos florais (KEVAN \& BAKER, 1983). Variadas investigações que tratam de interações competitivas têm sido realizadas, entre as quais citam-se Johson \& Hubbel (1974), HeInRICH (1975), Morse (1977), Inouye (1978), Roubik (1980) e Tepedino \& Stanton (1981). No entanto, estudos relacionados à competição referem-se geralmente, segundo LinSLEY \& CAZIER (1970), às espécies de abelhas sociais (Apidae), de regiões tropicais ou temperadas, enquanto poucos são os que tratam de espécies solitárias.

SCHAFFER et al. $(1979,1983)$ observam que a competição por recursos tem uma função importante na determinação da extensão com que várias espécies de abelhas utilizam flores de Agave schottii. Assim, Apis mellifera (espécie introduzida), em virtude do elevado número de 
forrageiras presentes nestas flores explota os habitats com maior produtividade e que $B$. sonorus explota os de produtividade intermediária, enquanto que $X$. arizonensis é relegada aos locais de baixa produtividade.

No mundo contemporâneo, o homem tem alterado profundamente o ambiente em que vive, por meio de atividades como desmatamentos, queimadas, práticas agrícolas, urbanização e industrialização. Conseqüentemente, cresce o interesse em investigações cujos resultados qualitativos e quantitativos possibilitem a avaliação da alteração da fauna, os recursos necessários para a sua sobrevivência e a influência da ação humana sobre a mesma.

Estudos indicam que a fauna de abelhas da região de Nova York, EUA (Ginsberg, 1981) e de Hamburgo, Alemanha (TsharntKe, 1984), por exemplo, sofreram modificações em decorrência de atividades humanas. A degradação e destruição de habitats, bem como a introdução de muitas colônias de Apis mellifera, por exemplo, ameaçam deslocar e até mesmo conduzir à extinção várias espécies de abelhas (WiLliams, Corbet \& Osborne, 1991).

Em certas circunstâncias, algumas espécies de abelhas, podem no entanto, tornar-se relativamente abundantes em ambientes urbanos, pois são favorecidas pela existência de substrato apropriados para nidificação, recursos oriundos de espécies vegetais cultivadas e retirada de colônias de Apis mellifera (ver Tischler, 1973; TAURA \& LAROCA, 1991).

BATRA (1993) também argumenta que um número relativamente grande de espécies de abelhas polilécticas pode ser encontrado em parques e jardins urbanos, que possuem elevada diversidade de plantas com flores.

A realização de investigações que possibilitem análises comparativas ao longo do tempo, é considerada valiosa para o conhecimento de quais espécies estão se tornando raras, que modificações ocorreram em termos de abundância e quais os recursos necessários para a preservação das abelhas silvestres (PAXTON, 1995).

O presente estudo visa o conhecimento da estrutura faunística de abelhas silvestres, fenologia e relações com as flores, no Passeio Público, uma área restrita e com elevada dinâmica de modificações, localizada no centro de Curitiba, Paraná, Sul do Brasil, com base nos resultados obtidos em 1992/93 comparados com os de 1975 (Laroca, Cure \& Bortoli, 1982) e de 1986/87 (TAura, 1990). 


\section{MATERIALEMÉTODOS}

\section{Área de Estudo: A Cidade de Curitiba}

Curitiba - de origem Tupi “Ku'ri" + "tuba” = muito pinheiro, pinhal - , era conhecida como povoado de Nossa Senhora da Luz dos Pinhais de Curitiba, quando em março de 1693 foi elevada à categoria de Vila, passando à sede de comarca em 1812 e, à cidade em 1842. Uma vez desmembrada a Província do Paraná (Lei Imperial no 704, de 29 de agosto de 1853) (ver FerReIRA, 1996), passou a capital da recém criada Província do Paraná, por meio de uma das primeiras leis da Assembléia Provincial, feita e aprovada pela primeira legislatura do referido Parlamento com a participação do tataravô (Deputado Francisco de Paula Ferreira Ribas) de um dos autores do presente trabalho (SL).

O historiador paranaense RoMÁRIo MARTINS (edição de 1995) cita que Martim Francisco Ribeiro de Andrade (irmão do Patriarca da Independência), visitando Curitiba em 1802, na qualidade de Inspetor de Minas e Matas, escreveu que: "a Vila só era vista de muito próximo, por estar situada na encosta de uma elevação e tapada por espessos bosques, que era muito pantanosa, mas de agradável aspecto pela brancura e asseio de suas habitações. Os seus 12.000 habitantes, incluídos os de São José e da Lapa, trabalhavam na criação de gado e na cultura do trigo, do fumo e de frutas da Europa".

Segundo um de seus relatórios de viagem, SAINT-Hilaire (edição de 1978) narra que em 1820 - época que era Capitão-Mór da Comarca o Doutor Antônio Ribeiro de Andrade (também relacionado aos "avoengos" de SL), Curitiba possuía uma forma quase circular, composta de duzentas e vinte casas, pequenas, cobertas de telhas, quase todas de um único pavimento, feitas de pedra e que no quintal cultivavam-se macieiras, pessegueiros e outras árvores frutíferas européias. As ruas eram largas e bastante regulares, algumas totalmente pavimentadas, outras calçadas apenas diante das casas e com a praça pública quadrada, muito ampla e coberta por relva. Os habitantes da região, em sua maioria de europeus, dedicavam-se geralmente à agricultura, ocupando-se do cultivo de suas terras mais do que com a criação de gado. Nos arredores de Curitiba, naquela época existiam mais matas do que campos.

Nessa período, a agricultura da Comarca estava em franco progresso, em conseqüência aparentemente da política desenvolvida pelo Dr. Antônio Ribeiro de Andrade, que envolveu, entre outras coisas, a introdução e valorização do trabalho feminino na lavoura; esta foi a única vez, que o trigo produzido no Brasil, foi exportado para o exterior. 
Atualmente, a população do município é estimada em 1.315.035 habitantes para uma área de 431 quilômetros quadrados (Anu. est. Brasil., IBGE, 1996).

A cidade de Curitiba localiza-se a uma altitude de $930 \mathrm{~m}$, a $25^{\circ} 25^{\prime}$ 04" S e a 49 14 ' 30" W, no Planalto de Curitiba, uma das subdivisões do Primeiro Planalto Paranaense. Apresenta temperatura anual média de $16,5^{\circ} \mathrm{C}$, umidade relativa anual média de $81,5 \%$ e precipitação anual média de 1451,8 mm, com média de 179 dias de chuva por ano (MAACK, 1981).

O clima do Planalto de Curitiba é do tipo Cfb (Sistema de Koeppen), pluvial quente-temperado, úmido, com mais de cinco geadas anuais e raramente neve. Pelo sistema de classificação de zonas de vida (HOLDRIGE, 1967) é caracterizada como Floresta Úmida Montana Baixa Subtropical.

\section{CARACTERIZAÇÃO DO SÍTIO DE ESTUdOS}

A área de estudo propriamente dita, o Passeio Público (PP), situa-se no centro da cidade de Curitiba, Estado do Paraná, Sul do Brasil e compreende aproximadamente 57.000 metros quadrados, totalmente circundado por ruas e edifícios (Figs 1 e 2), constituindo-se em uma ilha isolada, especialmente para abelhas pequenas de reduzida capacidade de vôo (e.g., Dialictus, Hylaeus, Ceratinula) embora um pouco menos para as espécies de maior capacidade vôo (e. g., Xylocopa, Bombus).

O Passeio Público foi construído em 1885, sobre o charco marginal do Rio Belém (ver Ferreira, 1996).

Por ser considerada uma área de lazer, aberta à visitação pública, o PP apresenta em seu interior, edificações como restaurante, aquário, posto policial, sanitários, administração, bem como algumas jaulas e abrigos para pássaros e animais de pequeno porte. A cobertura vegetal é, também, constantemente modificada pela prática de jardinagem, visando uma floração relativamente contínua e variada, com elevado número de espécies introduzidas, e algumas destas alteradas pelo cultivo constante.

Observam-se algumas modificações na estrutura física do local (Fig. 3) quando comparada com aquela existente em 1986/87 (Fig. 4). Também, animais como ursos, onças e tigres, foram transferidos para o Zoológico da cidade.

Neste mesmo local, foram desenvolvidos estudos similares sobre a comunidade de Apoidea, por Laroca, em 1975 ( $c f$. LAROCA, CuRE \& BorToli, 1982) e por Taura, em 1986/87 (TAURA, 1990), cujos resultados são utilizados neste trabalho, para fins comparativos. 


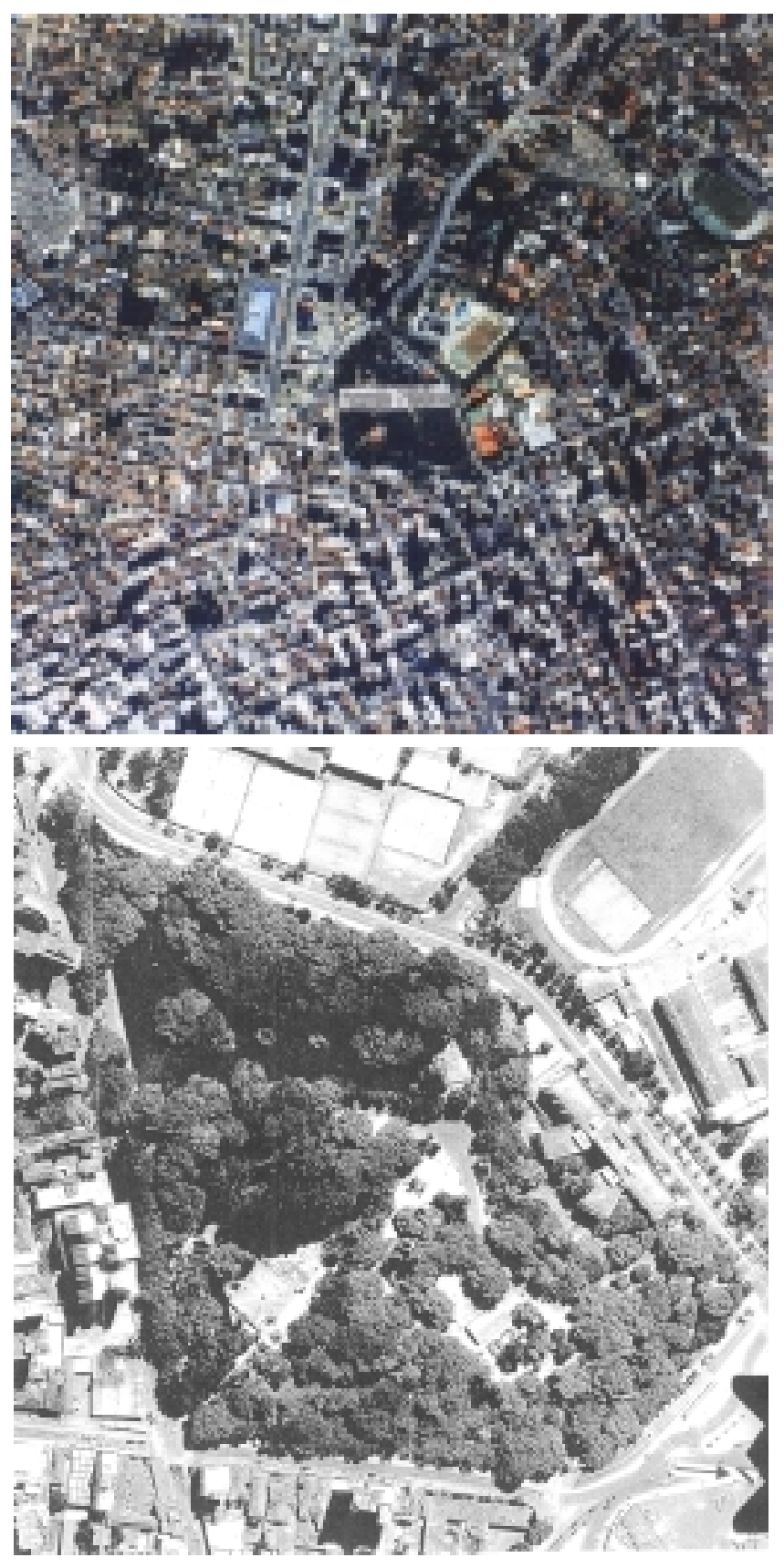

Figs 1 e 2. Sítio de estudos (vista aérea) 1, parte da cidade de Curitiba, Paraná; 2, idem, adjacências do sítio de estudo. (Foto original de 1996 - IPPUC). 


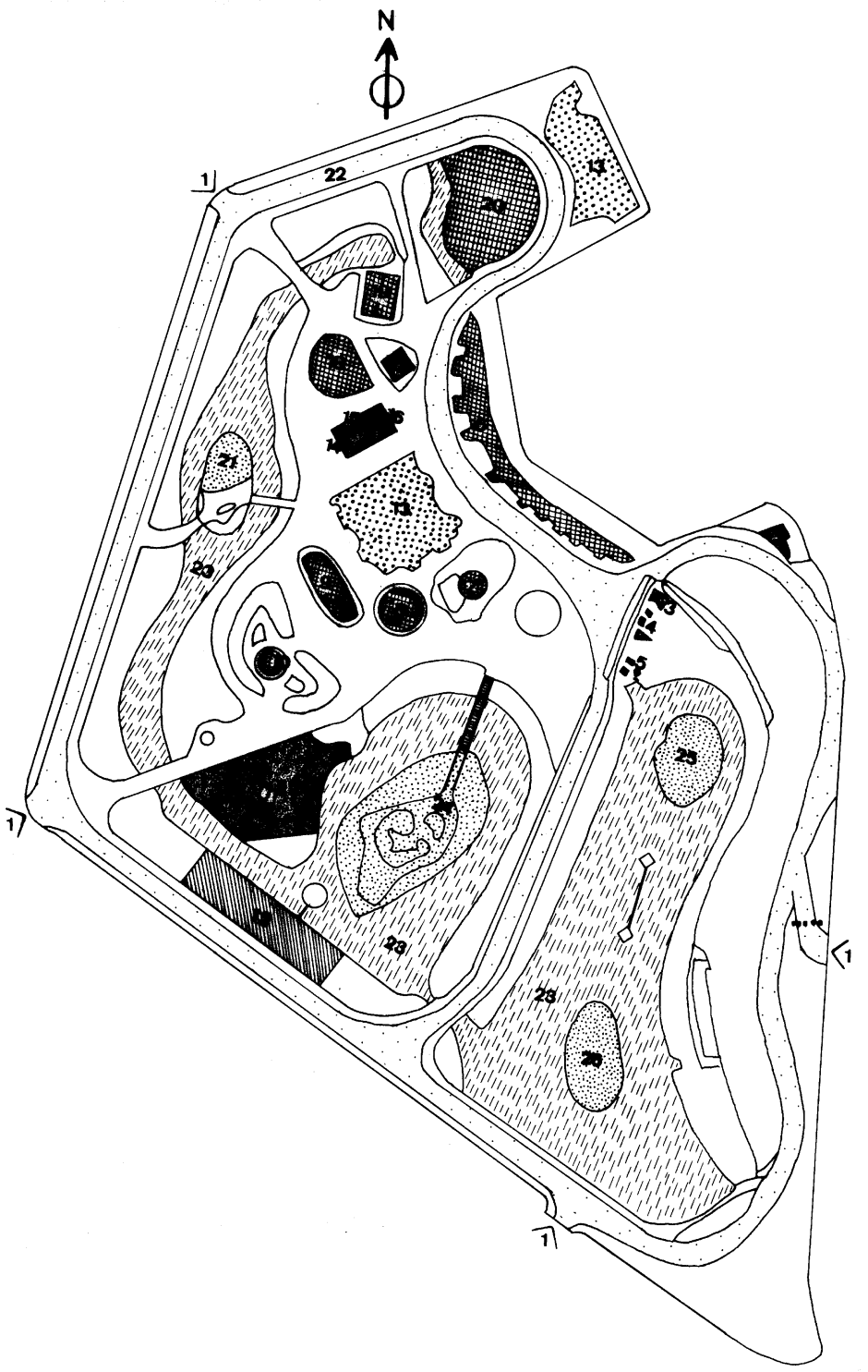

Fig. 3. Croqui do sítio de estudo (Passeio Público, Curitiba, PR), condições de 1992/1993, adaptado de uma planta fornecida pelo IPPUC e do Roteiro para Visitantes elaborado pela Administração. 1, acessos; 2, administração; 3, chimpanzé; 4, macacos pequenos; 5 , mamíferos doentes; 6, aves; 7, aquário; 8, macacos; 9, garças; 10, passarinhos; 11, restaurante; 12, porto dos pedalinhos; 13 , play-ground; 14 , guarda-florestal; 15 , aves canoras; 16 , sanitários; 17, casa das máquinas; 18, araras/tucano/pavão; 19, veados/jabutis; 20, canteiro de flores; 21 , ilha do amor; 22, asfalto; 23, lagoas; 24 , ilha da ilusão; 25, ilha dos macacos-aranha; 26, ilha do gibão e bugio; 27, lanchonete; 28, almoxarifado. 


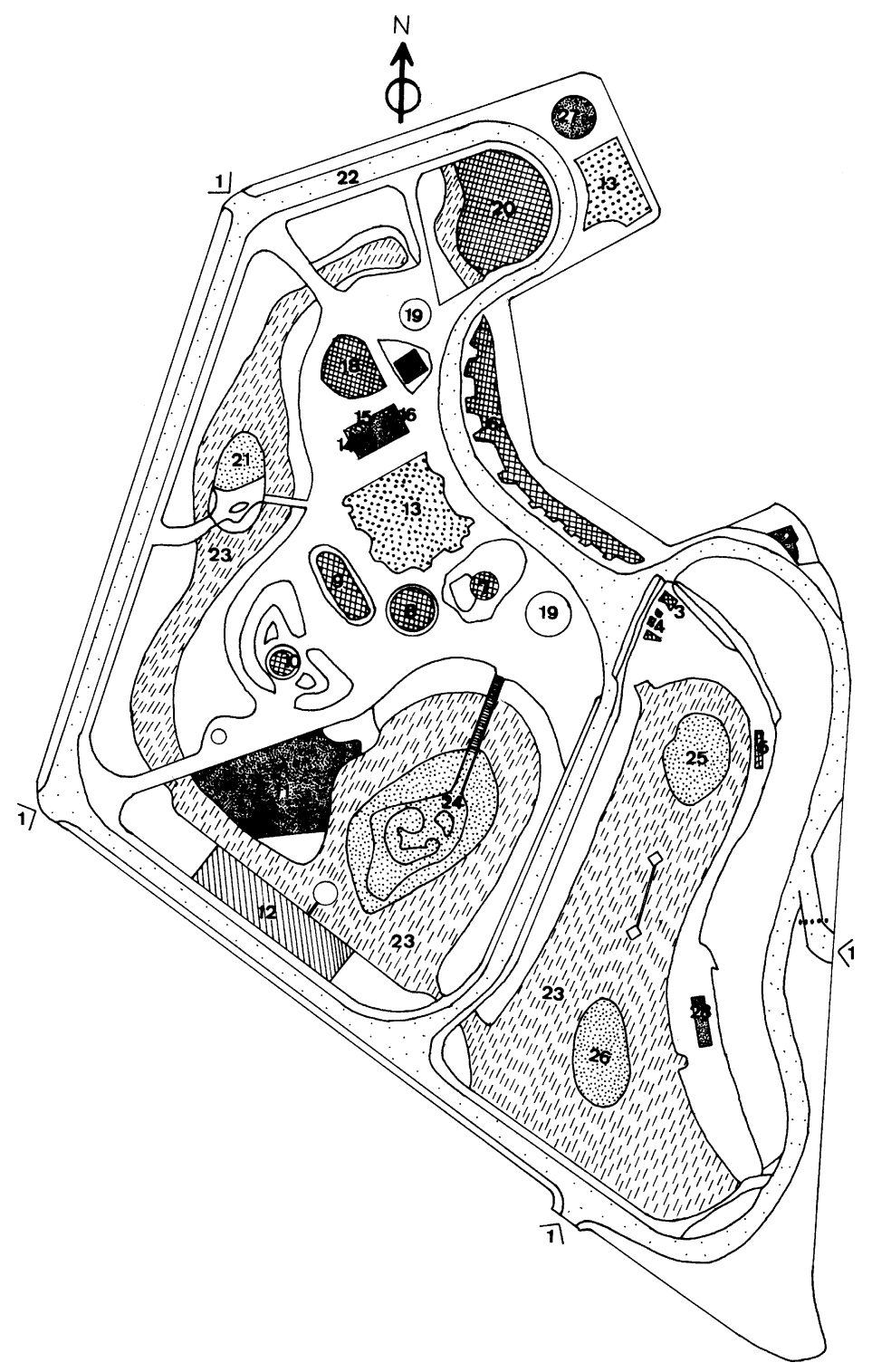

Fig. 4. Croqui do sítio de estudo (Passeio Público, Curitiba, PR), com as condições de 1986/87, adaptado de uma planta fornecida pelo IPPUC e do Roteiro para Visitantes elaborado pela Administração: 1, acessos; 2, administração; 3, chimpanzé; 4, macacos pequenos; 5 , mamíferos doentes; 6 , aves; 7, aquário; 8 , macacos; 9, garças; 10, passarinhos; 11, restaurante; 12 , porto dos pedalinhos; 13, play-ground; 14, guarda-florestal; 15, aves canoras; 16, sanitários; 17, casa das máquinas; 18, araras/tucano/pavão; 19, onças/tigres; 20, ursos/veados/jabutis; 21, ilha do amor; 22, asfalto; 23, lagoas; 24, ilha da ilusão; 25, ilha dos macacos-aranha; 26, ilha do gibão e bugio. 


\section{Amostragem DE ABELHAS}

Para a coleta de dados sobre abundância relativa, fenologia e flores visitadas foi utilizado o procedimento desenvolvido por Sakagami e Laroca (ver LAROCA, 1972), que consiste na captura de abelhas sobre flores ou em vôo, sem escolha.

Este autor, bem como SAKAGAMI \& FUKUDA (1973) citam que a técnica apresenta algumas distorções tais como: horário fixo com a conseqüente exclusão inevitável de espécies que apresentam períodos de atividades especiais, influência da remoção de indivíduos sobre o tamanho das populações e, impossibilidade de coleta em árvores muito altas. Entretanto, a mesma possibilita a obtenção de amostras que representam razoavelmente a estrutura apifaunística da área de estudo.

O estudo baseia-se em dados de 1975 (Laroca, Cure \& Bortoli, 1982), 1986/87 (TAURA, 1990) e 1992/93. Neste último censo citado, a amostragem foi feita periodicamente, duas vezes por mês, obtendo-se um total de 24 amostras entre junho de 1992 e maio de 1993. Ao contrário das coletas do ano de 1986/87, realizadas às segunda-feiras, dia em que o PP encontrava-se fechado à visitação pública, neste período foram feitas no dia com as condições meteorológicas consideradas as mais favoráveis à atividade das abelhas, uma vez a cada quinzena do mês, devido à abertura do $\mathrm{PP}$ todos os dias da semana. Também, o número de dias de coleta, por mês, foi reduzido para atenuar os efeitos da retirada de indivíduos das populações locais de abelhas, sendo similar ao número de dias de coleta de PP-75.

O período de coleta foi entre 9 e 14 horas, não tendo sido obedecido o horário de verão, em vigor entre outubro de 1992 e fevereiro de 1993. Os registros referentes a dia, hora, e o número de indivíduos das amostras coletadas, encontram-se apresentados na Tabela 1.

O PP foi dividido em quatro quadrantes, de tamanhos equivalentes, conforme a divisão feita para a amostragem em 1986/87 (TAURA, 1990). As "ilhas" do local não foram percorridas devido à dificuldade de acesso. Cada dia sucessivo de coleta, a primeira hora de amostragem foi feita em um quadrante diferente, buscando-se a alternância dos mesmos. Também, foram reservados 15 minutos, entre o encerramento e o início de cada hora de coleta para anotações dos dados meteorológicos, observações e transferência do material coletado dos frascos letais para os de plástico (utilizados como envelopes entomológicos).

As abelhas foram coletadas com rede entomológica, individualmente ou em grupo, quando pousadas nas flores ou logo após abandoná-las. 
Tabela 1. Número de indivíduos de abelhas silvestres (Hymenoptera, Apoidea) coletados em 1992/93 no Passeio Público, Curitiba, Paraná, com o respectivo dia de amostragem. O tempo de permanência refere-se ao período em que a área foi percorrida pela coletora e, as horas de coleta correspondem à fração deste em que pelo menos um exemplar de abelha silvestre foi capturado. (Início: 9 horas, Término: 14 horas).

\begin{tabular}{c|c|c|cc}
\hline DIA & $\begin{array}{c}\text { TEMPO DE } \\
\text { PERMANÊNCIA } \\
\text { (horas) }\end{array}$ & $\begin{array}{c}\text { COLETA } \\
\text { (horas) }\end{array}$ & $\begin{array}{c}\text { ABELHAS } \\
\text { SILVESTRES } \\
\text { COLETADAS } \\
\text { (número) }\end{array}$ & \\
\hline $08 / 06 / 92$ & 4 & 4 & 68 & \\
$23 / 06 / 92$ & 4 & 4 & 116 & (A) \\
$13 / 07 / 02$ & 4 & 3 & 89 & (B) \\
$27 / 07 / 92$ & 4 & - & - & (B) \\
$11 / 08 / 92$ & 4 & 4 & 118 & \\
$24 / 08 / 92$ & 4 & 2 & 120 & \\
$14 / 09 / 92$ & 4 & 4 & 118 & \\
$29 / 09 / 92$ & 4 & 4 & 88 & \\
$05 / 10 / 02$ & 4 & 4 & 110 & \\
$26 / 10 / 92$ & 4 & 4 & 80 & \\
$09 / 11 / 92$ & 4 & 4 & 77 & \\
$30 / 11 / 92$ & 4 & 3 & 39 & \\
$07 / 12 / 92$ & 4 & 4 & 53 & \\
$21 / 12 / 92$ & 4 & 4 & 61 & \\
$12 / 01 / 93$ & 4 & 4 & 56 & \\
$25 / 01 / 93$ & 4 & 4 & 57 & \\
$11 / 02 / 93$ & 4 & 4 & 46 & \\
$25 / 02 / 93$ & 4 & 4 & 109 & \\
$08 / 03 / 93$ & 4 & 4 & 95 & \\
$29 / 03 / 93$ & 4 & 4 & 63 & \\
$08 / 04 / 93$ & 4 & 4 & 34 & \\
$26 / 04 / 93$ & 4 & 4 & 39 & \\
$11 / 05 / 93$ & 4 & 4 & 31 & \\
$24 / 05 / 93$ & 4 & 3 & & \\
\hline
\end{tabular}

OBSERVAÇ̃̃ES - A, a área foi percorrida, porém, a chuva embora fraca, afetou a coleta; B, a área foi percorrida, porém, não houve atividade de abelhas (exceto de Apis mellifera), possivelmente devido ao frio; $\mathrm{C}, \mathrm{A}$, a área foi percorrida, porém, não houve atividade de abelhas (exceto de Apis mellifera) durante a primeira hora de coleta, devido provavelmente à "ameaça" de chuva. 
Foram mortas em frascos apropriados, contendo cianeto de potássio. Para cada um destes frascos correspondiam dados relativos a data, hora, quadrante e planta onde foram capturadas. Posteriormente, as abelhas foram alfinetadas e conservadas em gavetas entomológicas para a determinação do grupo sistemático. As abelhas que visitavam as árvores altas presentes no local não foram amostradas.

\section{Coleta DE EXCICATAS}

As amostras das angiospermas encontradas na área de estudo, recebessem ou não visitas de abelhas, foram coletadas ao término de cada dia de coleta e herborizadas para a posterior determinação por especialistas.

\section{INFORMAÇÕES SOBRE O AR ATMOSFÉRICO}

Informações referentes à temperatura e umidade relativa foram obtidas por meio de um termômetro e psicrômetro, colocados a cerca de um metro e meio do solo, sempre em local determinado e à sombra. A velocidade do vento foi estimada através da escala de Beaufort. Os gráus de insolação e nebulosidade foram determinados por observação direta da proporção de nuvens, em escala de zero (a ausência total) a dez (cobertura total).

A figura 5 apresenta a flutuação mensal da temperatura e precipitação em Curitiba, entre junho de 1992 e maio de 1993, fornecidos pela Estação Meteorológica de Curitiba e obtidos por instrumentos instalados no Centro Politécnico, Jardim das Américas. O padrão normal indicado nesta figura foi compilado de MAACK (1981) para fins de comparação.

Durante o período de estudo, os meses mais quentes são janeiro, fevereiro e março de 1993, enquanto que julho e agosto de 1992 são os meses mais frios. Observa-se também que os valores registrados de temperatura média mensal estiveram ligeiramente mais elevados que o padrão normal, nos meses de junho, outubro e dezembro de 1992, como também em janeiro, março, abril e maio de 1993. O contrário, isto é, a temperatura abaixo da normal, é verificado apenas em agosto de 1992.

Em relação à precipitação pluviométrica, segundo МАACK (1981), os meses considerados os mais secos do ano são abril, maio, julho e agosto, com médias inferiores a $100 \mathrm{~mm}$, enquanto que janeiro e fevereiro os mais chuvosos, com índices próximos a $200 \mathrm{~mm}$. Todavia, verifica-se que em julho e agosto de 1992 e maio de 1993, a pluviosidade obtida foi superior a $100 \mathrm{~mm}$. Ainda, no mês de janeiro de 1993 foi registrado valor próximo a $300 \mathrm{~mm}$. 
Os resultados de monitoramento da poluição do ar (partículas totais em suspensão e dióxido de enxofre), obtidos em 1975 e 1986, fornecidos pela Superintendência de Recursos Hídricos e Meio Ambiente (SUREHMA) e em 1992 e 1993, pelo Instituto Ambiental do Paraná (IAP), encontram-se nas Figs 6 e 7. Tais dados possibilitam apenas inferir sobre a qualidade do ar em Curitiba, devido à diferença nos locais de amostragem das duas instituições mencionadas anteriormente, isto é, na sede da UFPR na Praça Santos Andrade e na Santa Casa de Misericórdia, na Praça Rui Barbosa, ambos no centro da cidade e próximos ao PP.

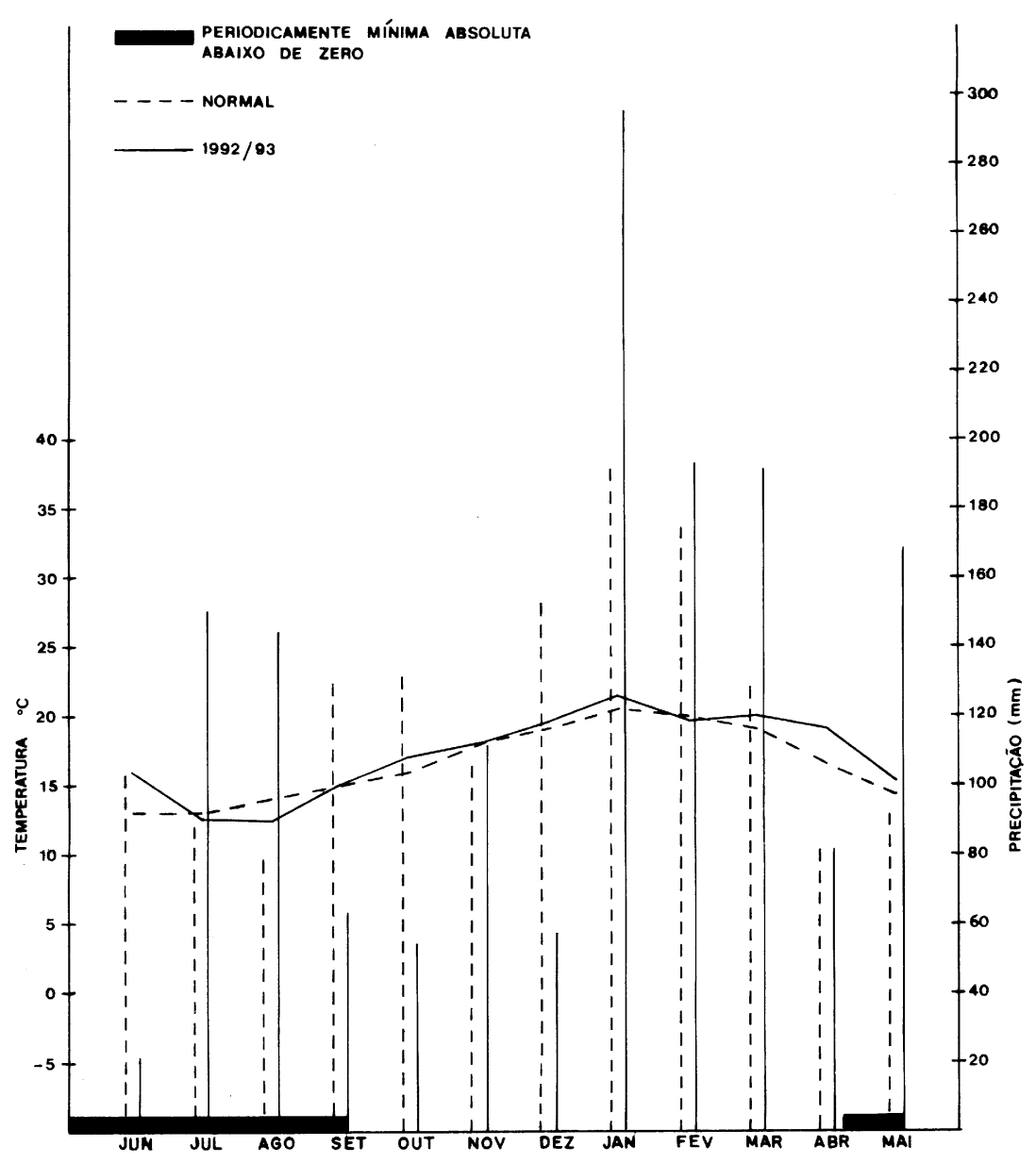

Fig. 5. Flutuação mensal da temperatura (linha horizontal) e precipitação pluviométrica (linha vertical) em Curitiba, Paraná, entre junho de 1992 e maio de 1993, fornecidos pela Estação Meteorológica de Curitiba. Padrão normal segundo MAACK (1981). 

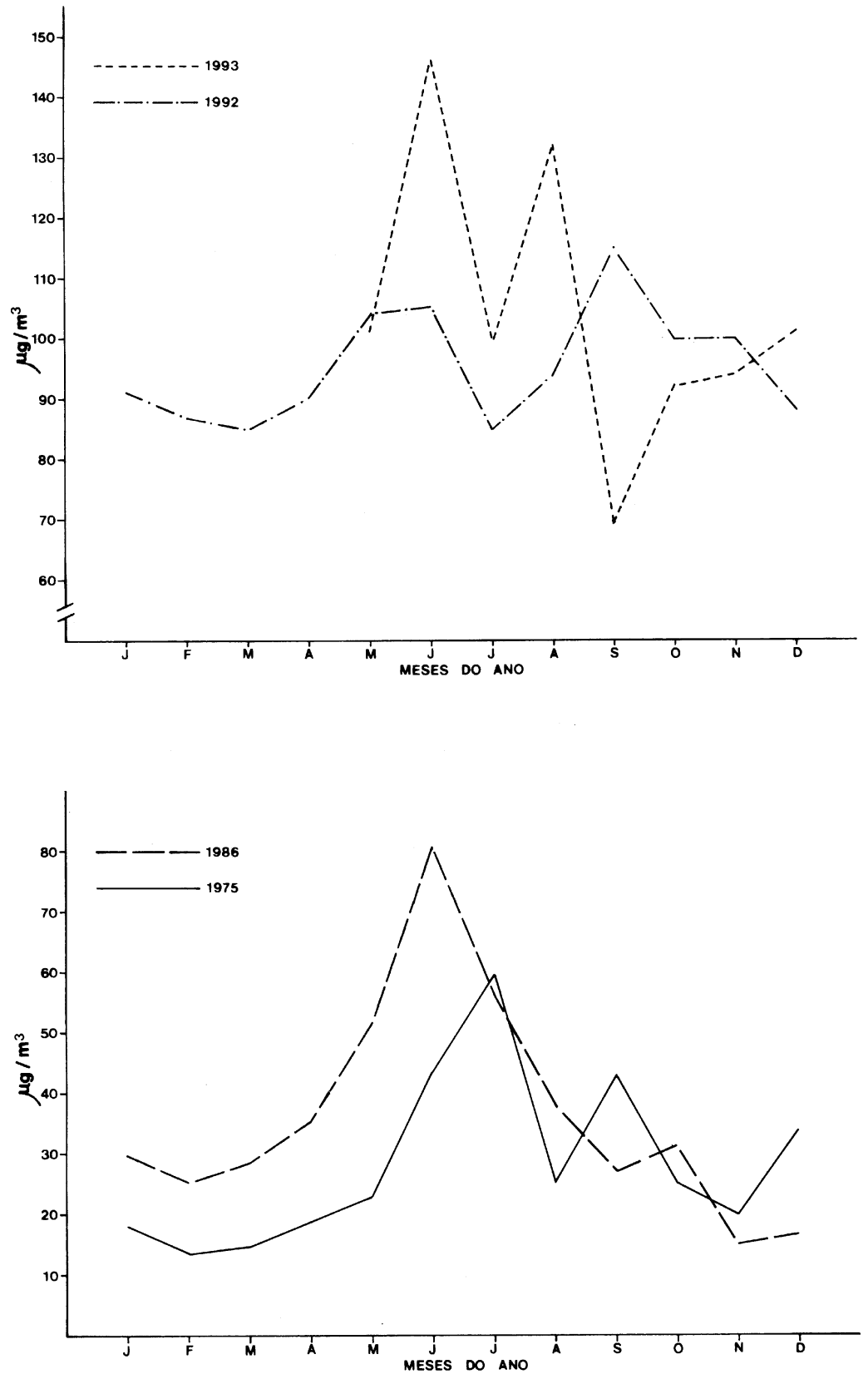

Fig. 6. Valores de concentrações de partículas totais em suspensão, obtidos na estação da Santa Casa de Misericórdia, Praça Rui Barbosa, em 1992 e 1993, cedidos pelo IAP e na estação da Faculdade de Odontologia da UFPR, Praça Santos Andrade, em 1975 e 1986, fornecidos pela SUREHMA, situadas nas proximidades do Passeio Público, Curitiba, Paraná. 

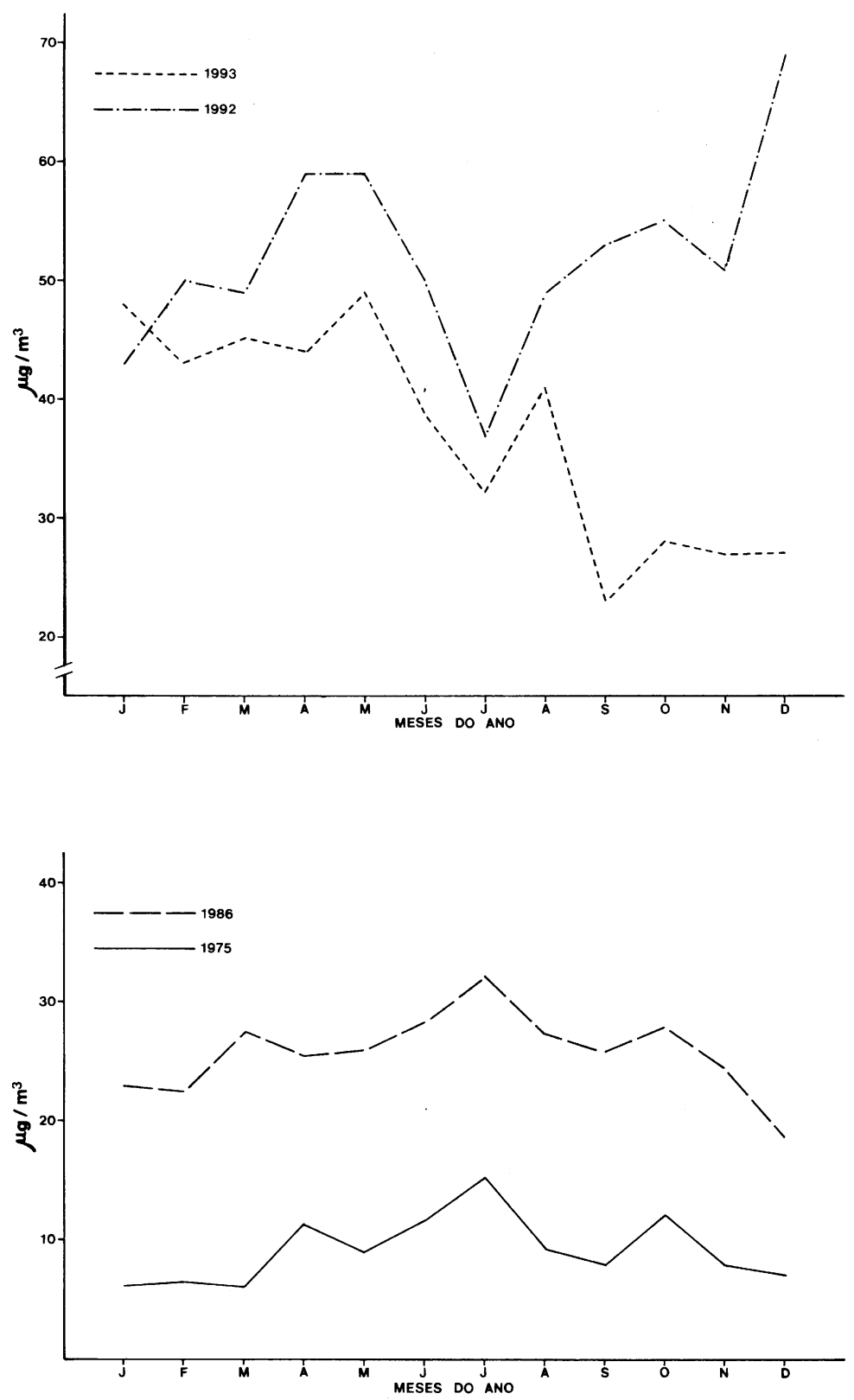

Fig. 7. Valores de concentrações de dióxido de enxofre (SO2), obtidas na estação da Santa Casa de Misericórdia, Praça Rui Barbosa, em 1992 e 1993, cedidas pelo IAP e na estação da Faculdade de Odontologia da UFPR, Praça Santos Andrade, em 1975 e 1986, fornecidas pela SUREHMA, situadas nas proximidades do Passeio Público, Curitiba, Paraná. 


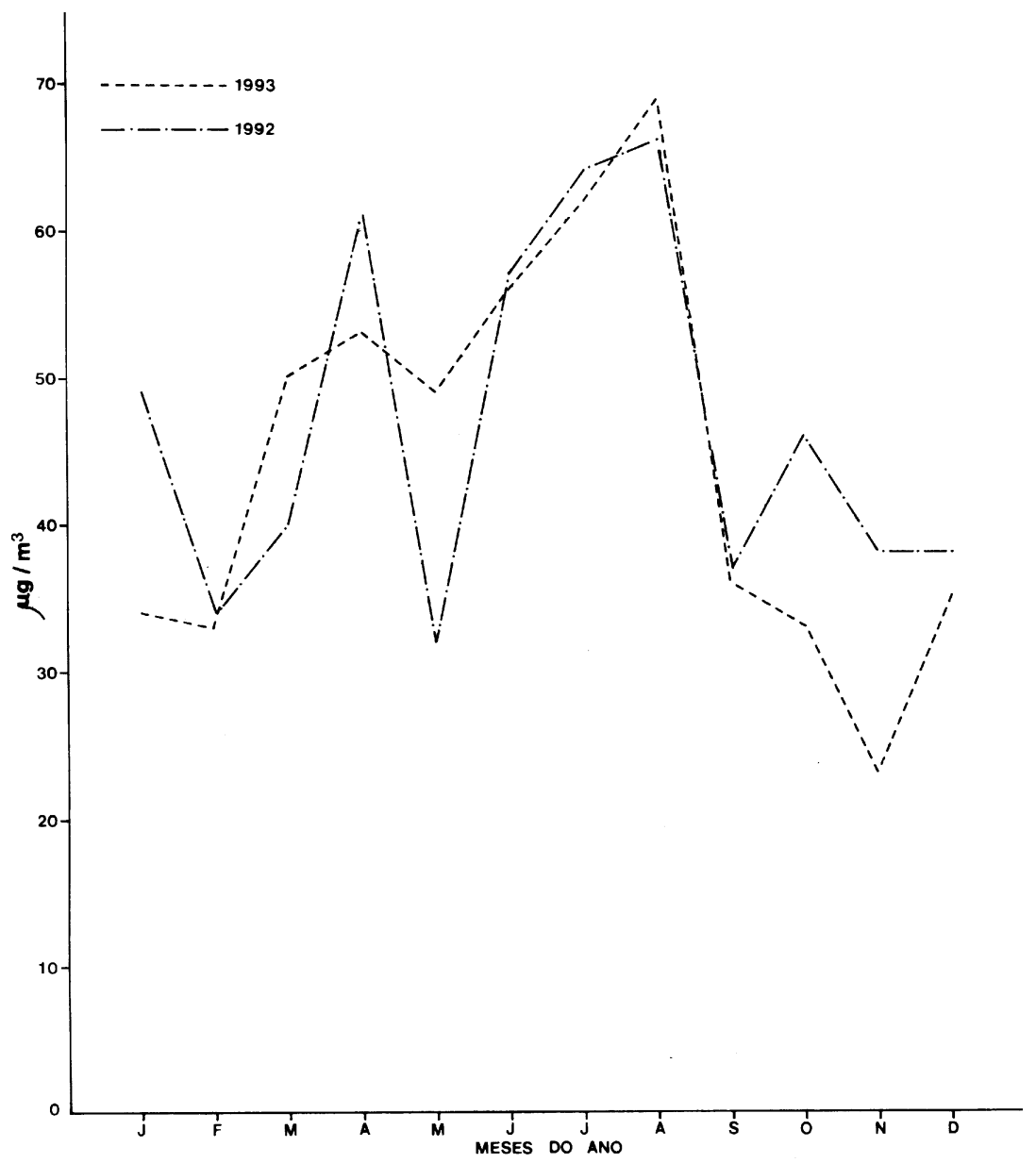

Fig. 8. Valores de concentrações de fumaça, obtidas em 1992 e 1993, na estação da Santa Casa de Misericórdia (Praça Rui Barbosa), situada nas proximidades do Passeio Público, Curitiba, Paraná e fornecidas pelo IAP.

Os índices mensais de fumaça, cedidos também pelo IAP e amostrados apenas em 1992 e 1993, encontram-se apresentados na Fig. 8.

\section{ANÁLISE DOS DADOS}

A identificação das abelhas silvestres e das plantas foi efetuada em nível de espécie. Em alguns casos, quando a identificação não foi possível devido à falta de estudos taxonômicos ou dificuldades devido à altera- 
ção pelo cultivo constante (no caso de plantas), as espécies foram listadas através de código numérico.

A estrutura do banco de dados relacionada a seguir, foi feita de maneira padronizada, semelhante à codificação de PP-86/87 (TAURA, 1990) visando facilitar as comparações entre as amostras e a obtenção de listagens de computador para a análise dos resultados.

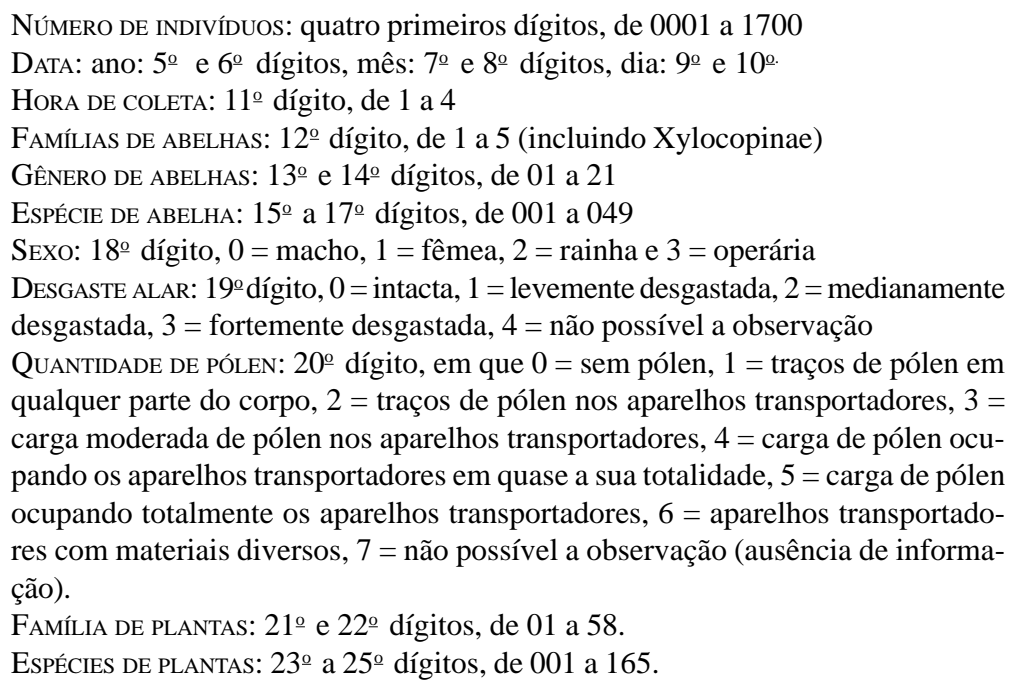

Para o cálculo dos limites de confiança da abundância relativa das espécies predominantes foi utilizado o método de Kato, Matsuda \& Yamashita (1952) (cf. Sakagami \& Matsumura, 1967 e Laroca, 1972).

Como espécies predominantes foram consideradas aquelas que apresentaram o limite inferior maior que a recíproca do número de espécies coletadas, multiplicada por 100.

A similaridade entre as amostras de PP-75, PP-86/87 e PP-92/93 foi comparada, através do quociente de Sorensen (QS) ( $c f$. Southwood, 1971).

O índice de diversidade foi estimado pelo método de Shannon-Wiener (cf. KreBs, 1972 e Poole, 1974). Os parâmetros riqueza (H) e equabilidade (E) deste índice, foi utilizado o programa "pg10-2.bas" (LAROCA, 1995).

Para a análise da diversidade foi utilizado o método de Laroca (LAROCA, CURe \& Bortoli, 1982), que consiste em correlacionar o número acumulado de indivíduos (em escala logarítmica) e o número acumulado de espécies.

A distribuição dos números de espécies entre as várias classes de abundância (oitavas) foi ajustada à log-normal, segundo o procedimento de Preston (1948)( $c f$. Laroca, 1995). 


\section{RESULTADOS EDISCUSSÃO}

\section{COMPOSIÇão FAUNÍSTICA}

\section{ESPÉCIES DE ABELHAS}

As abelhas capturadas no Passeio Público (PP), em 1992/93, encontram-se relacionadas abaixo, por família e espécie, com os respectivos códigos numéricos à direita, os quais foram utilizados para a obtenção de listagem de computador e parte da análise dos resultados obtidos.

Os exemplares estão depositados no Museu Entomológico do Departamento de Zoologia da Universidade Federal do Paraná.

COLLETIDAE

Bicolletes sp. 101001

HALICTIDAE

Augochlora (Augochlora) amphitrite (Schrottky, 1909) 202002

A. (A.) neivai (Moure, 1940)

A. (A.) sp. 1 a 2

202003

Augochlorella ephyra (Schrottky, 1910)

202004 a 202005

A. michaelis (Vachal, 1911) 203007

Augochloropsis cupreola (Cockerell, 1900)

203006

A. lampronota Moure,1944 204009

A. sp. 1 a 3

204008

Caenohalictus palumbens (Vachal, 1903)

204010 a 204012

C. sp. 1

205013

Dialictus (Dialictus) sp.

205014

D. (Chloralictus) anisitsianus (Strand, 1910)

D. (C.) opacus (Moure, 1940)

D. (C.) rhytidophorus Moure, $1956 \quad 206018$

D. (C.) spp.1 a $12 \quad 206019$ a 206030

Neocorynura (Neocorynura) aenigma (Gribodo, 1894) 207031

Pseudagapostemon (Neagapostemon) cyanomelas

Moure, 1958

208032

Pseudaugochloropsis graminea (Fabricius, 1804) 209033

ANTHOPHORIDAE

Ceratina (Crewella) asuncionis Strand, 1910

Ceratinula lucidula (Smith, 1854) 411035

C. sclerops Schrottky, 1907

C. turgida Moure, 1941

Lophopedia sp. 312038

Paratetrapedia sp. $\quad 313039$

Thygater (Thygater) analis (Lepeletier, 1841) 314040

Xylocopa (Neoxylocopa) augusti Lepeletier, 1841

X. (Stenoxylocopa) artifex Smith, 1874

APIDAE

Bombus (Fervidobombus) atratus Franklin, 1913 


$\begin{array}{lr}\text { B. }(\text { F.) morio (Swederus, 1787) } & 516044 \\ \text { Nannotrigona (Scaptotrigona) bipunctata } & \\ \text { (Lepeletier, 1836) } & 517045 \\ \text { Partamona helleri Friese, 1900 } & 518046 \\ \text { Plebeia (Plebeia) emerina (Friese, 1900) } & 519047 \\ \text { Trigona (Tetragonisca) angustula fiebrigi (Schwarz, 1938) } 520048 \\ \text { Trigona (Trigona) spinipes (Fabricius, 1793) } & 520049\end{array}$

\section{ABUNDÂNCIA RELATIVA E DIVERSIDADE}

As comparações entre resultados de vários levantamentos realizados no mesmo local, possibilitam o conhecimento mais preciso sobre a estrutura da comunidade de Apoidea. Laroca , Cure \& Bortoli (1982) constatam a necessidade da realização de estudos semelhantes, durante períodos mais extensos, para a obtenção de informações mais precisas sobre as modificações sofridas pelo conjunto de abelhas silvestres no interior de cidades. Neste sentido, foram efetuados no PP de Curitiba, os seguintes estudos envolvendo a associação de abelhas: em 1975, por LAROCA, CuRe \& Bortoli (1982) e em 1986/87 e 1992/97 pela autora deste estudo. Os dados de 1986/87 encontram-se em Taura (1990).

O número de espécies e de indivíduos por família e gênero de abelhas silvestres, capturados no PP, em 1992/93, 1986/87 e 1975, encontram-se relacionados na Tabela 2. Para a realização destes três levantamentos, utilizou-se basicamente a mesma técnica de coleta, a qual apesar de variações quanto ao número total de horas de amostragem e eficácia de coletores, permite a obtenção de estimativas razoáveis para fins de comparações entre a abundância relativa e diversidade apresentadas pela apifauna no referido local.

Alguns resultados de outros estudos foram compilados, para fins de comparação. Tais dados, apresentados na tabela 3, referem-se ao número de indivíduos, gêneros e espécies de abelhas, obtidos em censos realizados no Planalto de Curitiba: Boa Vista (BV) efetuado em 1963/64 (Laroca, 1972); Parque da Cidade (PC) em 1981/82 (Cure, 1983); São José dos Pinhais (SJP-62/63) em 1962/63 (SaKagami, Laroca \& Moure, 1967) e em 1981/82 (SJP-81/82) (BorTOLI \& LAROCA, 1990).

As famílias de Apoidea coletadas nestas áreas $(\mathrm{CO}=$ Colletidae, $\mathrm{AD}$ $=$ Andrenidae HA $=$ Halictidae, $\mathrm{MG}=$ Megachilidae, $\mathrm{AT}=$ Anthophoridae, $\mathrm{AP}=$ Apidae) estão relacionadas a seguir, em ordem decrescente de abundância. Como padrão geral do Planalto de Curitiba, foi considerada a somatória dos resultados dos levantamentos citados acima. 


\section{Espécies Indivíduos}

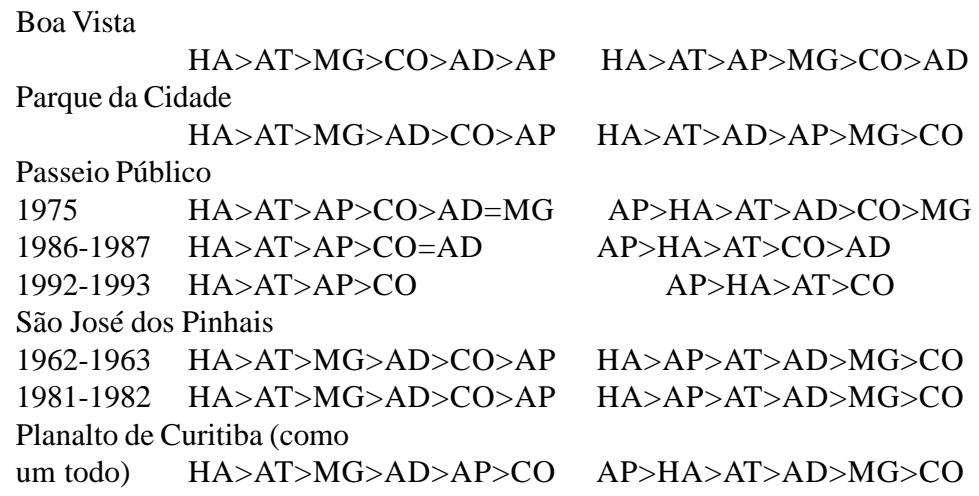

Em termos de riqueza de espécies, nota-se a predominância de Halictidae, seguida por Anthophoridae, em todas as áreas mencionadas. Entretanto, as demais famílias de Apoidea apresentam-se de forma diferenciada nestes locais, sendo que em PP, a terceira família em termos de importância é Apidae, enquanto nos demais registra-se a ocorrência de Megachilidae.

B ATRA (1993) cita que em áreas urbanas, as espécies de Megachilidae, como por exemplo, Osmia e outras que nidificam em cavidades de paredes, vigas de madeira e ramos de plantas, são relativamente abundantes.

No PP, entretanto, indivíduos pertencentes a Megachilidae, somente foram capturados, durante a amostragem realizada em 1975 (LAROcA, CuRE \& Bortoli, 1982). Estes autores comentam que o estabelecimento desta família no PP, possivelmente seja dificultado devido aos seus hábitos de nidificação, pois costumam construir seus ninhos com pequenos pedaços de folhas de plantas herbáceas e arbustivas e neste local, verifica-se a presença de muitas espécies vegetais introduzidas. Segundo os mesmos autores, indivíduos pertencentes a esta família de abelhas apresentam também elevada sensibilidade às variações de intensidade da luz, cessando repentinamente a atividade nas flores, quando o céu torna-se nublado, e possivelmente a atmosfera enfumaçada no centro da cidade esteja, portanto, influenciando.

Ao contrário de outras localidades, Apidae é a família que apresenta elevada representatividade no PP, registrando-se também a presença de Partamona helleri em PP-92/93 e PP-86/87, ausente em PP-75. TISCHLER (1973) sugere que algumas espécies de abelhas silvestres podem ser favorecidas em parques e jardins, em decorrência da existência de 
substratos apropriados para nidificação e recursos oriundos de espécies cultivadas.

No PP, as possibilidades de nidificação por algumas espécies de Apidae, especialmente Meliponinae, mui provavelmente são aumentadas pelas atividades humanas, como também pela presença de cavidades naturais e artificiais em árvores de grande porte (TAURA \& LAROCA, 1991). Os Meliponinae podem ainda, estar sendo favorecidos pela retirada constante de colônias de A. mellifera pelos funcionários do local (devido à sua agressividade ao público e aos animais ali presentes) e assim as cavidades que seriam ocupadas por esta espécie ficam disponíveis para nidificação por outras.

Verifica-se também no PP, a presença de uma colônia de Lestrimelitta limao (Smith), espécie não incluída nas amostragens de PP-92/93, PP86/87 e PP-75. Esta espécie cleptobiótica foi descoberta no local em 1962, conforme SAKAGAMI \& LAROCA (1963) e sua ocorrência constatada ainda em 1987 e 1991 (Taura \& Laroca, 1991). Durante o censo de PP92/93, foi novamente observada na área, porém o ninho encontrava-se em local diferente do observado em 1987 e 1991. L. limao ataca ninhos de diversas espécies de Meliponinae, bem como colônias fracas de $A$. mellifera e pilha os alimentos e materiais para construção de ninhos (Michener, 1974; LAROCA \& ORTH, 1984). Na região de Curitiba, P. emerina é a espécie de Meliponinae preferencialmente atacada por L. limao (SAKagami \& Laroca,1963; Laroca \& ORTH, 1984).

A elevada diversidade observada em Halictidae, em todas as áreas amostradas do Planalto de Curitiba, deve-se tanto à ocorrência de variados gêneros como de espécies, neste caso pertencentes especialmente a Dialictus e Augochloropsis.

A amostra obtida por ORTH (1983) em Caçador, SC, indica que também neste local, Halictidae é a família mais numerosa em espécies, devido à ocorrência de muitas espécies de Dialictus e Augochloropsis, sendo portanto neste sentido, similar ao padrão verificado em Curitiba.

Considerando-se os estudos realizados na região centro-sul do Brasil, Halictidae nem sempre é dominante em relação ao número de espécies. Assim, em Ribeirão Preto (CAMARGo \& MAZUCATO, 1984) a sua freqüência (26,9\%) é superada por Anthophoridae (36,8\%), enquanto que na Reserva de Corumbataí, SP (CAMPOS, 1989), Anthophoridae apresenta 58 espécies, isto é, 49,57\% do total e Halictidae, apenas 20 espécies $(17,09 \%)$.

Na região sul, LAROCA \& AlmEIDA (1994) citam também que no cerrado da região de Jaguariaíva, Paraná, Anthophoridae $(43,6 \%)$ é predominante sobre as demais famílias, inclusive Halictidae $(25,6 \%)$. 
Tabela 2. Número de espécies e de indivíduos por gênero de abelhas silvestres (Hymenoptera, Apoidea), capturadas no Passeio Público,Curitiba, Paraná, em 1992/93, 1986/87 e 1975. A abreviatura dos gêneros é a utilizada nas figuras do presente trabalho.

\begin{tabular}{|c|c|c|c|c|c|c|c|c|c|}
\hline \multirow{3}{*}{ TAXON } & \multicolumn{3}{|c|}{ NÚMERO DE ESPÉCIES } & \multicolumn{6}{|c|}{ NÚMERO DE INDIVÍDUOS } \\
\hline & \multirow[t]{2}{*}{ PP-92/93 } & \multirow[t]{2}{*}{ PP-86/97 } & \multirow[t]{2}{*}{ PP-75 } & \multicolumn{2}{|c|}{ PP-92/93 } & \multicolumn{2}{|c|}{ PP-86/87 } & \multicolumn{2}{|c|}{ PP-75 } \\
\hline & & & & $\mathrm{F}$ & $\mathrm{M}$ & $\mathrm{F}$ & $\mathrm{M}$ & $\mathrm{F}$ & $\mathrm{M}$ \\
\hline COLLETIDAE & 1 & 2 & 4 & 7 & 3 & 13 & 6 & 29 & 28 \\
\hline Bicolletes (Bc.) & 1 & 1 & 1 & 7 & 3 & 12 & 6 & 4 & 6 \\
\hline “Chilicola”(Ch.) & & & 1 & & & & & 1 & 1 \\
\hline Dipaltoglossa (Dp.) • & & & 1 & & & & & 1 & \\
\hline Hylaeus (Hy.) & & 1 & 1 & & & 1 & & 23 & 21 \\
\hline ANDRENIDAE & & 2 & 3 & & & 5 & 3 & 33 & 26 \\
\hline Anthrenoides (An.) & & 1 & & & & 4 & & & \\
\hline Psaenythia (Рy.) & & & 1 & & & & & 1 & \\
\hline PANURGINAE • • & & 1 & 2 & & & 1 & 3 & 32 & 26 \\
\hline HALICTIDAE & 32 & 47 & 45 & 253 & 72 & 409 & 128 & 417 & 189 \\
\hline Augochlora (Au.) & 4 & 3 & 1 & 59 & 40 & 67 & 25 & 66 & 7 \\
\hline Augochlorella (Ag.) & 2 & 2 & 2 & 59 & 11 & 175 & 26 & 51 & 8 \\
\hline Augochloropsis (As.) & 5 & 2 & 6 & 10 & 2 & 6 & 1 & 10 & 4 \\
\hline Caenohalictus (Cn.) & 2 & 2 & 1 & 4 & 2 & 2 & 3 & 1 & 1 \\
\hline Dialictus (Dl.) & 16 & 34 & 32 & 116 & 7 & 131 & 37 & 242 & 123 \\
\hline Neocorynura $(\mathrm{Nc})$. & 1 & 1 & 2 & 3 & 4 & 18 & 9 & 40 & 42 \\
\hline Pseudagapostemon (Ps.) & 1 & 1 & & 1 & & 4 & & & \\
\hline Pseudaugochloropsis (Pg.) & 1 & 1 & 1 & 1 & 6 & 5 & 27 & 7 & 4 \\
\hline Rhynocorynura (Rc.) & & 1 & & & & 1 & & & \\
\hline MEGACHILIDAE & & & 3 & & & & & 8 & 1 \\
\hline Megachile $(\mathrm{Mg})$. & & & 3 & & & & & 8 & 1 \\
\hline
\end{tabular}




\begin{tabular}{|c|c|c|c|c|c|c|c|c|c|c|}
\hline & & & & & & & & & & Tabela 2 (conclusão) \\
\hline ANTHOPHORIDAE & 9 & 12 & 13 & 22 & 1 & 58 & 4 & 77 & 12 & \\
\hline Ceratina $(\mathrm{Ct})$. & 1 & 3 & 2 & 2 & & 4 & 2 & 3 & 4 & \\
\hline Ceratinula (Cl.) & 3 & 3 & 6 & 11 & & 34 & & 24 & 5 & \\
\hline Exomalopsis (Ex.) & & 2 & 1 & & & 2 & & 2 & 2 & \\
\hline Melissoptila (M1.) & & & 1 & & & & & 4 & 1 & \\
\hline Thygater (Th.) & 1 & 1 & 1 & 4 & 1 & 11 & 2 & 24 & & \\
\hline Xylocopa (Xу.) & 2 & 3 & 2 & 3 & & 7 & & 20 & & \\
\hline Lophopedia (Lo.) & 1 & & & 1 & & & & & & \\
\hline Paratetrapedia (Pr.) & 1 & & & 1 & & & & & & \\
\hline APIDAE & 7 & 7 & 6 & 1342 & & 2585 & 5 & 1673 & 17 & \\
\hline Bombus (Bo.) & 2 & 2 & 2 & 23 & & 34 & 3 & 116 & & \\
\hline Nannotrigona (Nn.) & 1 & 1 & 1 & 63 & & 80 & & 23 & 5 & \\
\hline Partamona $(\mathrm{Pa})$. & 1 & 1 & & 50 & & 147 & & & & \\
\hline Plebeia $(\mathrm{Pb})$. & 1 & 1 & 1 & 483 & & 1519 & 1 & 1081 & 11 & \\
\hline Tetragonisca $(\mathrm{Te})$. & 1 & 1 & 1 & 59 & & 89 & & 38 & & \\
\hline Trigona $(\mathrm{Tr})$. & 1 & 1 & 1 & 664 & & 716 & & 415 & 1 & \\
\hline
\end{tabular}

TOTAL $\begin{array}{llll}49 & 70 & 74 & 1624\end{array}$ 
Segundo MichenER (1974), Halictidae apresenta distribuição mundial e exibe um espectro comportamental que varia desde o solitário até o primitivamente eusocial.

No que se refere às três amostras realizadas no PP (PP-92/93, PP86/87 e PP-75), encontram-se mencionados a seguir, o número e a percentagem de espécies por família de abelhas silvestres, para fins de comparação.

$\begin{array}{lccc} & \text { PP-92/93 } & \text { PP-86/87 } & \text { PP-75 } \\ \text { COLLETIDAE } & 1(2,0 \%) & 2(2,9 \%) & 4(5,4 \%) \\ \text { ANDRENIDAE } & 0 & 2(2,9 \%) & 3(4,1 \%) \\ \text { HALICTIDAE } & 32(65,3 \%) & 47(67,1 \%) & 45(60,8 \%) \\ \text { MEGACHILIDAE } & 0 & 0 & 3(4,1 \%) \\ \text { ANTHOPHORIDAE } & 9(18,4 \%) & 12(17,1 \%) & 13(17,5 \%) \\ \text { APIDAE } & 7(14,3 \%) & 7(10,0 \%) & 6(8,1 \%) \\ \text { TOTAL } & 49 & 70 & 74\end{array}$

No PP, as famílias com menor representatividade em termos de número de espécies são Colletidae, Andrenidae e Megachilidae. Esta última apresenta a menor diversidade na amostragem PP-75, estando ausente na de PP-86/87 e PP-92/93. Nesta área, verifica-se também a redução gradativa do número de espécies de Colletidae e Andrenidae nos censos de PP-86/87 e PP-92/93, e a ausência de Andrenidae em PP92/93.

Em número de indivíduos por família de abelhas silvestres, observa-se que Apidae é a mais abundante nas três amostras do PP, enquanto que, nas demais localidades do Planalto de Curitiba, o maior número de indivíduos capturados pertence a Halictidae.

A distribuição do número de indivíduos (I) por espécies (E), segundo o arranjo I/E, em PP-92/93, PP-86/87 e PP-75, citada a seguir, evidencia que poucas são as espécies com um grande número de indivíduos. Considerando-se, ainda, as espécies com um e dois indivíduos capturados, observa-se a redução gradativa na proporção $(48,6 \% ; 45,7 \% ; 40,8 \%)$ obtida nos censos de PP-75, PP-86/87 e PP-92/93. 


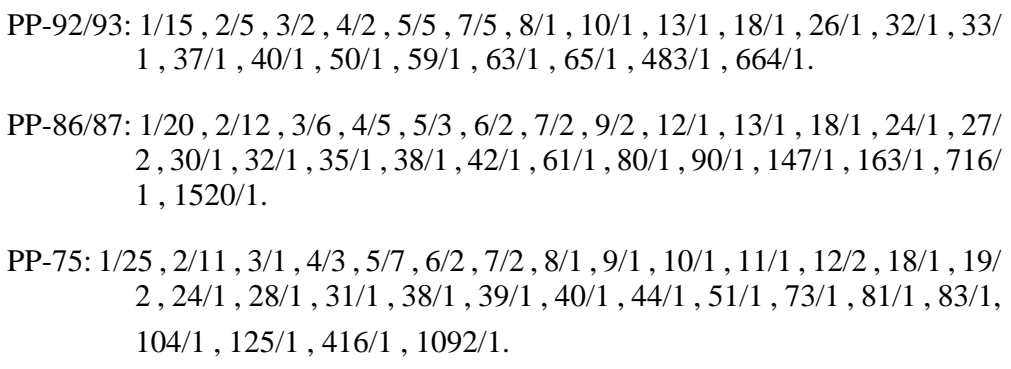

Os resultados de PP-92/93, PP-86/87 e PP-75, agrupados segundo as classes de abundância (oitavas), conforme o método de Preston (1948), também indicam que a maioria das espécies encontra-se representada por um pequeno número de indivíduos (Fig. 9). Como se observa nos gráficos da figura, também é menor o ajustamento à curva lognormal. Conforme Laroca (ver LAROCA, BECKER \& ZANELLA (1989), tal situação pode estar refletindo um certo "caos" na distribuição de indivíduos por espécie, em decorrência de perturbações do espaço de recursos por atividades humanas.

No que se refere à similaridade, em nível de gêneros, os quocientes (de Sörensen, 1948 - $c f$. Southwood, 1971) apresentados a seguir, indicam que as áreas comparadas com índice superior a $70 \%$ são BV e SJP62/63, PC e SJP-62/63, PC e SJP-81/82, PP-75 e PP-86/87, PP-75 e PP92/93, PP-86/87 e PP-92/93.

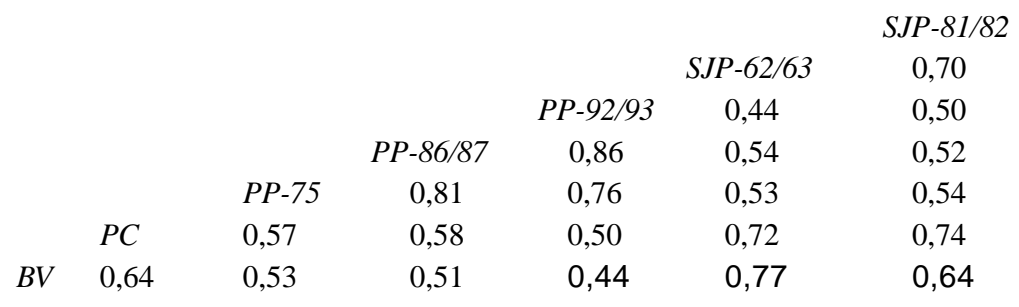

Observam-se semelhanças relativamente elevadas entre censos realizados em períodos de tempo mais próximos, como por exemplo entre PP-75 e PP-86/87 e entre PP-86/87 e PP-92/93, com índices acima de $80 \%$. O contrário também é notório, como por exemplo, entre BV e PP92/93 e entre SJP-62/63 e PP-92/93, onde se observam os menores índices $(44 \%)$.

Dentre as localidades restritas estudadas na região de Curitiba, PP é onde se observa a menor riqueza na associação de abelhas, em termos de gêneros e de espécies. Entre as três amostras do PP, verifica-se a ocorrência de muitos gêneros considerados comuns, os quais foram também 
Tabela 4. Ocorrência de gêneros de abelhas silvestres (Hymenoptera, Apoidea) nas várias áreas do Planalto de Curitiba, Paraná.

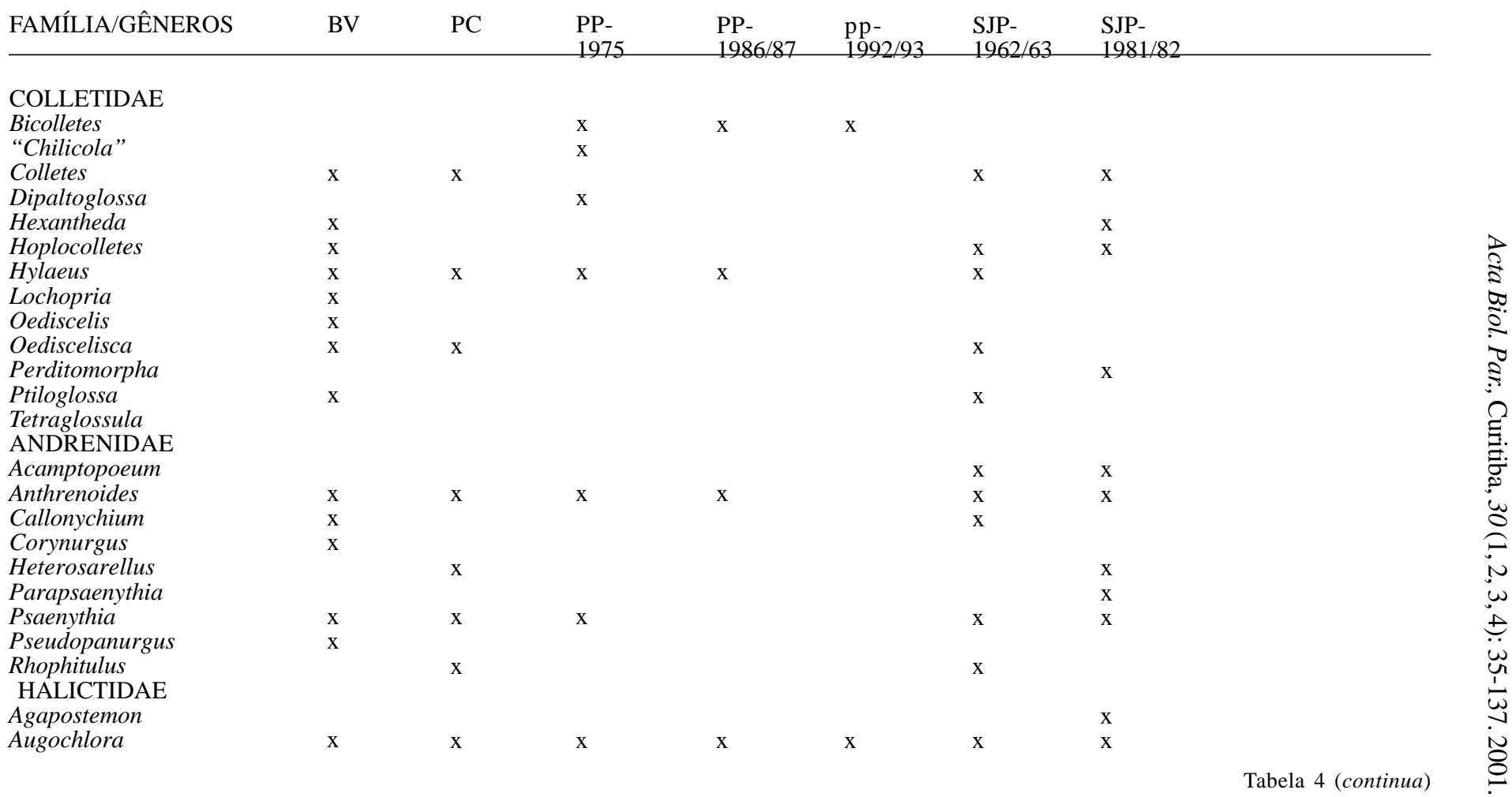


Tabela 4 (continuação)

\begin{tabular}{|c|c|c|c|c|c|c|c|}
\hline FAMÍLIA/GÊNEROS & $\mathrm{BV}$ & $\mathrm{PC}$ & $\begin{array}{l}\text { PP- } \\
1975\end{array}$ & $\begin{array}{l}\text { PP- } \\
1986 / 87\end{array}$ & $\begin{array}{l}\text { pp- } \\
1992 / 93\end{array}$ & $\begin{array}{l}\text { SJP- } \\
1962 / 63\end{array}$ & $\begin{array}{l}\text { SJP- } \\
1981 / 82\end{array}$ \\
\hline Augochlorella & $\mathrm{x}$ & $\mathrm{x}$ & $\mathrm{x}$ & $\mathrm{x}$ & $\mathrm{x}$ & $\mathrm{x}$ & $\mathrm{x}$ \\
\hline Augochlorodes & & $\mathrm{x}$ & & & & $\mathrm{x}$ & \\
\hline Augochloropsis & $\mathrm{x}$ & $\mathrm{x}$ & $\mathrm{x}$ & $\mathrm{x}$ & $\mathrm{x}$ & $\mathrm{x}$ & $\mathrm{x}$ \\
\hline Caenohalictus & $\mathrm{x}$ & $\mathrm{x}$ & $\mathrm{x}$ & $\mathrm{x}$ & $\mathrm{x}$ & $\mathrm{x}$ & $\mathrm{x}$ \\
\hline Ceratalictus & $\mathrm{x}$ & $\mathrm{x}$ & & & & $\mathrm{x}$ & $\mathrm{x}$ \\
\hline Dialictus & $\mathrm{x}$ & $\mathrm{x}$ & $\mathrm{x}$ & $\mathrm{x}$ & $\mathrm{x}$ & $\mathrm{x}$ & $\mathrm{x}$ \\
\hline Halictilus & $\mathrm{x}$ & & & & & & \\
\hline Neocorynura & $\mathrm{x}$ & $\mathrm{x}$ & $\mathrm{x}$ & $\mathrm{x}$ & $\mathrm{x}$ & $\mathrm{x}$ & $\mathrm{x}$ \\
\hline Paraxystoglossa & $\mathrm{x}$ & $\mathrm{x}$ & & & & $\mathrm{x}$ & $\mathrm{x}$ \\
\hline Pseudagapostemon & $\mathrm{x}$ & $\mathrm{x}$ & & $\mathrm{x}$ & $\mathrm{x}$ & $\mathrm{x}$ & $\mathrm{x}$ \\
\hline Pseudaugochloropsis & $\mathrm{x}$ & $\mathrm{x}$ & $\mathrm{x}$ & $\mathrm{x}$ & $\mathrm{x}$ & $\mathrm{x}$ & $\mathrm{x}$ \\
\hline Rhectomia & $\mathrm{x}$ & $\mathrm{x}$ & & & & & \\
\hline Rhynchalictus & & $\mathrm{x}$ & & & & & $\mathrm{x}$ \\
\hline Rhynocorynura & & $\mathrm{x}$ & & $\mathrm{x}$ & & $\mathrm{x}$ & \\
\hline Sphecodes & & & & & & $\mathrm{x}$ & $\mathrm{x}$ \\
\hline Temnosoma & $\mathrm{x}$ & & & & & $\mathrm{x}$ & \\
\hline $\begin{array}{l}\text { Thectochlora } \\
\text { MEGACHILIDAE }\end{array}$ & $\mathrm{x}$ & $\mathrm{x}$ & & & & & $\mathrm{x}$ \\
\hline Coelioxys & $\mathrm{x}$ & $\mathrm{x}$ & & & & $\mathrm{x}$ & $\mathrm{x}$ \\
\hline Ctenanthidium & $\mathrm{x}$ & & & & & & \\
\hline Dianthidium & & $\mathrm{x}$ & & & & & \\
\hline $\begin{array}{l}\text { Epanthidium } \\
\text { Escla } 4 \text {. }\end{array}$ & & & & & & $\mathrm{x}$ & \\
\hline Hypanthidium & $\mathrm{x}$ & & & & & & \\
\hline Megachile & $\mathrm{x}$ & $\mathrm{x}$ & $\mathrm{x}$ & & & $\mathrm{x}$ & \\
\hline ANTHOPHORIDAE & & & & & & & \\
\hline Anthophora & $\mathrm{x}$ & & & & & $\mathrm{x}$ & $\mathrm{x}$ \\
\hline Centris & & & & & & $\mathrm{x}$ & \\
\hline
\end{tabular}




\begin{tabular}{|c|c|c|c|c|c|c|c|c|}
\hline & & & & & & & & Tabela 4 (conclusão) \\
\hline Ceratina & $\mathrm{x}$ & $\mathrm{x}$ & $\mathrm{x}$ & $\mathrm{x}$ & $\mathrm{x}$ & $\mathrm{x}$ & $\mathrm{x}$ & \\
\hline Ceratinula & $\mathrm{x}$ & $\mathrm{x}$ & $\mathrm{x}$ & $\mathrm{x}$ & $\mathrm{x}$ & $\mathrm{x}$ & $\mathrm{x}$ & \\
\hline Epeolus & & $\mathrm{x}$ & & & & & & \\
\hline Exomalopsis & $\mathrm{x}$ & $\mathrm{x}$ & $\mathrm{x}$ & $\mathrm{x}$ & & $\mathrm{x}$ & $\mathrm{x}$ & \\
\hline Gaesischia & $\mathrm{x}$ & $\mathrm{x}$ & & & & $\mathrm{x}$ & $\mathrm{x}$ & \\
\hline Isepeolus & $\mathrm{x}$ & & & & & $\mathrm{x}$ & & \\
\hline Lanthanomelissa & $\mathrm{x}$ & $\mathrm{x}$ & & & & $\mathrm{x}$ & $\mathrm{x}$ & \\
\hline Lophopedia & & & & & $\mathrm{x}$ & & & \\
\hline Melissodes & & & & & & & $\mathrm{x}$ & \\
\hline Melissoptila & $\mathrm{x}$ & $\mathrm{x}$ & $\mathrm{x}$ & & & $\mathrm{x}$ & $\mathrm{x}$ & \\
\hline Melitoma & & $\mathrm{x}$ & & & & & & \\
\hline Nomada & $\mathrm{x}$ & & & & & $\mathrm{x}$ & & \\
\hline Paratetrapedia & & $\mathrm{x}$ & & & $\mathrm{x}$ & & $\mathrm{x}$ & \\
\hline Peponapis & $\mathrm{x}$ & & & & & & & \\
\hline Ptilothrix & $\mathrm{x}$ & & & & & & & \\
\hline Tapinotaspis & & $\mathrm{x}$ & & & & & $\mathrm{x}$ & \\
\hline Tapinotaspoides & & & & & & $\mathrm{x}$ & & \\
\hline Thygater & $\mathrm{x}$ & $\mathrm{x}$ & $\mathrm{x}$ & $\mathrm{x}$ & $\mathrm{x}$ & $\mathrm{x}$ & $\mathrm{x}$ & \\
\hline Triepeolus & $\mathrm{x}$ & & & & & & & \\
\hline Trophocleptria & $\mathrm{x}$ & & & & & $\mathrm{x}$ & & \\
\hline $\begin{array}{l}\text { Xylocopa } \\
\text { APIDAE }\end{array}$ & $\mathrm{x}$ & $\mathrm{x}$ & $\mathrm{x}$ & $\mathrm{x}$ & $\mathrm{x}$ & $\mathrm{x}$ & $\mathrm{x}$ & \\
\hline Bombus & $\mathrm{x}$ & $\mathrm{x}$ & $\mathrm{x}$ & $\mathrm{x}$ & $\mathrm{x}$ & $\mathrm{x}$ & $\mathrm{x}$ & \\
\hline Eulaema & $\mathrm{x}$ & & & & & & & \\
\hline Melipona & $\mathrm{x}$ & & & & & $\mathrm{x}$ & & \\
\hline Nannotrigona & $\mathrm{x}$ & & $\mathrm{x}$ & $\mathrm{x}$ & $\mathrm{x}$ & & & \\
\hline Partamona & & & & $\mathrm{x}$ & $\mathrm{x}$ & & & \\
\hline Plebeia & $\mathrm{x}$ & $\mathrm{x}$ & $\mathrm{x}$ & $\mathrm{x}$ & $\mathrm{x}$ & $\mathrm{x}$ & & \\
\hline Tetragonisca & & & $\mathrm{x}$ & $\mathrm{x}$ & $\mathrm{x}$ & & & \\
\hline Trigona & $\mathrm{x}$ & & $\mathrm{x}$ & $\mathrm{x}$ & $\mathrm{x}$ & $\mathrm{x}$ & $\mathrm{x}$ & \\
\hline
\end{tabular}

FONTES: BV (Laroca, 1972); PC (Cure, 1983); PP-75 (Laroca, Cure \& Bortol, 1982); PP-86/87 (Taura, 1990); PP-92/93 (LEVANTAMENTO dE 1992/93); SJP-62/63 (SakaGami, Laroca \& Moure, 1967); SJP$81 / 82$ (Bortoli \& LAROCA, 1990). 
capturados nas demais áreas do Planalto de Curitiba (Tabela 4). Para LARoca, Cure \& Bortoli (1982), este local é comparável a uma "ilha" no meio de uma cidade onde reina a instabilidade e com alta frequiencia de espécies exóticas de plantas. Assim, é provável que a estrutura da comunidade de abelhas observada, seja decorrência de sua localização e isolamento com limitações em receber novos imigrantes, acentuados pelas ações humanas, como a prática de jardinagem, urbanização crescente, poluição do ar, ruídos e intervenção direta de visitantes.

Estudos indicam que determinadas atividades humanas contribuem para a ocorrência de alterações na fauna de abelhas. Por exemplo, GinsBERG (1981) registra profundas mudanças na região de Ithaca, nordeste dos EUA, após a colonização, principalmente com a introdução de Apis mellifera e modificações da flora regional.

Verifica-se que censos realizados na década de 60, isto é, BV e SJP62/63, são os que apresentam maior diversidade de gêneros capturados, enquanto que nos mais recentes (PC, SJP-81/82, PP-86/87 e PP-92/93), há a tendência de simplificação. Possivelmente, diversas atividades humanas como desmatamentos, queimadas, crescimento urbano, poluição, entre outros, têm contribuído para a diminuição constatada na composição apifaunística. Neste sentido, Odum (1985) comenta que a diversidade tende a ser reduzida em comunidades bióticas que sofrem estresse.

Para se estimar a diversidade de abelhas do PP e BV (Fig. 10), foi utilizado o método de correlação entre o número acumulado de espécies e o número acumulado de indivíduos (em escala logarítmica) empregado por Laroca (LARoca, Cure \& Bortoli, 1982). Segundo os autores acima, o coeficiente angular " $b$ " da equação $y=a+b x$, fornece uma estimativa da diversidade da associação de Apoidea de um dado local. Considerando-se este critério para as três amostras obtidas no PP, observa-se a tendência à diminuição da diversidade neste local, isto é, PP-75 apresentando a maior enquanto que PP-92/93 a menor diversidade. Obviamente, em relação à BV , também PP apresenta maior simplificação na composição apifaunística.

Em relação à mensuração da diversidade, foi também utilizado o método de Shannon-Wienner (1949) (Krebs, 1972 e Poole, 1974), o qual considera os componentes riqueza de espécies $(\mathrm{H})$, representada pelo número total de espécies e eqüabilidade (E), isto é, distribuição de indivíduos entre as espécies. Assim sendo, para as amostras do PP e BV, os indices calculados através desta técnica são:

$\begin{array}{lllll} & \text { PP-92/93 } & \text { PP-86/87 } & \text { PP-75 } & \text { BV } \\ \text { H } & 2,9930 & 2,8622 & 3,3661 & 5,6556 \\ \text { E } & 0,5331^{\prime} & 0,4670 & 0,5404 & 0,7734\end{array}$



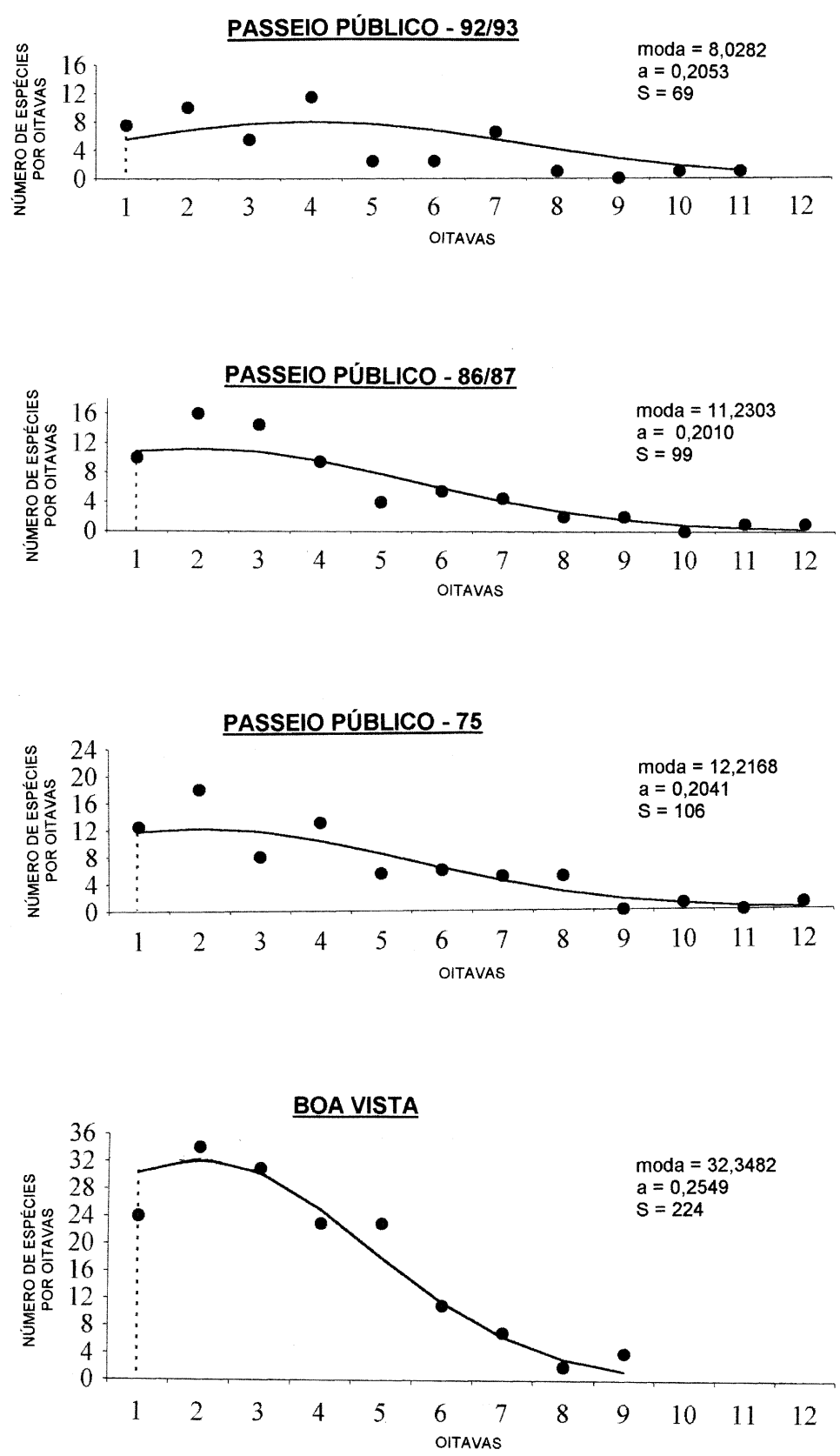

Fig. 9. Freqüência de espécies de abelhas silvestres (Hymenoptera, Apoidea) capturadas no Passeio Público, Curitiba, Paraná, em 1992/93, 1986/87 e 1975, distribuídas segundo as oitavas de abundância, conforme o método de Preston (1948).Fontes: PP-75 (Laroca, Cure \& Bortoli, 1982); PP-86/87 (TAURA, 1990). 


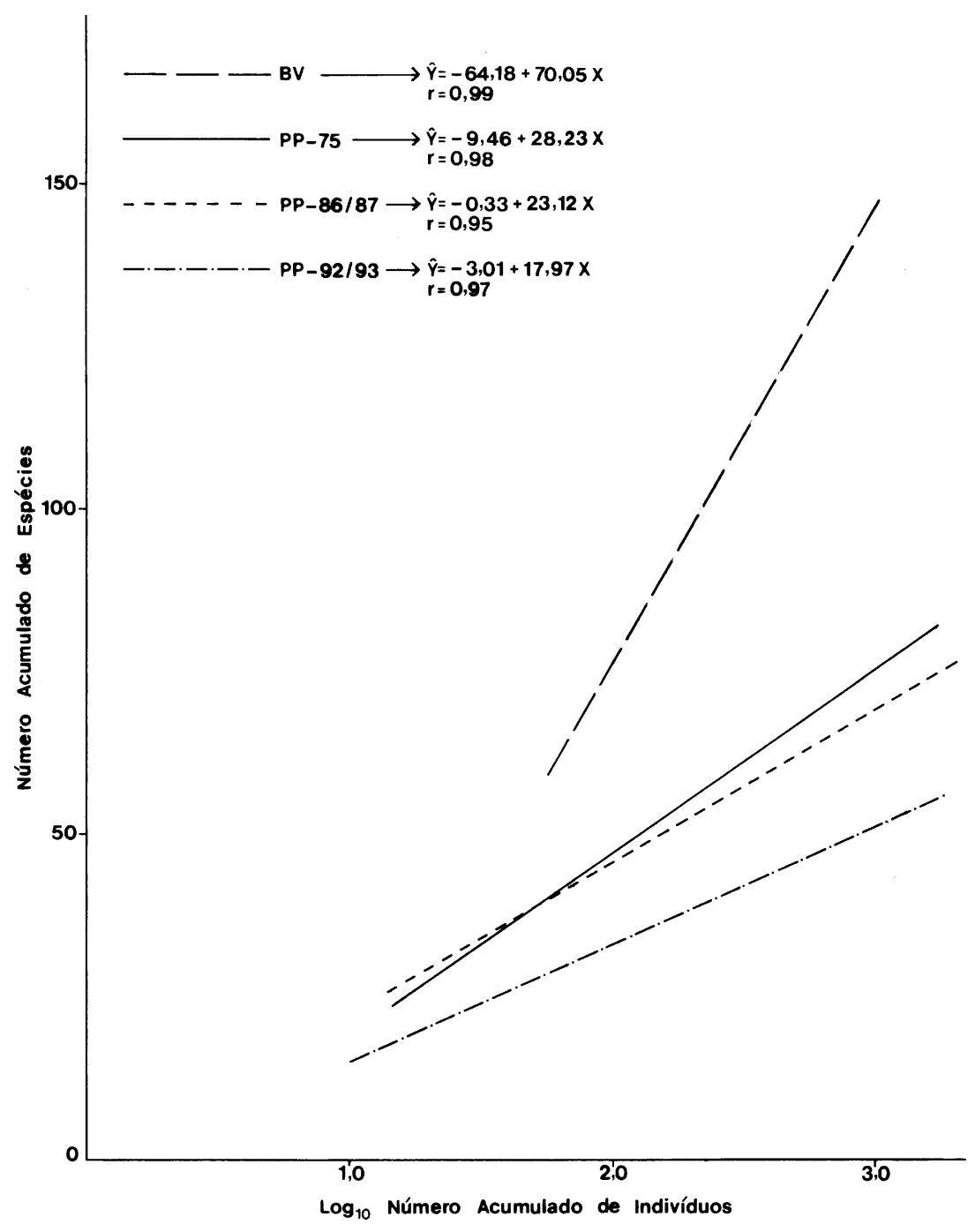

Fig. 10. Relação entre o número de espécies e de indivíduos de abelhas silvestres (Hymenoptera, Apoidea), capturados durante o período de 1963/64 em Boa Vista, Curitiba, Paraná e em 1992/93, 1986/87 e 1975 no Passeio Público, Curitiba, Paraná. 


\section{ESPÉCIES PREDOMINANTEMENTE CAPTURADAS}

Na figura 11 estão representadas simultaneamente, as espécies predominantes na amostra de PP-92/93 (6 espécies), PP-86/87 (7 espécies) e PP-75 (9 espécies). Para o cálculo dos limites de confiança superior e inferior $(\mathrm{p}=0,05)$ foi utilizado o método de Kato, Matsuda \& Yamashita (1952) ( $C F$. SAKAGAMI \& Matsumura, 1967 e Laroca, 1972).

Evidenciam-se algumas variações entre as três épocas de estudos realizados no PP. Assim, em PP-75, nota-se a ocorrência de espécies de Apidae, Halictidae, Colletidae e Andrenidae, como predominantemente capturadas. Entretanto, em PP-86/87 e PP-92/93, a representatividade baseia-se quase que exclusivamente por Apidae, com exceção de $A$. michaelis na primeira amostra citada e A. (A.) amphitrite na segunda.

A espécie predominantemente capturada em PP-92/93, é $T$. (T.) spinipes (39\%), enquanto que $P$. (P.) emerina consta como a mais abundante nos levantamentos de PP-86/87 e PP-75, com 47\% e 44\%, respectivamente.

Algumas espécies como $B$. (F.) atratus, $N$. (N.) aenigma, $H$. rivalis, $D$. (Chloralictus) sp.1 e sp.14, Panurginae sp.1, são consideradas predominantes apenas na amostra de PP-75. Observa-se também a ausência de $H$. rivalis e Panurginae sp.1 no levantamento de PP-92/93.

Espécies como $T$. (T.) angustula fiebrigi e $N$. (S.) bipunctata, não predominantes em PP-75, assim como Partamona helleri, ausente nesta amostragem, mostram acréscimos na abundância, sendo consideradas predominantemente capturadas em PP-86/87 e PP-92/93.

A organização social de Apidae contribui para a predominância desta família, especialmente de Meliponinae, constatada nas amostragens efetuadas em PP-92/93, PP-86/87 e PP-75. Conforme MichENER (1974), espécies eusociais, como Meliponinae, possuem densidades populacionais variáveis entre uma centena e 180.000 indivíduos, neste caso observado em $T$. (T.) spinipes.

Os Meliponinae apresentam, ainda, hábitos diversificados de nidificação, pois controem seus ninhos em cavidades de árvores viva ou secas, no interior de formigueiros ou termiteiros, subterraneamente, como também de forma exposta entre ramos em copas de árvores (KerR et al., 1967; Nogueira Neto, 1970).

No PP, a disponibilidade de locais propícios para nidificação de Meliponinae, segundo TAURA \& LAROCA (1991) é aumentada por ações humanas, como: edificações, paredões de concreto, trabalho de preservação de árvores atacadas por cupins e que tiveram as cavidades parci- 
Acta Biol. Par., Curitiba, 30 (1, 2, 3, 4): 35-137. 2001.

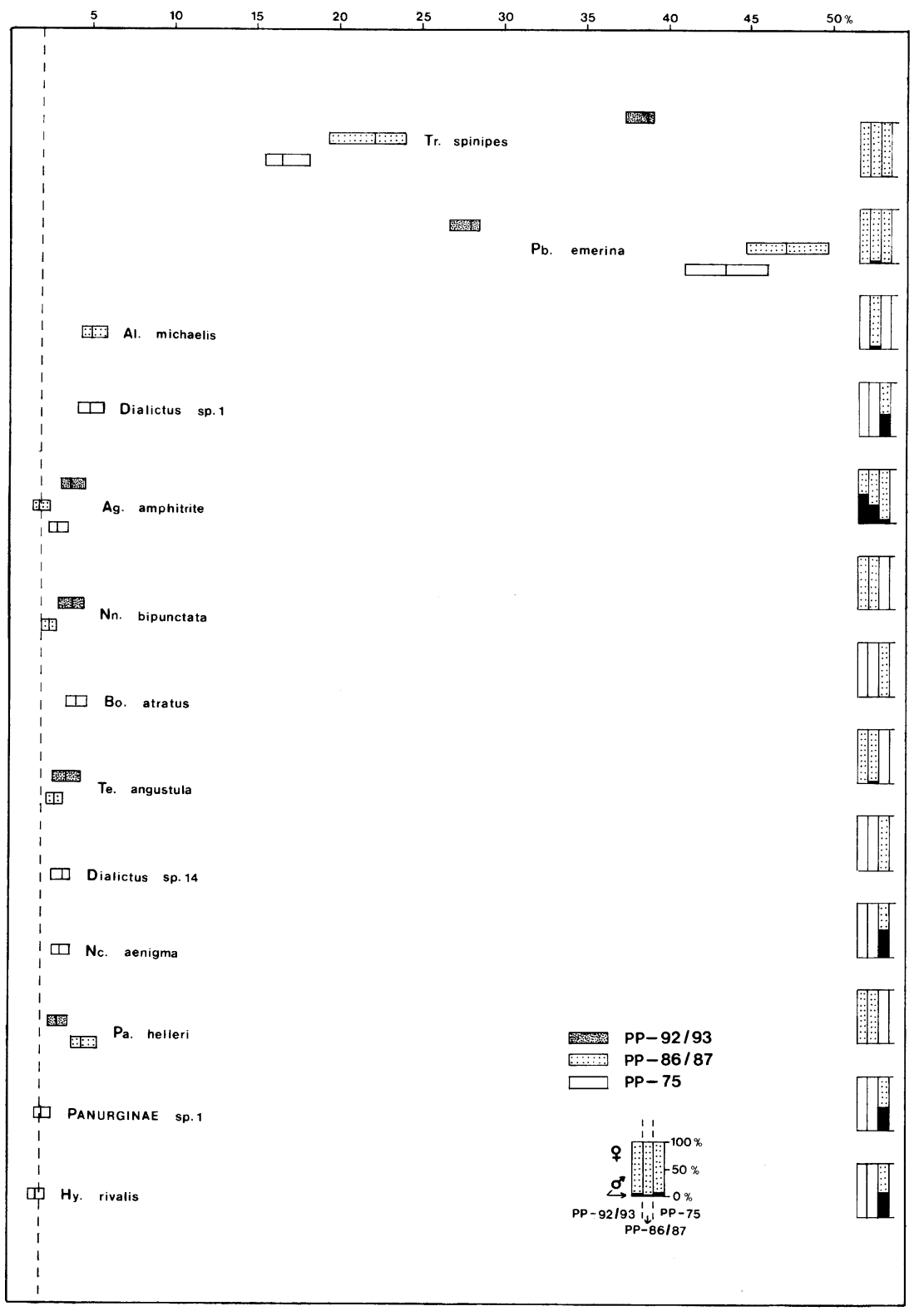

Fig. 11. Abundância relativa (\%) das espécies de abelhas silvestres (Hymenoptera, Apoidea) predominantemente capturadas no Passeio Público, Curitiba, Paraná, em 1992/93, 1986/87 e 1975. Os limites de confiança foram calculados pelo método de Kato, MATSUDA \& YAMASHITA (1952) e encontram-se representados pelas barras horizontais com escala na parte superior. A proporção sexual (\%) das espécies citadas é apresentada no lado direito. A linha tracejada vertical mostra a recíproca do número de espécies coletadas em PP-92/93, multiplicado por 100. Os gêneros encontram-se abreviados conforme a tabela 2. Fonte: PP-75 (LAROCA, CURE \& BorTOLI, 1982); PP-86/ 87 (TAURA, 1990). 
almente preenchidas por cimento, ocupadas posteriormente por abelhas desta subfamília. A retirada de colônias de A. mellifera pelos funcionários do local, devido à sua agressividade em relação aos animais e ao público, possivelmente também favorece os Meliponinae.

Durante as observações realizadas em 1987, 1988 e 1991, TAURA \& LAROCA (1991) constataram que os locais apropriados para nidificação de Apidae, geralmente encontram-se ocupados, sobretudo por $P$. (P.) emerina.

A espécie $T$. (T.) spinipes apresenta uma ampla distribuição geográfica, estando presente em quase todo o território brasileiro, desde o Pará até o Rio Grande do Sul, alcançando a Argentina e o Paraguai (AlmeidA \& LAROCA, 1988). Estes autores comentam que a abundância verificada em boa parte dos biótopos brasileiros, possivelmente deve-se à agressividade das operárias, inacessibilidade dos locais onde os ninhos são contruídos, versatilidade na localização de ninhos, no grande número de espécies de flores onde as operárias coletam pólen, e falta de interesse do homem na exploração de seus produtos.

Distribuição DE NinHos DE MELIPONINAE:

TEORIAS SOBRE VIABILIDADE GENÉTICA

Em relação à viabilidade de colônias de Apidae, especialmente de Meliponinae, presentes em determinada área em número restrito, existe no momento uma discussão com teorias e argumentações diferenciadas a respeito (Kerr \& Vencovsky, 1982; Kerr, 1987; Nogueira-Neto, 1997). Apesar de não terem sido realizados experimentos específicos relacionados ao referido tema no PP, algumas considerações são feitas a seguir, no sentido de trazer alguma contribuição ao debate.

Devido à localização do PP, no centro de uma cidade, circundado por construções, muitas destas, com 10 metros de altura ou mais, e ruas pavimentadas apresentando contínuo fluxo de veículos automotores, a probabilidade de fundação de novas colônias por indivíduos oriundos de áreas adjacentes torna-se relativamente baixa.

As únicas áreas verdes circunvizinhas ao PP, são os jardins do Colégio Estadual do Paraná e Praça Santos Andrade, onde são cultivadas algumas espécies de plantas, porém ambos são de porte razoavelmente pequeno. Mesmo entre estes três locais, indivíduos de abelhas teriam, possivelmente, dificuldades de locomoção, pela existência de obstáculos como prédios elevados e tráfego contínuo. 


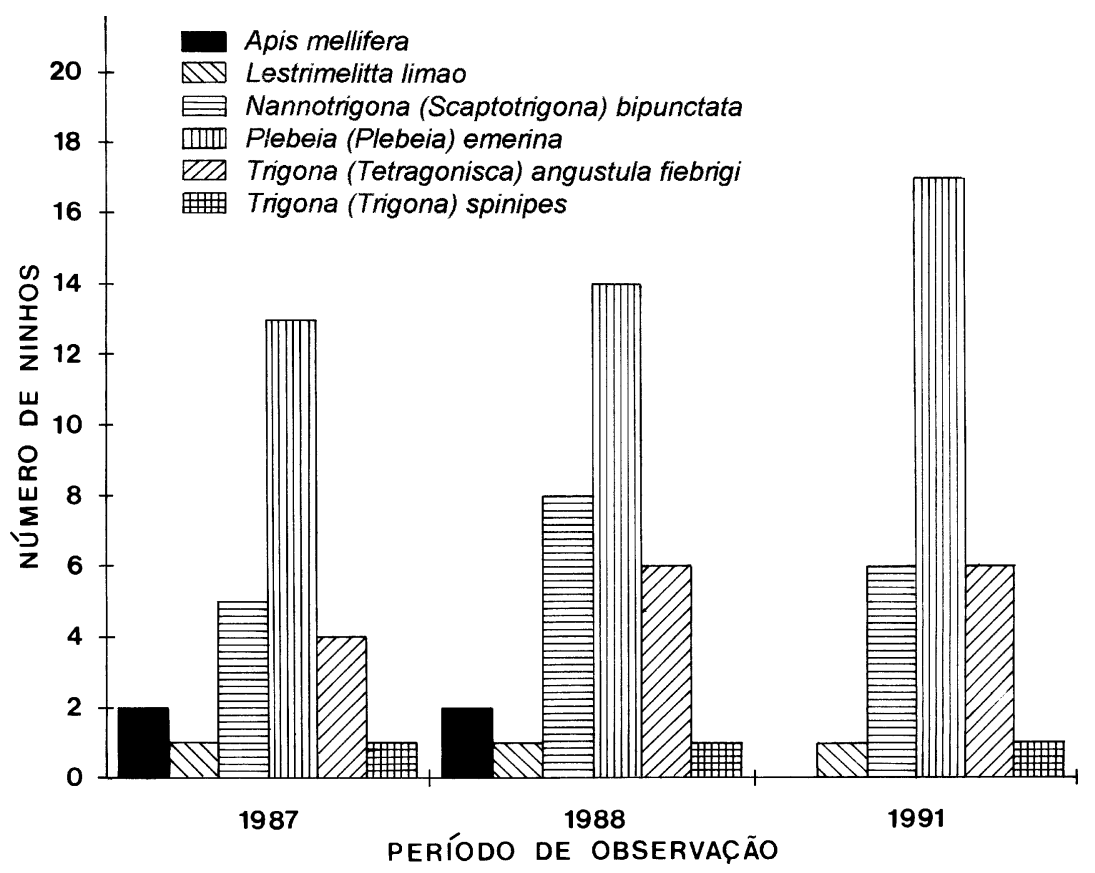

Fig. 12. Número de ninhos de abelhas altamente sociais (Apidae) encontrados no Passeio Público, Curitiba, Paraná, em 1987, 1988 e 1991. 
Em situações como a constatada no PP, a freqüência de endocruzamento aumenta em relação às áreas menos isoladas. Estudos com abordagem em endocruzamentos de abelhas sociais têm sido realizados, todavia, as considerações feitas pelos autores divergem à respeito da descendência destes cruzamentos, especialmente em relação à produção de machos diplóides. Assim, Whiting (1943) (cf. Nogueira-Neto, 1997) formulou a teoria conhecida atualmente como o Principio de Whiting, segundo o qual quando ocorrer endocruzamento, a descendência será de fêmeas se forem heterozigotas e de machos diplóides se forem homozigotas, em relação a certos alelos sexuais.

Baseado no Princípio de Whiting, para NogueIRA-Neto (1997), toda vez que ocorrer endocruzamento em uma colônia de Meliponinae, espera-se que $50 \%$ das vezes toda a descendência diplóide seja feminina, constituída por operárias e rainhas e em outros $50 \%$ dos casos, a sua descendência diplóide seja metade feminina e metade constituída por machos diplóides. Resultados de experimentos realizados por este pesquisador indicam, entretanto, que o princípio mencionado é válido somente quando existem condições de estresse ecológico.

Os machos diplóides são considerados praticamente inúteis e representam segundo NogUeIRA-NeTo (1997), uma sobrecarga para a colônia, pois, consomem para se desenvolver a mesma quantidade de alimentos que uma fêmea em crescimento. Portanto, se ao invés de produzir como indivíduos diplóides $100 \%$ de operárias e rainhas, vier a produzir $50 \%$ de operárias e rainhas e $50 \%$ de machos diplóides, será uma colônia fraca.

A teoria formulada por KerR \& VEncovski (1982) e KerR $(1985,1987)$ indica a necessidade do número mínimo de 40 e 44 colônias, respectivamente, para a sobrevivência da população local de uma determinada espécie de Meliponinae.

No PP, verificam-se colônias de Meliponinae abaixo do número de viabilidade indicado pelos autores mencionados acima. Observações realizadas em 1987, 1988 e 1991 (Fig. 12), mostram a existência de espécies de Meliponinae com número de colônias bastante restrito (TAURA \& LAROCA, 1991). Por exemplo, um ninho de Lestrimelitta limao foi constatado neste local em 1962, por SAKAGAMI \& LAROCA (1963) e cuja ocorrência verificada também em 1987, 1988, 1991 e durante o censo de PP-92/ 93. A espécie Plebeia (Plebeia) emerina, considerada a mais abundante em termos de indivíduos capturados em PP-75 (Laroca, Cure \& Bortoli, 1982) e PP-86/87 (TAURA, 1990) e em número de colônias localizadas por TAURA \& LAROCA (1991), apresenta o número máximo de 17 ninhos em 1991. 

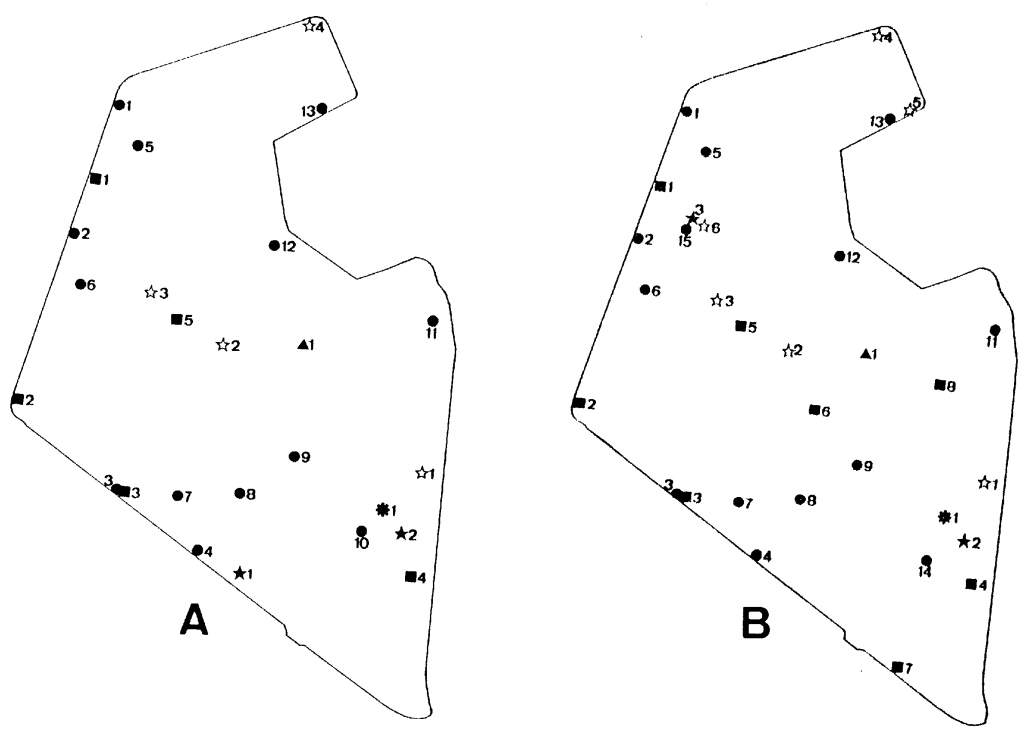

$\star$ Apis mellifera

- Lestrimelitta limao

- Nannotrigona (Scaptotrigona) bipunctata

- Plebeia (Plebeia) emerina

is Trigona (Tetragonisca) angustula fiebrigi

* Trigona (Trigona) spinipes

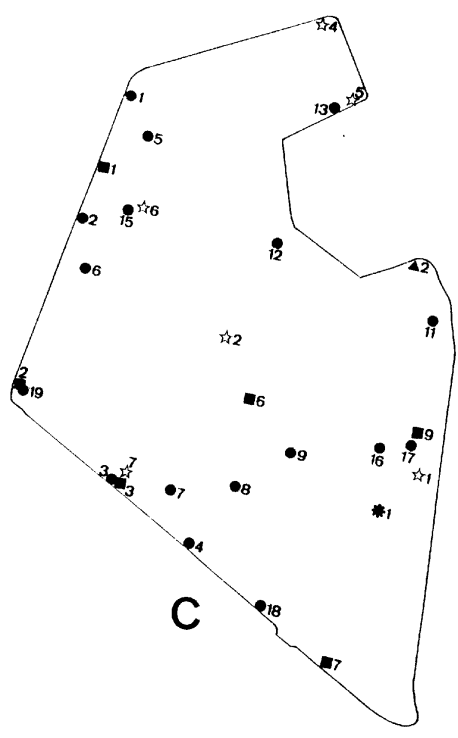

Fig. 13. Distribuição de ninhos de abelhas altamente sociais (Apidae) no Passeio Público, Curitiba, Paraná, em 1987 (A), 1988 (B) e 1991 (C). Fonte: Taura \& Laroca (1991). 
Observa-se também no PP, uma dinâmica no processo de estabelecimento e desaparecimento de colônias de Meliponinae como também de Apis mellifera, como pode ser visualizado na figura 13 (TAURA \& LAROCA,1991). Todavia, em relação às colônias de Apis mellifera, as modificações são causadas pela retirada das mesmas por funcionários do local, devido à sua agressividade, conforme informação dos mesmos. Em termos de ninhos de Meliponinae, por exemplo, em 1987 foram constatadas quatro colônias de Trigona (Tetragonisca) angustula fiebrigi, sendo seis o número total de ninhos desta espécie constatado em 1988 (destes, quatro estavam nos lugares observados em 1987, sendo possivelmente as mesmas colônias, mais um nidificado em local anteriormente desocupado e outro em local não observado no ano anterior, devido dificuldade de acesso).

Em 1991, cinco colônias estavam estabelecidas ainda nos locais previamente verificados e um em local antes desocupado).

Considerando-se os ninhos de Nannotrigona (Scaptotrigona) bipunctata encontrados no PP, alterações na freqüência também foram constatadas. Em 1987, foram observados cinco ninhos. Entretanto, em 1988, oito colônias foram verificadas, sendo que destas, cinco nos mesmos locais do ano anterior, dois em locais previamente desocupadas e um situado na "ilha dos macacos aranhas" (esta última, embora não sendo possível obter amostras de indivíduos para identificação, foi atribuída como sendo desta espécie, devido à nidificação em troncos de árvores e ao comportamento agressivo das abelhas em relação à proximidade dos macacos). Em 1991, somente cinco colônias foram encontradas nas cavidades observadas em 1988, e mais uma em local não ocupado anteriormente.

Segundo os Profs. S. Laroca e Y. Terada (comunicação pessoal) algumas espécies de Meliponinae, como T. (T.) angustula, entretanto, nidificam em cavidades existentes em muros de concreto, postes de iluminação de ruas e paredes de edifícios, no interior de cidades. Indivíduos de tais colônias podem estar tendo acesso ao PP, em busca principalmente de recursos alimentares.

Nogueira-Neto (1997), com base em seus estudos, contesta o número mínimo de 44 colônias. Uma das bases de seu argumento é a constatação de que na natureza existem espécies raras de Meliponinae, com número muito pequeno de colônias. Nestes casos, segundo o pesquisador, a produção de machos diplóides poderia estar sendo compensada ou evitada por uma ampla interação genética-ambiental-hormonal. Esta teoria, ainda em estudos, explicaria a viabilidade de pequenas popu- 
lações bem adaptadas ao clima e a outras circunstâncias locais ou gerais favoráveis. Em condições ambientais favoráveis, o autor acima mencionado, acredita que na fase inicial do desenvolvimento de embriões diplóides, aumentaria a quantidade de substância hormonal que colocaria em ação os genes feminilizantes, resultando em indivíduos diplóides fêmeas, mesmo em situações de homozigose e que somente em casos de estresse contínuo, verificar-se-ia produções de machos diplóides.

No PP, além do número de colônias de Meliponinae ser razoavelmente reduzidas, estas provavelmente sofrem influências de diversas atividades decorrentes da urbanização.

Meliponinae é o grupo de abelhas arborícolas eminentemente tropicais. Assim, espera-se que populações que se encontram em áreas subtropicais, de transição, como por exemplo, na região de Curitiba, apresentem maior plasticidade ou capacidade de resistência a mudanças, o que possivelmente explicaria a capacidade de colonização de algumas espécies de Meliponinae em ambiente urbano, sujeito às modificações inerentes.

\section{ESPÉCIES DE FLORES VISITADAS}

As famílias e as espécies de plantas que receberam visitas de abelhas silvestres no PP-92/93, encontram-se relacionadas a seguir, com os respectivos códigos numéricos à direita, os quais foram utilizados para a obtenção de listagem de computador e análise dos resultados.

$\begin{array}{lc}\text { ACANTHACEAE } & \\ \text { Thumbergia laurifolia } \text { Lindl. } & 01143 \\ \text { AMARYLLIDACEAE } & \\ \text { Agapanthus africanus } \text { Hoffmgg } & 04126 \\ \text { ANACARDIACEAE } & \\ \begin{array}{l}\text { Schinus terebinthifolius } \text { Raddi } \\ \text { APOCYNACEAE }\end{array} & 05136 \\ \text { Allamanda schottii Pohl. } & \\ \text { Catharanthus roseus } \text { (L.) G. Don } & 06037 \\ \text { ARACEAE } & 06164 \\ \text { Calladium } \text { sp. } & \\ \text { ASTERACEAE } & 07038 \\ \begin{array}{l}\text { Bidens pilosus } \text { L. } \\ \text { Jaegeria hirta } \text { (Lagasca) Lessing }\end{array} & \\ \text { Tagetes patula L. } & 08086 \\ \text { BALSAMINACEAE } & \\ \text { Impatiens } \text { sp. } & \\ \text { BIGNONIACEAE } & 08091 \\ \text { Jacaranda mimosaefolia } \text { D. Don } & \\ \text { Jacaranda puberula } \text { Chamisso } & \\ \end{array}$


BOMBACACEAE

Chorisia speciosa St. Hilaire 11165

BRASSICACEAE

Iberis sempervirens $\mathrm{L}$.

BROMELIACEAE

Aechmea disticantha Lem.

Tillandsia tenuifolia $\mathrm{L}$. 13096

CAESALPINIACEAE

Senna araucarietorum Irwim \& Barneby 14144

$\begin{array}{ll}\text { Senna sp. } 2 & 14129\end{array}$

CAPPARIDACEAE

Cleome rosea Vahl. 15001

CELASTRACEAE

Maytenus sp. 17070

CONVOLVULACEAE
Cuscuta racemosa Martius

ERICACEAE
Rhododendron indicum "var. 1" Sw.

Rhododendron indicum "var. 2" Sw. 22003

Rhododendron indicum "var. 3" Sw. 22004

Rhododendron indicum "var. 4" Sw. 22005

Rhododendron indicum "var. 5" Sw. 22006

Rhododendron indicum "var. 6" Sw. 22060

Rhododendron indicum "var. 7" Sw. 22061

Rhododendron indicum "var. 8" Sw. 22062

EUPHORBIACEAE

Euphorbia splendens Boyer 23049

FABACEAE

Anthyllis vulneraria L. 24161

Crotalaria subdecurrens Mart. ex Benth. 24021

FLACOURTIACEAE

Casearia sylvestris Swartz $\quad 25150$

IRIDACEAE
Iris sp.

LABIATAE

$\begin{array}{ll}\text { Leonurus sibiricus L. } & 27040 \\ \text { Salvia splendens Sellow ex Roemer et Schultes } & 27101\end{array}$

LILIACEAE

Chlorophytum sp. 28023=28024

Cordyline dracaenoides Kunth 28071

Cordyline sp. $\quad 28014$

Hemerocallis fulva L. $\quad 28032$

Kniphofia uvaria Hook 28033

LYTHRACEAE

Lagerstroemia indica L 290125

MAGNOLIACEAE
Magnolia grandiflora L.

MALVACEAE
Abutilon mulleri-friderici Gurke et K. Schum

$\begin{array}{ll}\text { Abutilon mulleri-friderici Gurke et K. Schum } & 31044 \\ \text { Hibiscus rosa-sinensis L. } & 31063\end{array}$ 


\section{MARANTACEAE}

Stromanthe papillosa O. E. Peters 32132

MELASTOMATACEAE

Miconia hiemalis St. Hilaire et Naudin ex Naudin 33069

Tibouchina sellowiana (Chamisso) Cogniaux 33019

MIMOSACEAE

Acacia podalyriaefolia Cunn.

34084

Calliandra selloi (Sprengel) MacBride $\quad 34015$

Calliandra tweediei Bentham 34013

Inga edulis Mart. $\quad 34010$

MUSACEAE
Heliconia brasiliensis Hook

MYRTACEAE

$\begin{array}{ll}\text { Callistemon sp. } & 37092 \\ \text { Psidium cattleyanum Sabine } & 37095\end{array}$

Psidium cattleyanum Sabine $\quad 37095$

Jasminum (?) sp. $\quad 39045$

Ligustrum lucidum Mill. $\quad 39080$

Ligustrum japonicum Thunb. 39114

PALMAE

Butia eriospatha (Martius ex Drude) Beccari 40036

PITTOSPORACEAE

Pittosporum undulatum Guill. 41112

PROTEACEAE
Grevillea banksii R. Br.

ROSACEAE
Cotoneaster lacteus W. W. Smith

$\begin{array}{ll}\text { Rosa } \mathrm{sp.} & 45078\end{array}$

Rubus sp $\quad 45100$

SAPINDACEAE
Allophylus edulis (St. Hilaire) Radlkofer ex Warming

SCROPHULACEAIACEA
Veronica persica

SOLANACEAE

Brunfelsia brasiliensis var. acuminata (Pohl) Smith \& Downs 52008

Datura suaveolens Humb. \& Bonp ex Willd 52012=52120

Solanum americanum Mill. $\quad 52065$

Vassobia breviflora (Sendtn.) Hunz. $\quad 52067$

STERCULIACEAE

Dombeya wallichii(Lindley) Bentham et Hooker 53042

THEACEAE

Camellia japonica $\mathrm{L}$. 54051

THYMELAEACEAE

Daphnopsis racemosa Grisebach 55058

URTICACEAE

Phenax sp.

56141

VERBENACEAE

Vitex montevidensis Cham. $\quad 57104$

VIOLACEAE

Viola sp. 


\section{ABUNDÂNCIA RELATIVA DE FAMÍLIAS DE ABELHAS}

SOBRE AS FAMÍLIAS DE PLANTAS

A vegetação do PP é freqüentemente alterada para que esteja florida continuamente. Consequentemente, a ocorrência de espécies introduzidas neste local é elevada, representando $44,26 \%$ do total de plantas que floresceram, durante a amostragem realizada em 1992/93.

Algumas das espécies de plantas, quer sejam nativas ou introduzidas, encontram-se alteradas pelo cultivo constante, dificultando sua identificação

Em PP-92/93 foram coletadas 1674 exemplares (1598 fêmeas e 76 machos) de abelhas silvestres, nas flores de 69 espécies de plantas pertencentes a 44 famílias. Os dados referentes ao número de espécies e de indivíduos de Apoidea capturadas nas flores por família de plantas, encontram-se na Tabela 5 e são utilizadas para análise comparativa com os de PP-86/87 (Taura, 1990) e PP-75 (Laroca, Cure \& Bortoli, 1982), apresentados nas tabelas 6 e 7, respectivamente.

A quase totalidade das abelhas silvestres, em PP-92/93, foi capturada sobre as flores, sendo que dos 1700 exemplares coletados, apenas 14 fêmeas de Plebeia emerina o foram sobre as "vagens" de C. roseus (Apocynaceae) e 12 fêmeas de Trigona (Tetragonisca) angustula fiebrigi enquanto sobrevoavam folhas de A. podalyriaefolia (Mimosaceae).

Em PP-86/87, todos os indivíduos de abelhas foram capturados quando em visita às flores e em PP-75, do total de 2510 indivíduos, 2451 foram coletados enquanto visitavam flores.

O número total de famílias de plantas visitadas é ligeiramente maior em PP-86/87 com 51, seguida por PP-92/93 com 44 e PP-75 com 32 (Figura 14). Dentre estas, as famílias exclusivas em determinado período de estudo são dez $(15,9 \%)$ em PP-86/87, seis $(9,5 \%)$ em PP-75 e quatro $(6,3 \%)$ em PP-92/93. Vinte e um $(33,3 \%)$ são comuns às três amostras.

Entre PP-92/93 e PP-86/87, nota-se também uma elevada semelhança, nos quais $38(60,3 \%)$ famílias são comuns em ambas as amostragens.

Ericaceae é a família que apresenta a maior frequiência de visitas de abelhas silvestres, com 445 e 1181 indivíduos coletados em PP-92/93 e PP-86/87, respectivamente, em sua maioria representantes de Apidae. No entanto, Liliaceae é a que mostra os maiores índices de visitas, em termos de espécies de abelhas capturadas (Tabelas 5 e 6). Em PP-75, Polygonaceae é a família mais visitada, tanto em número de indivíduos como de espécies (Tabela 7). 
Tabela 5. Número de espécies e de indivíduos de abelhas silvestres (Hymenoptera, Apoidea), capturados em flores por famílias de plantas do Passeio Público, Curitiba, Paraná, em 1992/93.

\begin{tabular}{|c|c|c|c|c|c|c|c|c|c|c|c|c|}
\hline \multirow[t]{2}{*}{ PLANTAS } & \multicolumn{2}{|c|}{ COLLETIDAE } & \multicolumn{2}{|c|}{ HALICTIDAE } & \multicolumn{6}{|c|}{ ANTHOPHOR. XYLOCOPIN. APIDAE } & \multicolumn{2}{|c|}{ TOTAL } \\
\hline & ESP. & IND. & ESP. & IND. & ESP. & IND. & ESP. & IND. & ESP. & IND. & ESP. & IND. \\
\hline Asteraceae & & & 4 & 6 & & & & & 3 & 7 & 7 & 13 \\
\hline Ericaceae & & & 5 & 16 & & & 1 & 4 & 5 & 425 & 11 & 445 \\
\hline Malvaceae & & & 3 & 13 & & & & & 2 & 238 & 5 & 251 \\
\hline Liliaceae & & & 20 & 104 & 1 & 2 & 3 & 3 & 5 & 65 & 29 & 174 \\
\hline Mimosaceae & & & 13 & 98 & 1 & 1 & 1 & 1 & 7 & 42 & 22 & 142 \\
\hline Solanaceae & 1 & 10 & 4 & 5 & & & & & 4 & 78 & 9 & 93 \\
\hline Melastomataceae & & & 1 & 1 & 1 & 1 & & & 5 & 62 & 7 & 64 \\
\hline Sterculiaceae & & & & & & & & & 3 & 59 & 3 & 59 \\
\hline Araceae & & & & & & & & & 1 & 53 & 1 & 53 \\
\hline Balsaminaceae & & & & & & & & & 3 & 53 & 3 & 53 \\
\hline Apocynaceae & & & 8 & 19 & 1 & 2 & 1 & 1 & 3 & 26 & 13 & 48 \\
\hline Oleaceae & & & 4 & 5 & 1 & 1 & 1 & 1 & 3 & 31 & 9 & 38 \\
\hline Anacardiaceae & & & 7 & 9 & & & 1 & 1 & 4 & 20 & 12 & 30 \\
\hline Palmae & & & 2 & 3 & & & 1 & 2 & 2 & 25 & 5 & 30 \\
\hline Brassicaceae & & & 4 & 7 & & & & & 3 & 19 & 7 & 26 \\
\hline Convolvulaceae & & & 4 & 4 & & & & & 1 & 14 & 5 & 18 \\
\hline Acanthaceae & & & & & & & & & 2 & 14 & 2 & 14 \\
\hline Fabaceae & & & 2 & 9 & & & 1 & 1 & 2 & 4 & 5 & 14 \\
\hline Lythraceae & & & 1 & 1 & & & & & 2 & 10 & 3 & 11 \\
\hline
\end{tabular}




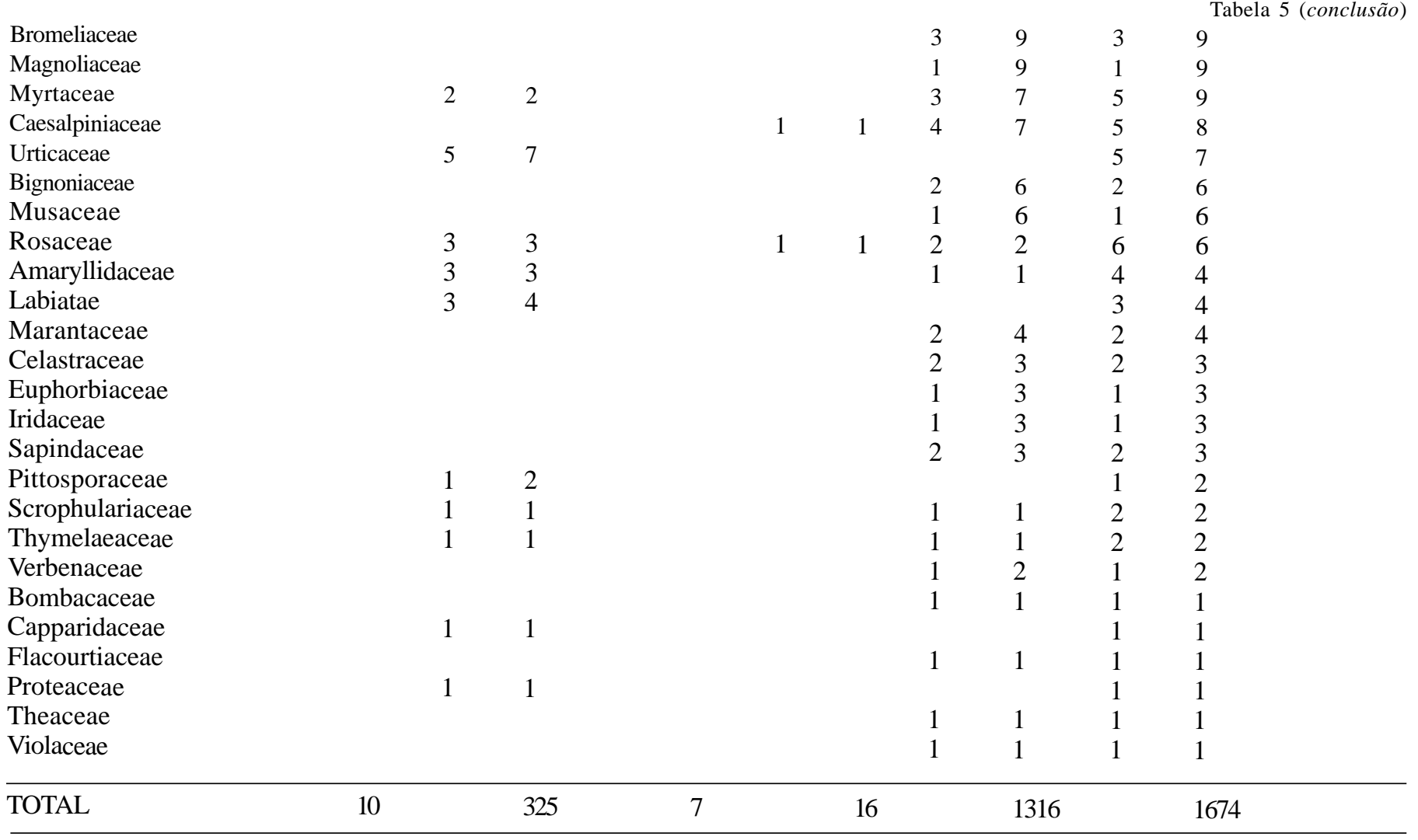


Tabela 6. Número de espécies e de indivíduos de abelhas silvestres (Hymenoptera, Apoidea), capturados em flores por famílias de plantas do Passeio Público, Curitiba, Paraná, em 1986/87.

\begin{tabular}{|c|c|c|c|c|c|c|c|c|c|c|c|c|c|c|}
\hline \multirow[t]{2}{*}{ PLANTAS } & \multicolumn{2}{|c|}{ COLLETIDAE } & \multicolumn{2}{|c|}{ ANDRENIDAE } & \multicolumn{2}{|c|}{ HALICTIDAE } & \multicolumn{2}{|c|}{ ANTHOPHOR. } & \multicolumn{2}{|c|}{ XYLOCOPIN. } & \multicolumn{2}{|c|}{ APIDAE } & \multicolumn{2}{|c|}{ TOTAL } \\
\hline & ESP. & IND. & ESP. & IND. & ESP. & IND. & ESP. & IND. & ESP. & IND. & ESP. & IND. & ESP. & IND. \\
\hline Asteraceae & & & & & 8 & 12 & & & 4 & 4 & 1 & 1 & 13 & 17 \\
\hline Ericaceae & & & & & 8 & 90 & 1 & 1 & 2 & 2 & 5 & 1088 & 16 & 1181 \\
\hline Liliaceae & & & 1 & 2 & 21 & 73 & 1 & 3 & 2 & 3 & 5 & 249 & 30 & 330 \\
\hline Balsaminaceae & 1 & 1 & 1 & 1 & 11 & 23 & & & 2 & 3 & 3 & 230 & 18 & 258 \\
\hline Oleaceae & & & & & 17 & 33 & & & 1 & 1 & 4 & 210 & 22 & 244 \\
\hline Palmae & 1 & 1 & & & 5 & 16 & & & 1 & 11 & 3 & 146 & 10 & 174 \\
\hline Solanaceae & 1 & 17 & & & 8 & 12 & 1 & 1 & & & 3 & 112 & 13 & 142 \\
\hline Mimosaceae & & & & & 11 & 83 & & & 1 & 4 & 4 & 31 & 16 & 118 \\
\hline Sterculiaceae & & & & & 1 & 2 & & & & & 5 & 112 & 6 & 114 \\
\hline Capparidaceae & & & & & 4 & 33 & & & & & 1 & 36 & 5 & 69 \\
\hline Melastomataceae & & & & & 2 & 2 & 1 & 5 & 1 & 1 & 5 & 44 & 9 & 52 \\
\hline Sapindaceae & & & & & 7 & 8 & & & 2 & 2 & 4 & 33 & 13 & 43 \\
\hline Lythraceae & & & & & 2 & 2 & & & & & 3 & 39 & 5 & 41 \\
\hline Malvaceae & & & 2 & 3 & 4 & 14 & & & & & 1 & 23 & 7 & 40 \\
\hline Celastraceae & & & & & 4 & 4 & & & & & 4 & 35 & 8 & 39 \\
\hline Labiatae & & & & & 6 & 32 & & & 1 & 1 & 2 & 5 & 9 & 38 \\
\hline Caesalpiniaceae & & & & & 1 & 2 & 1 & 1 & & & 3 & 33 & 5 & 36 \\
\hline
\end{tabular}




\begin{tabular}{|c|c|c|c|c|c|c|c|c|c|c|c|c|c|}
\hline Bignoniaceae & & & & 2 & 2 & & & & & 4 & 21 & 6 & 23 \\
\hline Anacardiaceae & & & & 10 & 14 & & & 1 & 5 & 2 & 2 & 13 & 21 \\
\hline Loranthaceae & & & & & & & & 1 & 1 & 1 & 20 & 2 & 21 \\
\hline Portulacaceae & & & & 4 & 8 & & & & & 1 & 11 & 5 & 19 \\
\hline Polygonaceae & & & & 7 & 9 & & & & & 2 & 9 & 9 & 18 \\
\hline Apocynaceae & & & & 5 & 10 & 1 & 3 & 1 & 1 & 2 & 2 & 9 & 16 \\
\hline Araceae & & & & & & & & & & 1 & 16 & 1 & 16 \\
\hline Euphorbiaceae & & 1 & 1 & 1 & 1 & & & & & 2 & 14 & 4 & 16 \\
\hline Myrtaceae & & & & 1 & 1 & & & 1 & 1 & 3 & 13 & 5 & 15 \\
\hline Verbenaceae & & & & 1 & 1 & & & & & 2 & 13 & 3 & 14 \\
\hline Pittosporaceae & & & & 4 & 7 & & & & & 2 & 5 & 6 & 12 \\
\hline Caryophyllaceae & & & & 5 & 11 & & & & & & & 5 & 11 \\
\hline Fabaceae & & & & 3 & 4 & & & 2 & 5 & 2 & 2 & 7 & 11 \\
\hline Rubiaceae & & 1 & 1 & 7 & 8 & & & 1 & 1 & & & 9 & 10 \\
\hline Thymelaeaceae & & & & 1 & 2 & & & 1 & 1 & 1 & 7 & 3 & 10 \\
\hline Bromeliaceae & & & & & & & & & & 1 & 7 & 1 & 7 \\
\hline Iridaceae & & & & 1 & 5 & & & & & & & 1 & 5 \\
\hline Theaceae & & & & & & & & & & 2 & 5 & 2 & 5 \\
\hline Rutaceae & & & & & & & & & & 1 & 1 & 1 & 1 \\
\hline TOTAL & 19 & & 8 & & 537 & & 15 & & 47 & & 2590 & & 3216 \\
\hline
\end{tabular}


Tabela 7. Número de espécies e de indivíduos de abelhas silvestres (Hymenoptera, Apoidea), capturados em flores por famílias de plantas do Passeio Público, Curitiba, Paraná, em 1975.

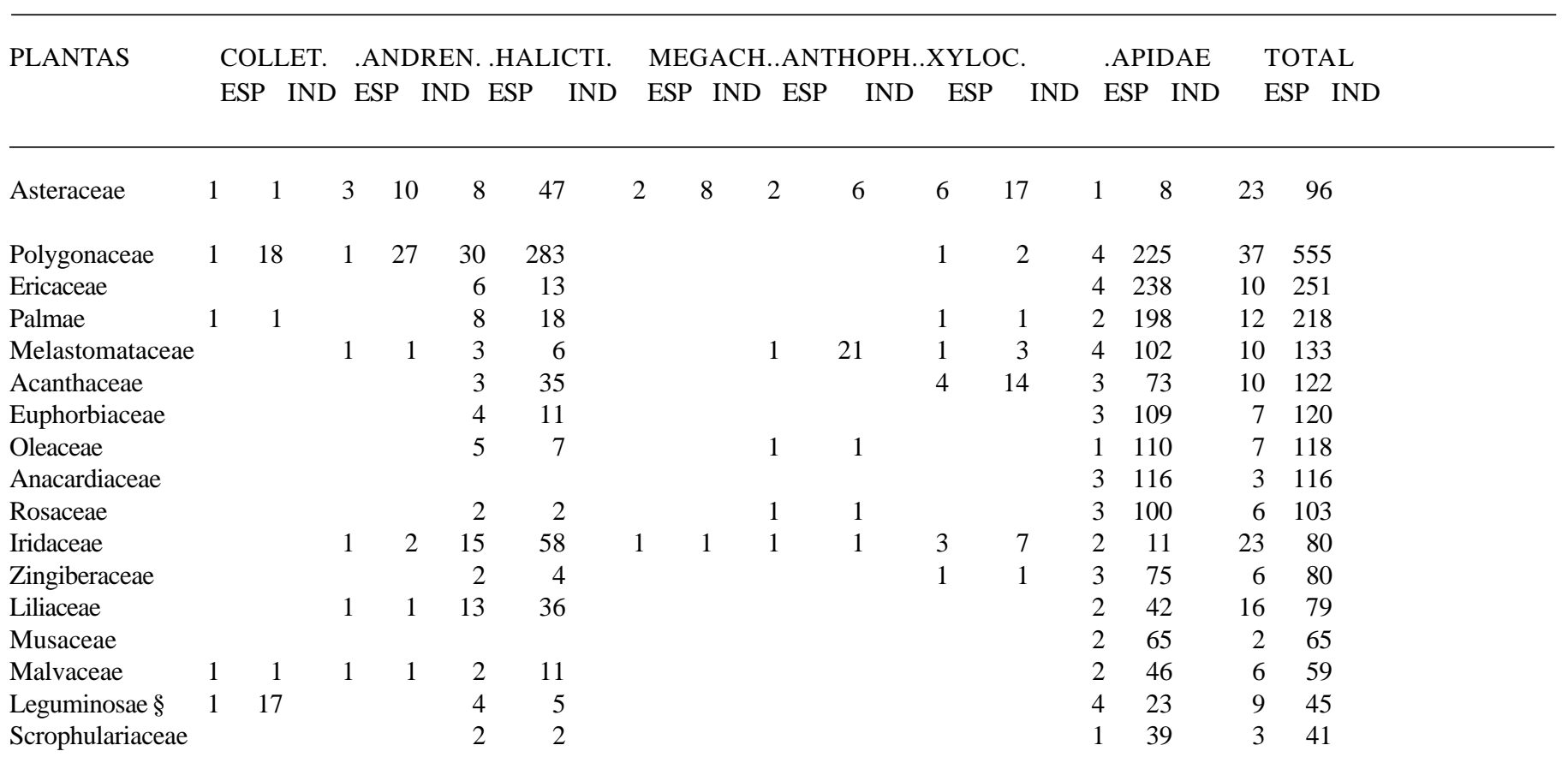




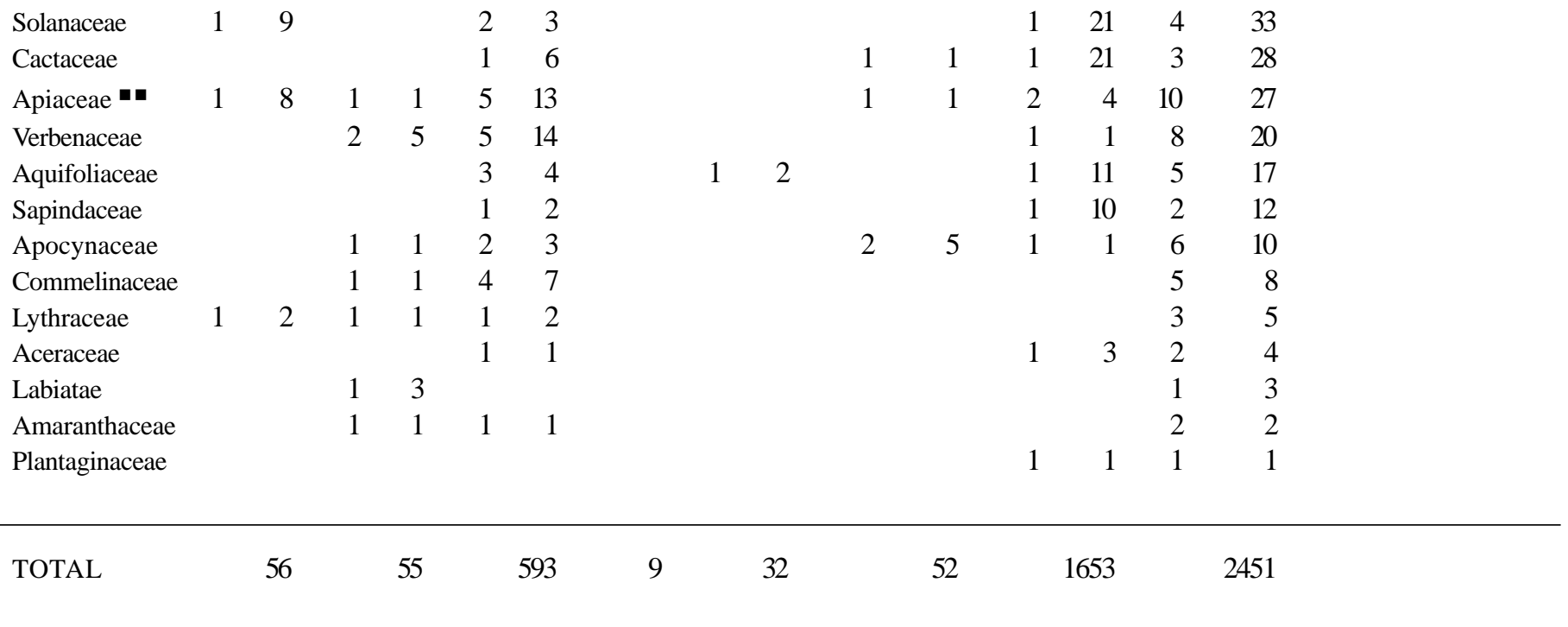

- Leguminosae = inclui Caesalpiniaceae, Fabaceae e Mimosaceae

- Apiaceae = Umbelliferae

FONTE: Passeio Público -1975 (Larroca, Cure \& Bortoli, 1982) 
Tabela 8. Número de espécies de plantas (Pl.) visitadas por abelhas silvestres (Hymenoptera, Apoidea) e o número de exemplares de abelhas (Ab.) capturados nas flores, por família de planta, no Passeio Público, Curitiba, Paraná, em 1992/93, 1986/87 e 1975.

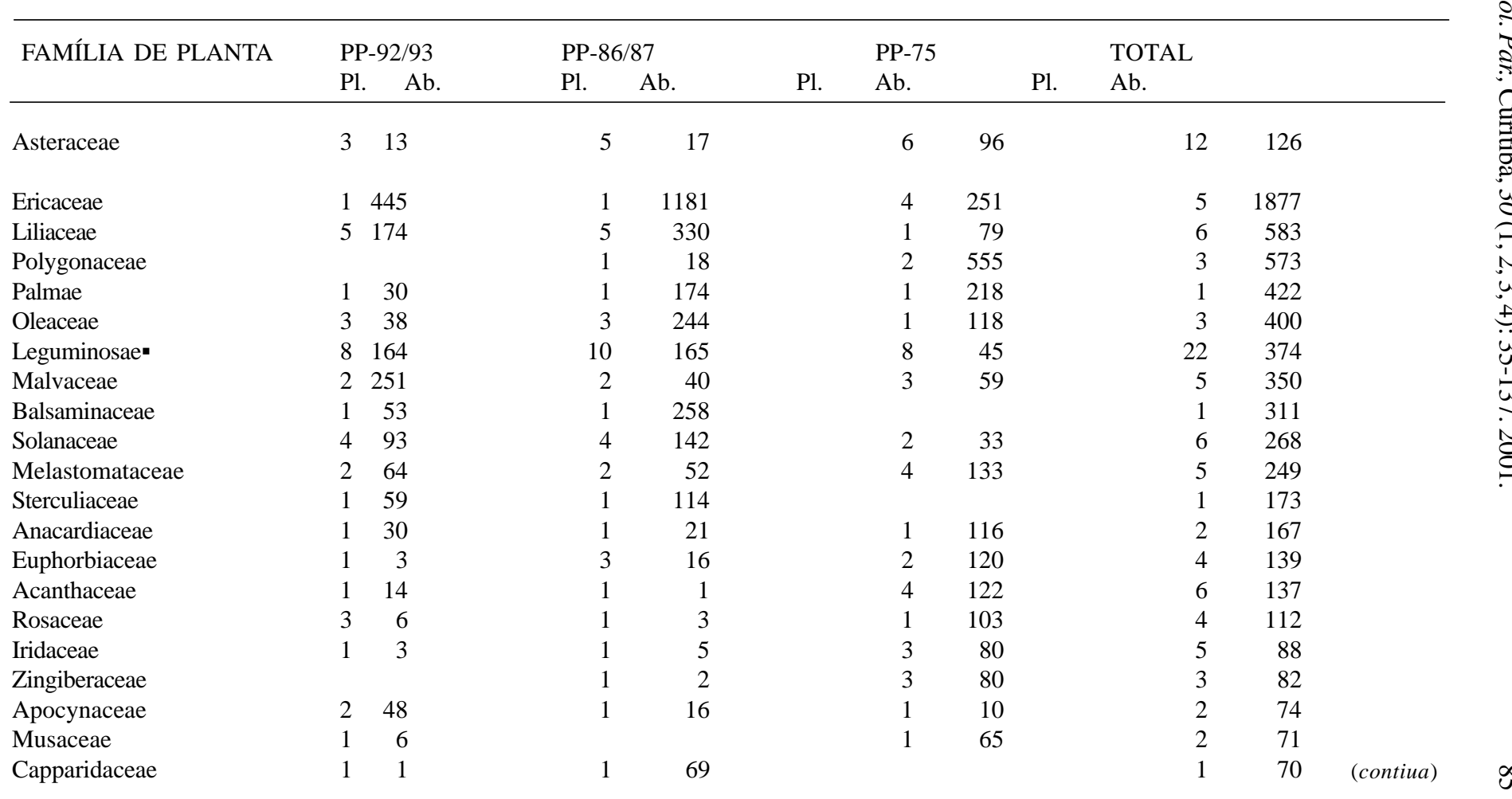


Tabela 8 (contiuação)

$\begin{array}{lrr}\text { Araceae } & 1 & 53 \\ \text { Sapindaceae } & 1 & 3 \\ \text { Lythraceae } & 1 & 11 \\ \text { Labiatae } & 2 & 4 \\ \text { Scrophulariaceae } & 1 & 2 \\ \text { Celastraceae } & 1 & 3 \\ \text { Verbenaceae } & 1 & 2 \\ \text { Bignoniaceae } & 2 & 6\end{array}$

Bignoniaceae

Cactaceae

Apiaceae -.

Brassicaceae

Myrtaceae

Loranthaceae

Convolvulaceae

Portulacaceae

Aquifoliaceae

Bromeliaceae

Pittosporaceae

Magnoliaceae

Thymelaeaceae

Caryophyllaceae

Commelinaceae

Rubiaceae

Urticaceae

Theaceae

Amaryllidaceae

16

43

38

39

14
23

$1 \quad 28$

126

29

$1 \quad 18$

15

21

2

7 
Tabela 8 (conclusão)

\begin{tabular}{|c|c|c|c|c|c|c|c|c|}
\hline FAMÍLIA DE PLANTA & PP-92/93 & \multicolumn{2}{|c|}{ PP-86/87 } & \multicolumn{3}{|c|}{ PP-75 } & \multicolumn{2}{|l|}{$\begin{array}{l}\text { TOTAL } \\
\mathrm{Ab} .\end{array}$} \\
\hline Aceraceae & & & & & 1 & 4 & 1 & 4 \\
\hline Marantaceae & 1 & & & & & & 1 & 4 \\
\hline Bombacaceae & 1 & 1 & 2 & & & & 1 & 3 \\
\hline Violaceae & 1 & 1 & 2 & & & & 1 & 3 \\
\hline Amaranthaceae & & & & & 1 & 2 & 1 & 2 \\
\hline Nyctaginaceae & & 1 & 2 & & & & 1 & 2 \\
\hline Rhamnaceae & & 1 & 2 & & & & 1 & 2 \\
\hline Tiliaceae & & 1 & 2 & & & & 1 & 2 \\
\hline Cupressaceae & & 1 & 1 & & & & 1 & 1 \\
\hline Flacourtiaceae & 1 & & & & & & 1 & 1 \\
\hline Lauraceae & & 1 & 1 & & & & 1 & 1 \\
\hline Plantaginaceae & & & & & 1 & 1 & 1 & 1 \\
\hline Proteaceae & 1 & & & & & & 1 & 1 \\
\hline Rutaceae & & 1 & 1 & & & & 1 & 1 \\
\hline TOTAL & $69 \quad 1674$ & 85 & 3216 & 64 & 2451 & $157 *$ & 7341 & \\
\hline
\end{tabular}

- Leguminosae = inclui Caesalpiniaceae, Fabaceae e Mimosaceae

- Apiaceae = Umbelliferae

* Indica o número total dos três censos, considerando-se as espécies comuns.

FONTES: PP-75 (Laroca, Cure \& Bortoli, 1982); PP-86/87 (Taura, 1990). 


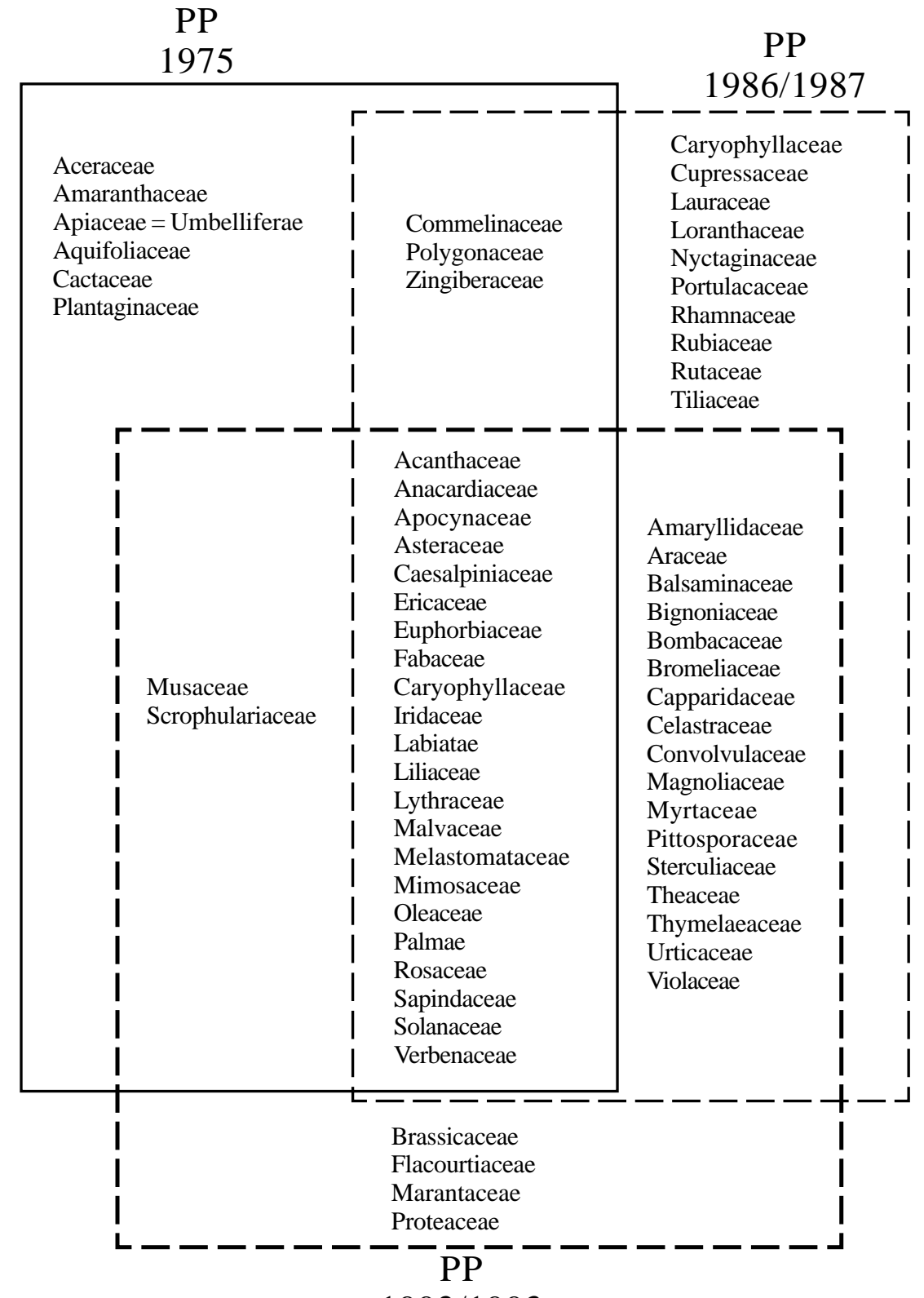

$1992 / 1993$

Fig. 14. Famílias de plantas visitadas por abelhas silvestres (Hymenoptera, Apoidea) no Passeio Público, Curitiba, Paraná, em 1992/93, 1986/87 e 1975. Fontes: PP-75 (Laroca, CuRE \& Bortoli, 1982); PP-86/87 (TAura, 1990). 
Na Tabela 8 encontram-se relacionados o número de espécies de plantas visitadas por abelhas silvestres e o número de exemplares de abelhas capturadas, por família de planta, amostrados durante os estudos efetuados no PP, em 1992/93, 1986/87 e 1975.

A família Asteraceae (=Compositae) é considerada por alguns autores como a família de plantas mais importante para a comunidade de abelhas, com o maior número de espécies visitadas e também, com a maior abundância de indivíduos visitantes (LAROCA, 1972; CuRE, 1983; Bortoli \& Laroca, 1990; Zanella, 1991; Barbola, 1993). Entretanto, no PP, observa-se tendência contrária, isto é, a ocorrência de poucas espécies em cada amostragem, assim como o número de abelhas coletadas em sua flores que é reduzida (Tabela 8).

No PP, segundo LAROCA, CURE \& Bortoli (1982), tal fato ocorre pela prática de jardinagem com capina regular e substituição das espécies nativas de Asteraceae por espécies ornamentais, como também pela existência de estrato arbóreo que propicia sombra e que impede o desenvolvimento das espécies de ervas dessa família.

As famílias de plantas mais procuradas e as freqüências (\%) de indivíduos por família de Apoidea coletadas nas flores, em PP-92/93, PP-86/ 87 e PP-75, encontram-se apresentadas nas figuras 15,16 e 17, respectivamente.

Considerando-se os três levantamentos realizados no PP, a seguir são comentadas algumas tendências observadas, nas relações entre as famílias de plantas preferencialmente visitadas e de abelhas silvestres visitantes.

\section{ERICACEAE}

Representada apenas por $R$. indicum, uma espécie exótica, em PP92/93 e PP-86/87, recebe visitas de Halictidae, Xylocopinae e Apidae. Nestas amostras é considerada a família com a maior abundância de abelhas coletadas. Em PP-75, esta família é constituída por quatro espécies de Rhododendron, apresenta visitas de Halictidae e Apidae, não sendo verificada a presença de Xylocopinae.

\section{MALVACEAE}

Encontra-se, em PP-92/93, composta por duas espécies: A. mullerifriderici e $H$. rosa-sinensis. Entretanto, a primeira espécie é a mais procurada. A referida família recebe visitas de Halictidae e principalmente de Apidae. Em PP-86/87 e PP-75, embora presente, apresenta freqüência mais reduzida de abelhas, não sendo portanto, considerada entre as famílias preferencialmente visitadas. 


\section{LILIACEAE}

Nas amostras de PP-92/93 e PP-86/87, é a família com o maior número de espécies de abelhas coletadas, perfazendo o total de 29 e 30 espécies, respectivamente.

Observa-se em PP-92/93 a ocorrência, em ordem descrescente de abundância, de Halictidae, Apidae, Xylocopinae e Anthophoridae. Na amostra de PP-86/87, além da presença das famílias anteriormente mencionadas, constata-se também a captura de Andrenidae, embora em número reduzido. Em PP-75, verifica-se visitas de Halictidae, Apidae e Andrenidae.

Em PP-92/93 e PP-86/87 é representada por Chlorophytum sp., $C$. dracaenoides, Cordyline sp., $H$. fulva e $K$. uvaria, enquanto que em PP-75, somente por Liriope muscari x variegata.

\section{LEGUMINOSAE}

Em PP-92/93, esta família é composta por oito espécies e recebe visitas, principalmente de Halictidae e Apidae, enquanto que Anthophoridae e Xylocopinae apresentam freqüências bastante reduzidas. Durante este período, observa-se elevada abundância de abelhas nas flores de $C$. selloi. No levantamento de PP-86/87 é representada por dez espécies e procurada por Halictidae, Apidae, Xylocopinae e Anthophoridae, com a predominância da primeira família de abelhas. Em PP-75, embora presente com oito espécies na amostra, devido a captura de um número menor de abelhas, não é relacionada como uma das preferencialmente procuradas.

\section{SOLANACEAE}

Presente nos três levantamentos realizados no PP, constata-se nestas amostras, a ocorrência da família Colletidae, representada por Bicolletes sp., uma espécie possivelmente oligolética, capturada nas flores de $V$. breviflora. Esta espécie de planta encontra-se citada como Acnistus breviflorus Sendtn. por LAROCA, CURE \& BORTOLI (1982). Considerandose a ordem decrescente de abundância de abelhas visitantes, esta família é procurada, em PP-92/93, por Apidae, Colletidae e Halictidae.

$\mathrm{Na}$ amostra de PP-86/87, observa-se a presença de Apidae, Colletidae, Halictidae e também de Anthophoridae. Em PP-75, embora não citada entre as preferencialmente visitadas, é procurada por Apidae, Colletidae e Halictidae.

\section{MELASTOMATACEAE}

Esta família é representada em PP-92/93 e PP-86/87, por $T$. sellowiana e M. hiemalis. No primeiro estudo mencionado, é visitada principalmente por Apidae, seguido por um número reduzido de Halictidae e Anthophoridae, enquanto que no segundo estudo, também é preferenci- 


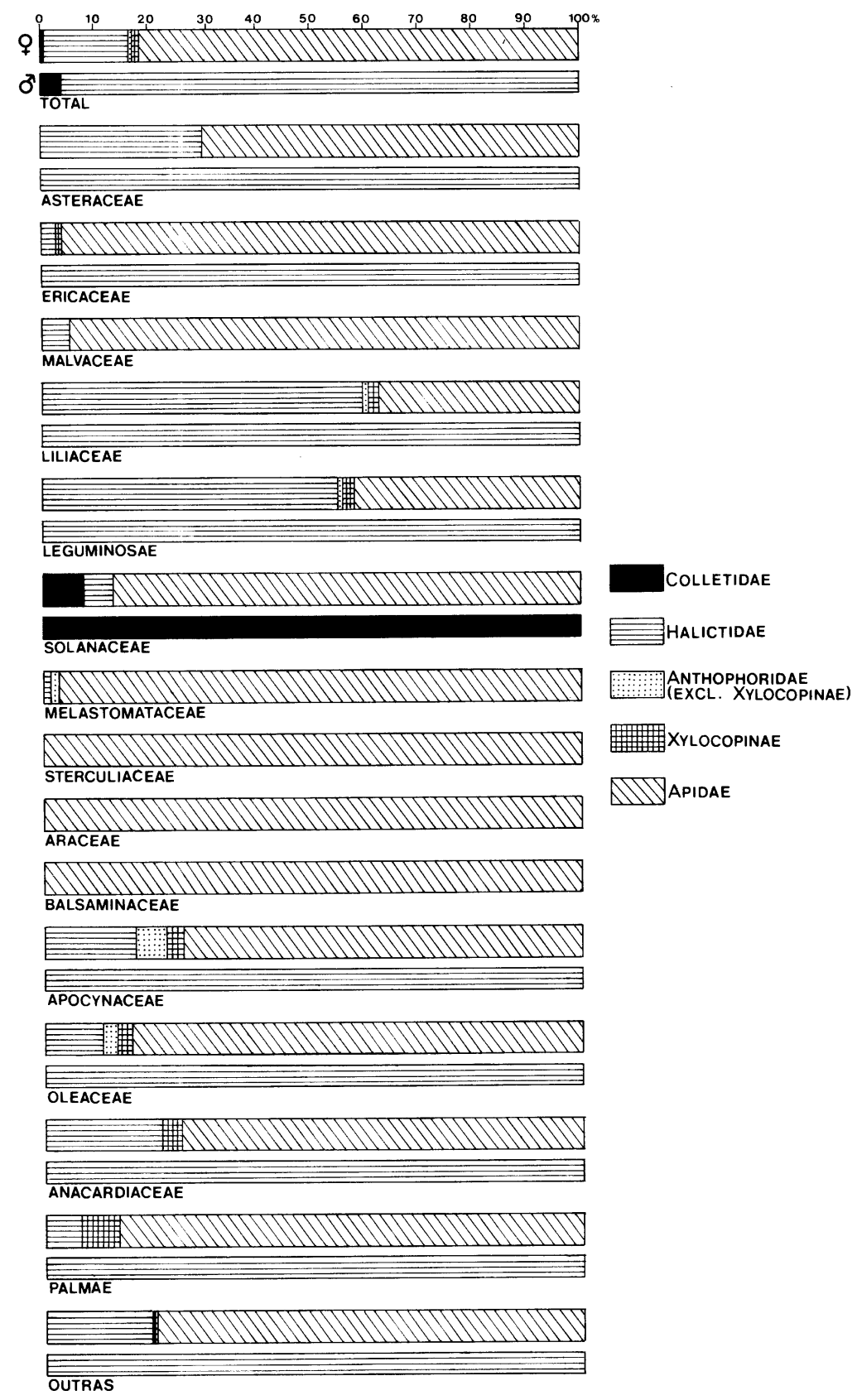

Fig. 15. Frequiência (\%) de indivíduos por família de abelhas (Hymenoptera, Apoidea), coletados nos vários grupos de plantas no Passeio Público, Curitiba, Paraná, em 1992/93. Fêmeas e machos são apresentados separadamente. A família Anthophoridae não inclui Xylocopinae. 


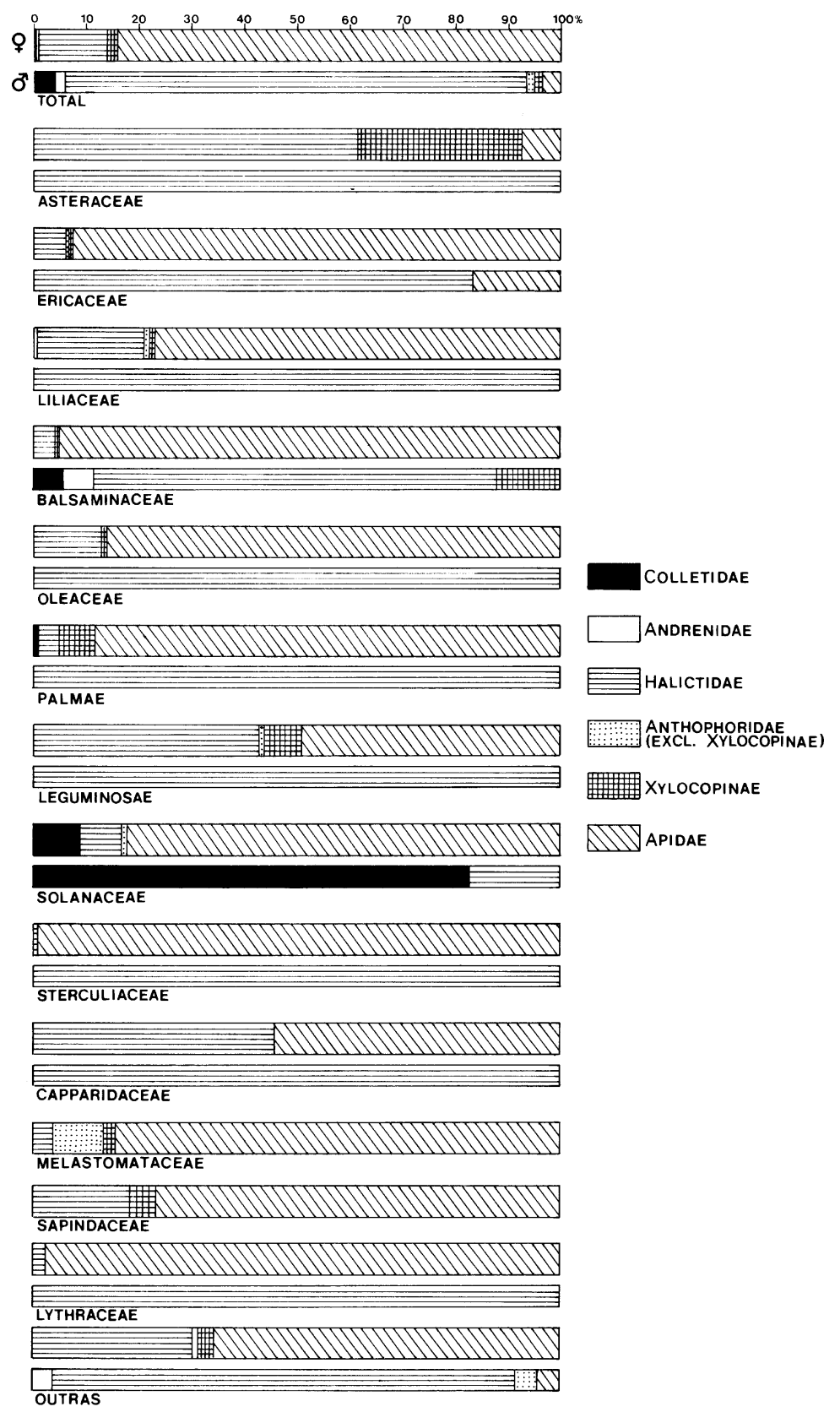

Fig. 16. Freqüência (\%) de indivíduos por família de abelhas (Hymenoptera, Apoidea), coletados nos variados grupos de plantas no Passeio Público, Curitiba, Paraná, em 1986/87. Fêmeas e machos são apresentados separadamente. A família Anthophoridae não inclui Xylocopinae. Fonte: PP-86/87 (TAURA, 1990). 


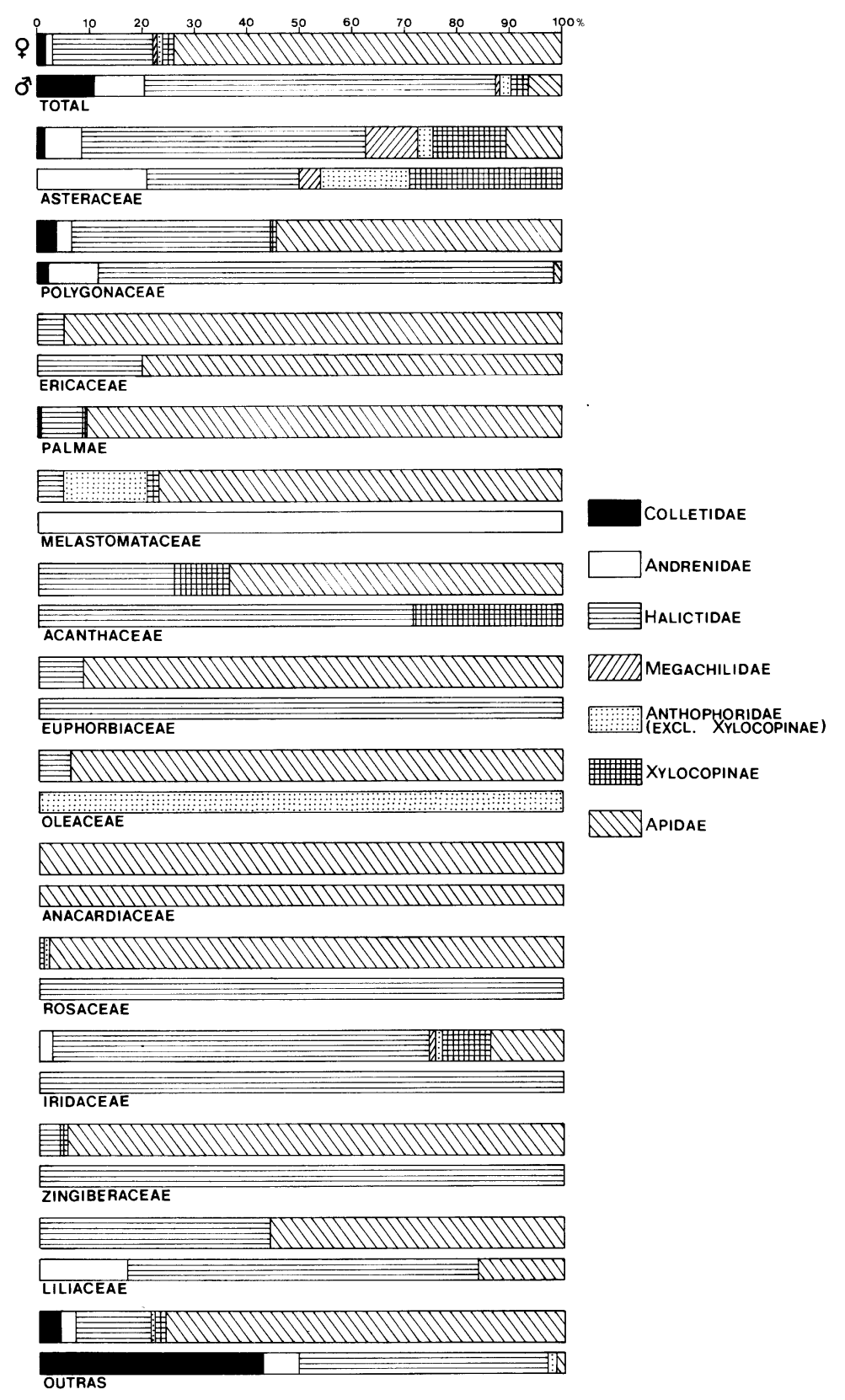

Fig. 17. Frequiência (\%) de indivíduos por família de abelhas (Hymenoptera, Apoidea), coletados nos vários grupos de plantas no Passeio Público, Curitiba, Paraná, em 1975. Fêmeas e machos são apresentados separadamente. A família Anthophoridae não inclui Xylocopinae. Fonte: PP-75 (Laroca, Cure \& Bortoli,1982) 
almente procurada por Apidae e por uma freqüência menor de Anthophoridae, Halictidae e Xylocopinae. Em PP-75, é constituída por quatro espécies de Tibouchina, observando-se visitas de Apidae, Anthophoridae, Halictidae e Xylocopinae.

STERCULIACEAE

Encontra-se representada por $D$. wallichii, com ocorrência apenas nas amostras de PP-92/93 e PP-86/87. Em PP-92/93 é visitada somente por operárias de Apidae, enquanto que em PP-86/87 é principalmente por Apidae, mas também apresenta um número reduzido de Halictidae.

ARACEAE

Com ocorrência constatada nos levantamentos de PP-92/93 e PP-96/ 87, é representada somente por Calladium sp. Em PP-75, encontra-se ausente. Também, é considerada como uma das preferencialmente visitadas apenas em PP-92/93, tendo sido procurada por operárias de Apidae, ou seja, especialmente por Plebeia emerina e por um número reduzido de Apis mellifera (não incluída nesta análise).

BALSAMINACEAE

Ausente em PP-75, é representada apenas por Impatiens sp. m PP92/93 e PP-86/87. Esta família é freqüentada, na amostra de PP-92/93, apenas por Apidae, enquanto que em PP-86/87 é visitada também por Halictidae, Xylocopinae, Colletidae e Andrenidae.

APOCYNACEAE

Em PP-92/93, é constituída por duas espécies, A. schottii e C. roseus, apresentando visitas em ordem decrescente de abundância, de Apidae, Halictidae, Anthophoridae e Xylocopinae. No levantamento de PP-86/87 e PP-75, esta família não é considerada como uma das preferencialmente visitadas, estando representada nestas épocas, apenas por A. schottii.

OLEACEAE

Nos censos realizados no PP, esta família é composta por três espécies, entre as quais $L$. lucidum é a mais visitada em PP-92/93 e $L$. japonicum em PP-86/87. A primeira amostra citada apresenta visitas de Apidae, Halictidae, Anthophoridae e Xylocopinae, enquanto que na segunda, nota-se a ausência de Anthophoridae. L. japonicum, embora presente em PP-92/93, não consta como a espécie com o maior número de abelhas coletadas, devido à elevada altura alcançada pelos seus indivíduos, permitindo que apenas parte de suas flores fossem amostradas. Em PP-75, é representada somente por L. japonicum, sendo esta procurada por Apidae, Halictidae e Anthophoridae. 


\section{ANACARDIACEAE}

Esta família é representada por S. terebinthifolius em PP-92/93 e PP-86/87 e por Spondia sp. em PP-75. No estudo efetuado durante 1992/93 e 1986/87, observa-se a presença de Apidae, Halictidae e Xylocopinae, sendo contudo considerada preferencialmente visitada somente em PP-92/93. Em PP-75, também com elevada percentagem de abelhas coletadas, apresenta no entanto, visitas exclusivamente de Apidae.

PALMAE

Nos três levantamentos realizados no PP, esta família encontra-se representada pela espécie $B$. eriospatha, sendo considerada uma das preferencialmente visitadas pelas abelhas.Em PP-92/93, constata-se a ocorrência de Apidae, com maior número de exemplares capturados, seguida por Halictidae e Xylocopinae, em menor proporção.

Na amostra de PP-86/87, nota-se também a predominância de Apidae, bem como a presença de Halictidae, Xylocopinae e Colletidae. Verificase também, neste período, a captura do único exemplar de Hylaeus sp. (uma fêmea) (Colletidae) quando em visita às flores desta família.

Durante o estudo em PP-75, Palmae é considerada a terceira família em ordem de importância em termos de indivíduos de abelhas coletados, sobretudo de Apidae, seguido por Halictidae, Colletidae e Xylocopinae.

CAPPARIDACEAE

Presente somente nas amostras de PP-92/93 e PP-86/87, é representada por $C$. rosea, em ambas as épocas de estudo.

É preferencialmente visitada em PP-86/87, por Apidae e Halictidae. Durante o levantamento realizado em 1992/93, ao contrário de 1986/87, constata-se a captura de apenas um exemplar fêmea de Halictidae.

SAPINDACEAE

Com ocorrência nos três levantamentos efetuados no PP, é representada nestas amostras por A. edulis. Em PP-92/93 é visitada por um número reduzido de Apidae, enquanto que em PP-86/87 por Apidae, Halictidae e Xylocopinae, constituindo-se em uma das famílias mais procuradas.

Em PP-75, todavia, embora procurada por Apidae e Halictidae, mostra diminuição na proporção de indivíduos coletados nas flores da referida espécie.

\section{LYTHRACEAE}

Esta família é diferencialmente representada nos três censos de PP. Constituída por L. indica em PP-92/93 e visitada por Apidae e Halictidae, possui proporção reduzida de abelhas capturadas. Em PP-86/87, com as espécies $L$. indica e $L$. pacari, é considerada como uma das famílias 
preferencialmente visitadas, sendo coletadas nesta oportunidade, indivíduos especialmente de Apidae e um número pequeno de Halictidae. Durante a amostragem de PP-75, observa-se pequena freqüência de Colletidae, Halictidae e Andrenidae. Neste período, a família é composta por Cuphea callophylla e Heymia myrtifolia.

POLYGONACEAE

Representada por Muehlenbeckia platyclada e Polygonum punctatum, em PP-75 é a mais procurada pelas abelhas silvestres, sendo verificada em ordem decrescente de abundância, indivíduos de Halictidae, Apidae, Andrenidae, Colletidae e Xylocopinae. Em PP-86/87, com ocorrência apenas de Homalocladium platycladum é visitada por um número reduzido de Halictidae e Apidae. Na amostra de PP-92/93, esta família encontra-se ausente.

ACANTHACEAE

Nos levantamentos realizados no PP, esta família é composta por espécies diferentes. Assim, em PP-92/93, é constituída por T. laurifolia, e visitada somente por um número reduzido de Apidae, enquanto que em PP-86/87, com a presença de Justicia sp., apresenta apenas um exemplar de Apidae capturada.

Em PP-75, contudo, é a quinta família em ordem de importância, dentre as mais procuradas pelas abelhas, entre as quais indivíduos pertencentes à Apidae, Halictidae e Xylocopinae. Nesta época, verifica-se a ocorrência de Chaetocalix sp., Jacobinia pauciflora, Justicia lachneis e Ruellia (?) sp.

\section{EUPHORBIACEAE}

Em PP-92/93 apresenta apenas três operárias de Apidae coletadas nas flores de E. splendens. Na amostra de PP-86/87, é representada por Euphorbia pulcherrima, E. splendens e Aleurites fordii, e visitada por Apidae, Andrenidae e Halictidae, embora em pequeno número. Em PP75 , é composta por E. pulcherrima e E. splendens. Todavia, constatase elevada frequiência de abelhas capturadas, principalmente exemplares de Apidae, e também por um número menor de Halictidae.

\section{ROSACEA}

Esta família é considerada como uma das preferencialmente visitadas somente em PP-75. Nesta ocasião, é constituída por Spiraea sp., sendo procurada principalmente por Apidae, seguida por uma proporção reduzida de Halictidae e Anthophoridae.

Em PP-92/93 é representada por C. lacteus, Rosa sp. e Rubus sp. Mostra pequeno número de indivíduos de Apoidea coletados, distribuídos entre Halictidae, Apidae e Xylocopinae. 
Na amostragem de PP-86/87, verifica-se a ocorrência de somente um exemplar de Halictidae e dois de Apidae, coletados nas flores de Rosa sp.

\section{ASTERACEAE}

Encontra-se presente nas três amostras do PP, porém a proporção de visitas e a composição de espécies visitantes varia em cada uma, sendo considerada como uma das famílias preferencialmente procurada somente em PP-75. Em PP-92/93, é representada por três espécies e recebe visitas somente de Apidae e Halictidae, sendo T. patula a espécie mais frequientada. Em PP-86/87, observa-se a ocorrência maior de Halictidae, seguida por Xylocopinae. Apidae, entretanto, apresenta proporção reduzida. Na amostra de PP-75, verifica-se também a presença de Colletidae, Andrenidae e Megachilidae, enquanto Halictidae constitui-se na família mais abundante coletada nas suas flores. Durante o período de estudo, em 1975, é a décima família em ordem de importância em termos de indivíduos coletados.

\section{IRIDACEAE}

Mostra uma composição diferenciada em termos de espécies, entre as amostragens de PP-75 e as duas mais recentes. Assim, em PP-92/93 é representada exclusivamente por Iris sp., enquanto que em PP-86/87 pela espécie citada como também por Iris tigrina. Em PP-75, entretanto, é constituída por Crocosmia crocosmiflora, Iris japonica e Neomarica candida, caracterizando-se nesta época, como uma da famílias com proporções de visitas mais elevadas, sendo registradas a presença de Halictidae, Xylocopinae, Andrenidae, Apidae e Anthophoridae.

Nas amostras de PP-92/93 e PP-86/87, observa-se também tendência a uma simplificação na riqueza e freqüência de abelhas visitantes, sendo coletados apenas poucos exemplares pertencentes a Apidae e Halictidae, respectivamente.

\section{ZINGIBERACEAE}

Representada em PP-75 por Apinea henryi, Hedychium coronarium e Hedychium sp. é considerada nesta época, como uma das preferencialmente visitadas por abelhas, com indivíduos de Apidae, Halictidae e Xylocopinae coletados.Em PP-86/87, nota-se a ocorrência de $H$. coronarium, com a captura de apenas um exemplar de Halictidae e um de Apidae. Em PP-1992/93, a visita de abelhas não foi constatada nesta família. 


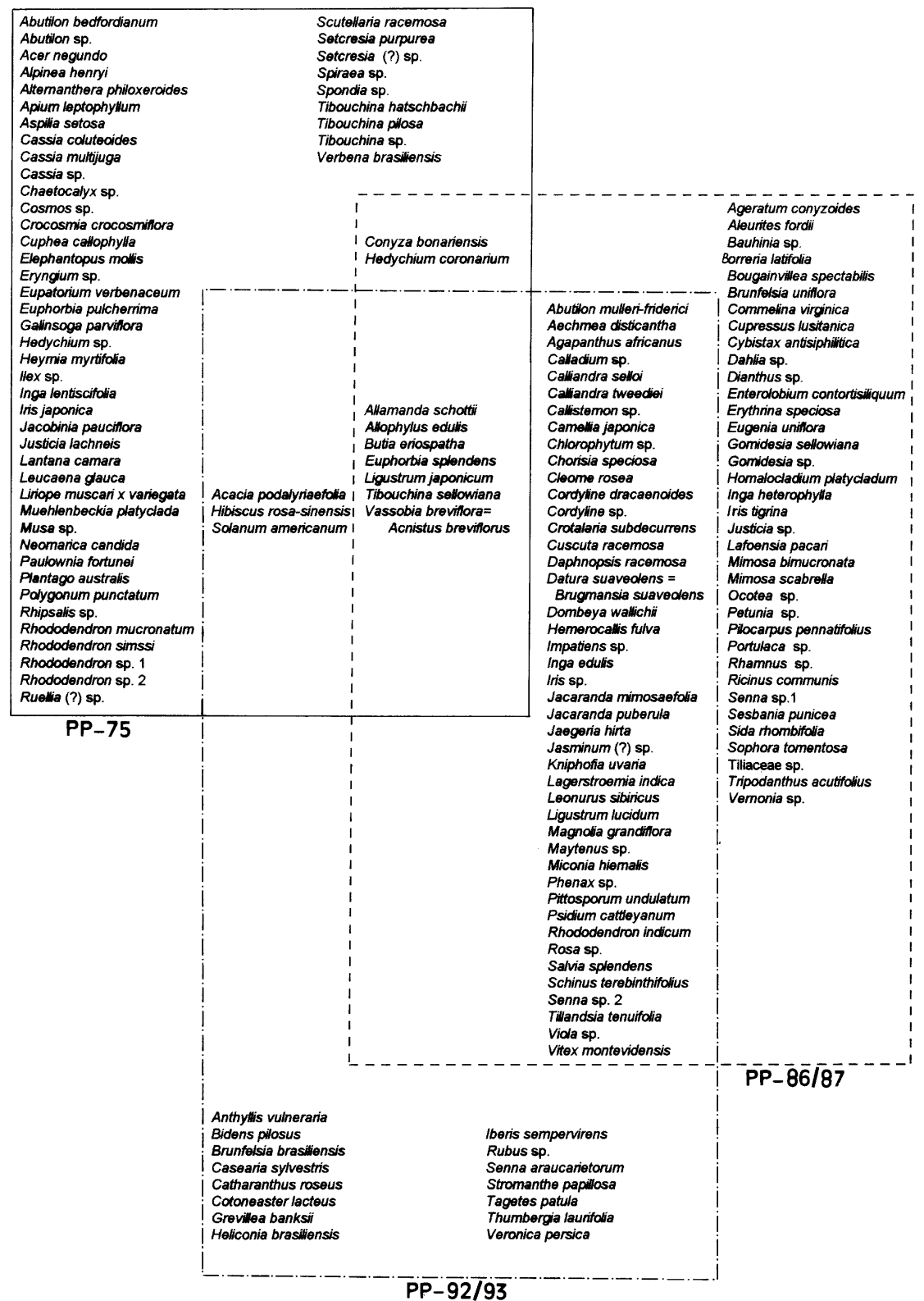

Fig. 18. Espécies de plantas comuns e exclusivas, visitadas pelas abelhas silvestres (Hymenoptera, Apoidea) no Passeio Público, Curitiba, Paraná, em 1992/93, 1986/87 e 1975. FONTE: PP-75 (Laroca, Cure \& Bortoli, 1982); PP-86/87 (TAURA, 1990). 


\section{ESPÉCIES DE PLANTAS COMUNS E EXCLUSIVAS}

Comparando-se os resultados obtidos em três levantamentos efetuados no $P P$, durante os períodos de 1992/93, 1986/87 e 1975, em relação às espécies de plantas visitadas, verifica-se a ocorrência de um número elevado de espécies exclusivas a cada uma das amostras (Fig. 18).

Do total de 157 espécies que floresceram nesta área, verifica-se que apenas sete $(4,5 \%)$ são comuns à PP-92/93, PP-86/87 e PP-75, devido especialmente à prática de jardinagem, o que acarreta em rotatividade acentuada de espécies herbáceas e arbustivas, neste local. Também, é constante a poda de árvores de grande porte.

Em PP-75, a ocorrência de espécies exclusivas é mais acentuada (31,8\%), enquanto que entre PP-92/93 e PP-86/87, por serem estudos realizados em períodos próximos, nota-se que $28,0 \%$ das espécies são comuns a ambas as amostras. Porém, mesmo assim, PP-86/87 e PP-92/ 93, apresentam $22,9 \%$ e $9,6 \%$ de plantas exclusivas, respectivamente.

Os qüocientes de similaridade, mostrados a seguir, indicam similaridade baixa na composição florística entre PP-75 e os dois outros levantamentos posteriores, com índices inferiores a 20\%. Ainda, mesmo entre PP-92/93 e PP-86/87, os dois períodos mais próximos cronologicamente, nota-se que a similaridade não é elevada

$\begin{array}{lll} & & \text { PP-75 } \\ \text { PP-92/93 } & 0,66 & 0,12 \\ & 0,67 & 0,15\end{array}$

\section{ESPÉCIES DE PLANTAS PREDOMINANTEMENTE VISITADAS}

As espécies vegetais predominantemente visitadas, assim como a abundância relativa e proporção sexual (\%) de indivíduos de abelhas silvestres coletados nas flores destas plantas, em PP-92/93, PP-86/87 e PP-75, encontram-se representadas na figura 19.

Do total de 69 espécies de plantas, em PP-92/93, nove são consideradas predominantemente procuradas - pelo método de KaTO, MATSUDA \& Yamashita (1952) (ver Sakagami \& Matsumura, 1967 e Laroca, 1972)—, isto é, as que apresentam freqüências elevadas de abelhas capturadas em suas flores. Em PP-86/87, apenas 11 são as predominantes entre 85 espécies que floresceram neste período, e em PP-75, somente 13 das 64 espécies visitadas pelos Apoidea. 


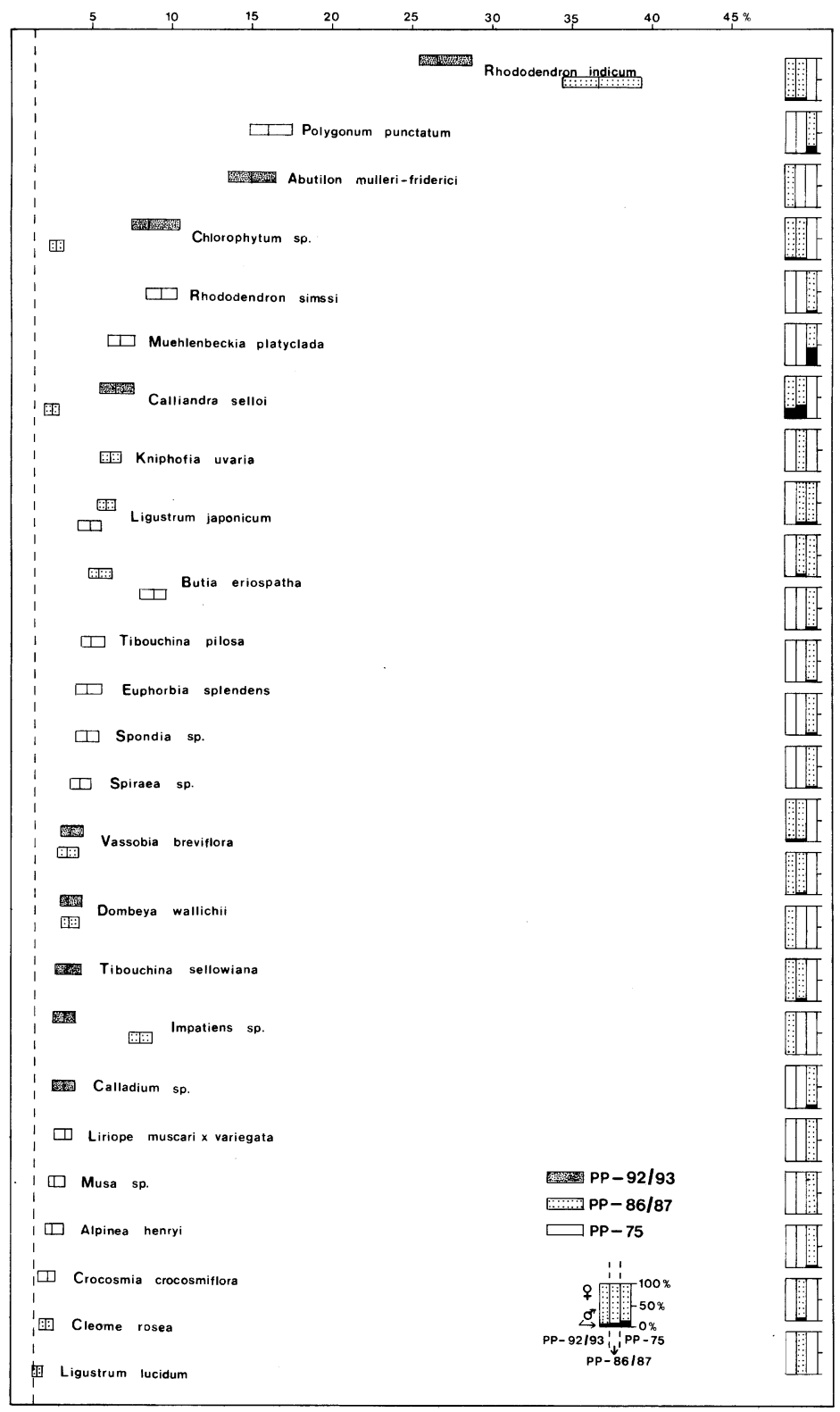

Fig. 19. Abundância relativa (\%) de indivíduos de abelhas silvestres (Hymenoptera, Apoidea), coletados sobre as flores das espécies de plantas predominantemente visitadas, no Passeio Público, Curitiba, Paraná, em 1992/93, 1986/87 e 1975. Os limites de confiança $(\mathrm{p}=0,05)$ foram calculados pelo método de KATO, MATSUDA \& YAMASHITA (1952) e representados pelas barras horizontais, com escala na parte superior. A proporção sexual (\%) de abelhas é apresentada no lado direito. A linha tracejada vertical mostra a recíproca do número de espécies coletadas em PP-92/93, multiplicado por 100. Fonte: PP-75 (LAROCA, CuRE \& Bortoli, 1982); PP-86/87 (TAURA, 1990). 
A comparação entre os três levantamentos do PP, indica variação na preferência de espécies de plantas freqüentadas pelas abelhas, e mesmo espécies como B. eriospatha, E. splendens, L. japonicum, T. sellowiana e $V$. breviflora, comuns às três épocas de estudo, apresentam-se como predominantemente visitadas em apenas uma ou no máximo duas das amostras.

$R$. indicum, espécie exótica, é a que apresenta o maior índice de visitas pelas abelhas em PP-92/93 e PP-86/87, enquanto que $P$. punctatum, em PP-75. Ressalta-se que em 1992/93 e 1986/87, esta última espécie mencionada encontra-se ausente.

Entre as plantas predominantemente procuradas, algumas apresentam elevada frequiência de Apidae, especialmente Meliponinae, como é o caso por exemplo de R. indicum, K. uvaria, D. wallichii, Impatiens sp. e Calladium sp., ao contrário de Calliandra selloi e Chlorophytum sp. que recebem visitas, preferencialmente de Halictidae.

Ainda, durante as três épocas de estudo realizado no PP, constata-se que $V$. breviflora, recebe visitas de uma espécie de Colletidae (Bicolletes sp.), uma espécie provavelmente oligolética, cujo período de atividade encontra-se em sincronia com o período de florescimento desta espécie vegetal.

\section{FenOlogia}

\section{ASPECTOS GERAIS}

A figura 20 apresenta os dados fenológicos referentes às flutuações dos fatores meteorológicos temperatura e precipitação pluviométrica.

Segundo MAAck (1981), no município de Curitiba, a temperatura média mensal mais elevada e o maior índice pluviométrico anual são registrados durante os meses de janeiro e fevereiro, sendo considerada, portanto, uma região com verão úmido e ameno. Ainda, junho e julho são os meses mais frios do ano, porém, com o inverno tendendo a ser mais seco.

No estudo realizado entre junho de 1992 e maio de 1993, constata-se que dezembro de 1992 e janeiro, fevereiro e março de 1993 são os meses mais quentes, com a média mensal mais elevada em janeiro, enquanto que julho e agosto de 1992, os meses mais frios.

Durante a amostragem de PP-86/87, observa-se que os meses mais quentes compreendem novembro de 1986 a março de 1987, com a média 
mensal máxima também em janeiro, e julho de 1986 e maio de 1987 os meses mais frios.

Em relação à PP-75, os meses que apresentam as médias mensais de temperatura mais elevadas são janeiro, fevereiro, março, novembro e dezembro de 1975, com a máxima registrada em fevereiro. Os meses de junho e julho possuem os valores mais baixos, sendo portanto, considerados os mais frios.

Nota-se assim algumas diferenças entre os variados períodos de amostragem no PP (PP-92/93, PP-86/87 e PP-75), bem como em relação ao padrão normal, especialmente quanto aos meses considerados os mais frios.

Em termos de precipitação pluviométrica, em PP-92/93 (gráfico B, Figura 22) os meses mais chuvosos são janeiro, fevereiro e março de 1993, com índices de 295,5 mm, 193,4 mm e 191,3 mm respectivamente, e junho de 1992 o mais seco, com 21,1 mm.

Verifica-se, entretanto, que em PP-86/87, o mês de maio de 1987 é o que apresenta o maior índice, isto é, $296,8 \mathrm{~mm}$, seguido por dezembro com 209,1 mm e fevereiro com 198,1 mm. Em PP-75, os meses de outubro com 224,9 mm, novembro com 187,9 mm e fevereiro com 182,5 mm são os mais chuvosos. O menor valor registrado em PP-86/87 é de 7,8 $\mathrm{mm}$ em agosto de 1986, e em PP-75 o índice de 48,3 $\mathrm{mm}$ em maio de 1975 (gráficos B' e B”, , Fig. 20).

O padrão normal de MAACK (1981) conforme a figura 20 (gráfico B"'), considera janeiro e fevereiro como sendo os meses mais chuvosos, com índices próximos de $200 \mathrm{~mm}$ e abril, maio, julho e agosto como os mais secos, com valores inferiores a $100 \mathrm{~mm}$.

Comparando-se os gráficos referentes à precipitação pluviométrica, nota-se variações entre os três períodos de amostragem realizados no $\mathrm{PP}$ (PP-92/93, PP-86/87 e PP-75), assim como em relação ao padrão normal.

O número de espécies de plantas visitadas por abelhas silvestres, nas três épocas de estudo realizados no PP, demonstra correspondência com as variações climáticas (gráficos A, A', A", Fig. 21). Os números são mais elevados durante a primavera e verão, porém diminuem no outono $\mathrm{e}$ inverno.

Em PP-92/93, durante a primavera observa-se a maior diversidade de espécies vegetais visitadas pelas abelhas, sendo que Abutilon mullerifriderici Malvaceae) é a preferencialmente procurada, seguida por Vassobia breviflora (Solanaceae) e Ligustrum lucidum (Oleaceae). No 


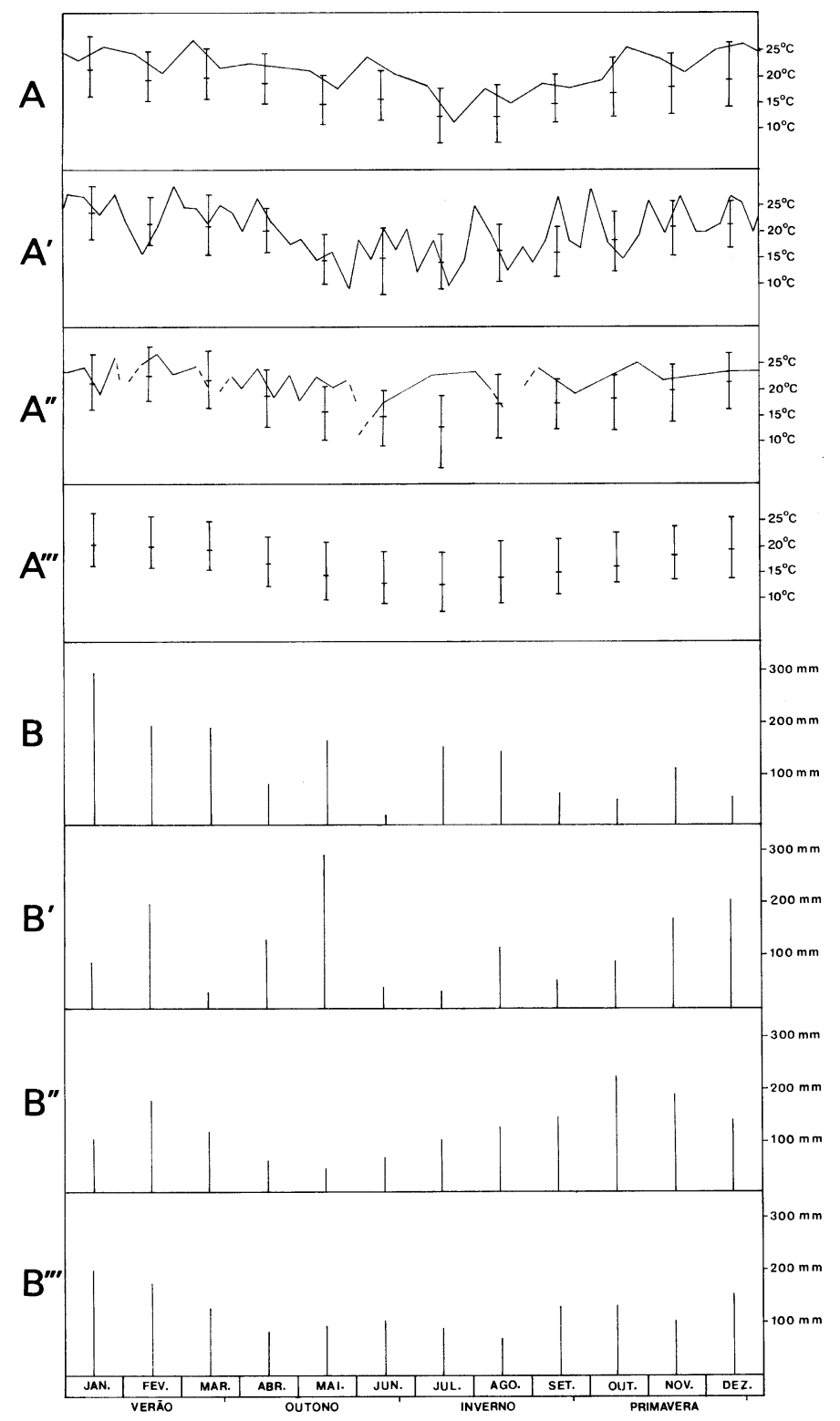

Fig. 20. Flutuação dos fatores climáticos temperatura e precipitação pluviométrica. A, A', A”. Temperatura: a linha contínua representa as médias diárias de coleta, obtidas no campo, no Passeio Público, Curitiba, Paraná, em 1992/ 93, 1986/87 e 1975, respectivamente. As extremidades das barras indicam as médias das máximas e mínimas mensais, e o traço intermediário, a média mensal, fornecidos pela Estação Meteorológica de Curitiba. A"'. Temperatura média mensal referente ao padrão normal conforme MAACK (1981). B, B', B'. Precipitação pluviométrica mensal registrado para os períodos de PP-92/93, PP-86/87 e PP-75, fornecidos pela Estação Meteorológica de Curitiba. B"'. Precipitação pluviométrica mensal do padrão normal, segundo MAACK (1981). Fontes: PP-75 (LAROCA, Cure \& Bortoli, 1982); PP-86/87 (TAura, 1990). 


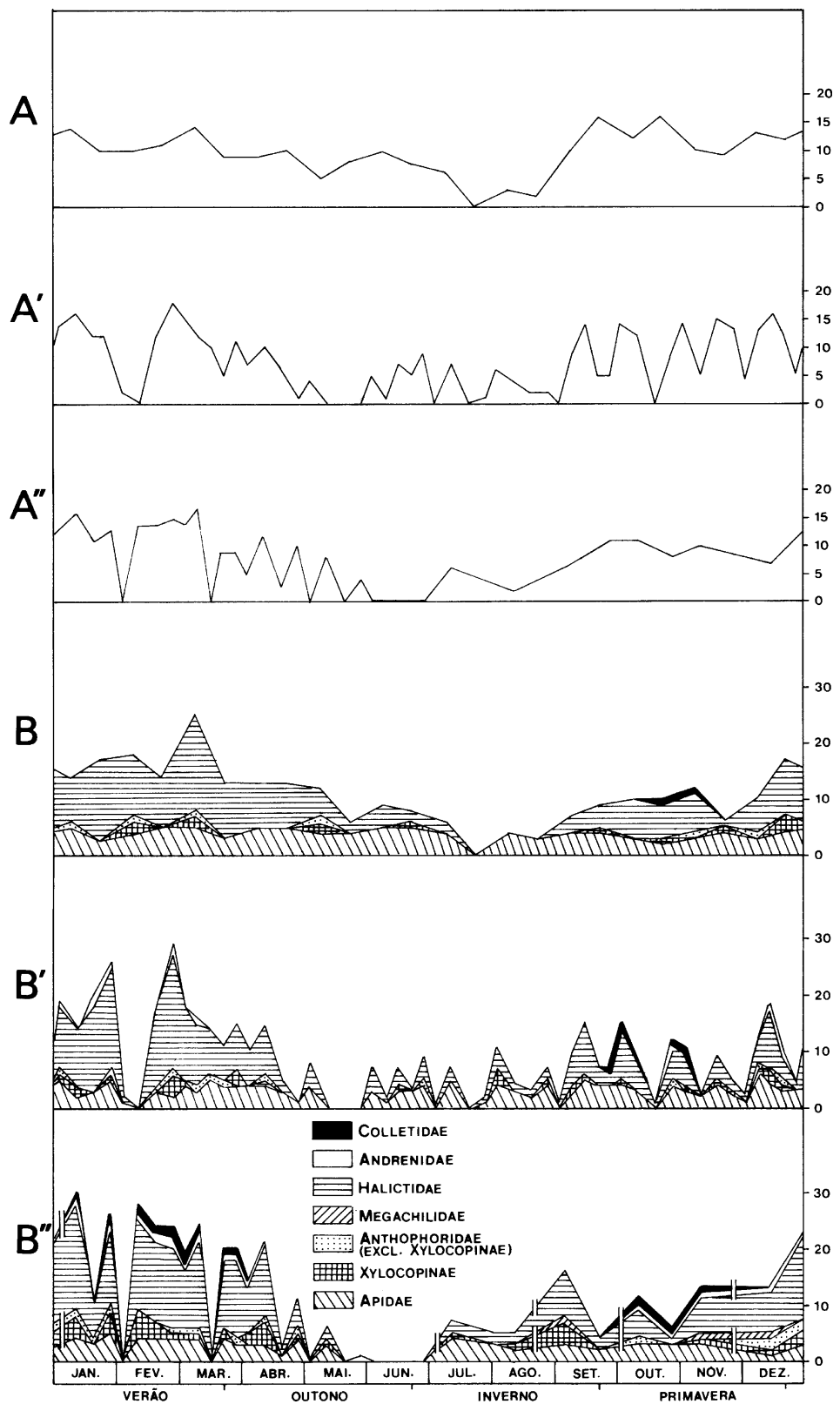

Fig. 21. Flutuação do número de espécies de plantas visitadas por família de abelhas silvestres (Hymenoptera, Apoidea) e número de espécies por família de abelhas no Passeio Público, Curitiba, Paraná. A, A', A": Número de espécies de plantas visitadas em 1992/93, 1986/87 e 1975, respectivamente. B, B', B": Número de espécies de abelhas capturadas em 1992/93, 1986/87 e 1975, respectivamente. Fontes: PP-75 (LAROCA, CURE \& BorTOLI, 1982); PP-86/87 (TAURA, 1990). 
verão, as flores de Chlorophytum sp. (Liliaceae), Calliandra selloi (Mimosaceae) e Impatiens sp. (Balsaminaceae) são as mais frequentadas, enquanto que Tibouchina sellowiana (Melastomataceae), Dombeya wallichii (Sterculiaceae), Calladium sp. (Araceae) e C. selloi no outono. Durante o inverno, a espécie Rhododendron indicum (Ericaceae) é a mais preferida, sendo que neste período, as flores de $A$. mulleri-friderici também são predominantemente visitadas.

Dentre as espécies vegetais mencionadas acima, Calladium sp., Chlorophytum sp., D. wallichii, Impatiens sp., L. lucidum e R. indicum são introduzidas e cultivadas no local para fins de ornamentação.

Algumas espécies de plantas procuradas preferencialmente pelas abelhas, para a obtenção de recursos alimentares em PP-86/87, são as mesmas observadas na amostragem citada anteriormente. Assim, durante a primavera verifica-se a ocorrência de visitas às flores de $R$. indicum, Butia eriospatha (Palmae), V. breviflora, Impatiens sp. e Ligustrum lucidum, enquanto que no verão, Ligustrum japonicum (Oleaceae) e Impatiens sp. são as mais requisitadas. No outono e inverno, as abelhas procuram mais por flores de $R$. indicum, Kniphofia uvaria (Liliaceae) e D. wallichii.

A composição florística de PP-75 difere bastante da observada em PP-92/93 e PP-86/87, sendo que a maioria das plantas visitadas pelas abelhas neste ano não mais encontram-se presentes nas duas amostragens posteriores. Tal fato, assim como a variação observada entre PP-92/93 e PP-86/87, deve-se principalmente ao processo de jardinagem efetuado constantemente no local, com renovação freqüente de algumas plantas, capinas e podas.

Em PP-75, as flores mais visitadas durante a primavera pertencem a Spondia sp. (Anacardiaceae) e Spiraea sp. (Rosaceae). No verão, $B$. eriospatha, Polygonum punctatum (Polygonaceae), L. japonicum e Liriope muscari $x$ variegata (Liliaceae) são as mais procuradas. $P$. punctatum e Muehlenbeckia platyclada (Polygonaceae) são as que se destacam no outono, enquanto que no inverno as visitas concentram-se mais em Rhododendron simssi (Ericaceae).

A flutuação do número de espécies de abelhas silvestres encontra-se representada na figura 21 e a flutuação do número de indivíduos na figura 22.

As espécies de Apoidea apresentam, no PP-92/93, atividade mais elevada durante os meses mais quentes do ano, ou seja, durante o verão e a primavera, e acentuada redução durante os meses mais frios. A mesma 
situação é constatada também em PP-86/87 e PP-75. Esta tendência encontra-se coerente com o padrão descrito para Curitiba (como um todo), Boa Vista (Curitiba) e São José dos Pinhais, Paraná ( $c f$. LARoca, 1972), o qual caracteriza-se pela diminuição do número de espécies em atividade durante o inverno.

Este autor destaca também, dois grupos fenologicamente distintos. O primeiro é composto por Colletidae, Andrenidae, Megachilidae e Anthophoridae (excluindo Xylocopinae) e que não apresenta forma ativa adulta no inverno. O segundo grupo é formado por Halictidae, Xylocopinae e Apidae, com adultos em atividade durante o ano todo, sem interrupção de vôo no inverno. As tendências fenológicas (ver SAKAGAMI, LAROCa \& Moure (1967), aproxima-se do padrão da região temperada pela característica de inverno, com a presença apenas do segundo grupo e do padrão tropical, devido a ausência da interrupção completa de atividade de adultos no inverno.

As oscilações observadas nas atividades das abelhas, em termos de espécies como de indivíduos (Figs 21 e 22, respectivamente), são também influenciadas por condições climáticas desfavoráveis no período da coleta. Assim, as depressões mais acentuadas que constam nos gráficos indicam dias de coleta com condições meteorológicas adversas. Todavia, os picos que mostram frequiências elevadas de adultos em atividade, indicam mais claramente as fases sazonais apresentadas pelos variados grupos taxonômicos.

Mesmo durante os meses mais frios, compreendidos entre junho e agosto, quando ocorre redução de atividade de vôo de abelhas, em dias ensolarados e propícios podem ser coletados muitos indivíduos e um número razoável de espécies. Por exemplo, na coleta realizada em 13 de julho de 1992 foram capturados 89 indivíduos e seis espécies, sendo que destas, quatro pertencem à Apidae e duas à Halictidae. No censo de PP-86/87, no dia 4 de agosto de 1986, foram coletados 263 indivíduos e onze espécies (quatro de Apidae, quatro de Halictidae e três de Xylocopinae) (Taura, 1990). Também, segundo Laroca, Cure \& Bortoli (1982), durante a amostragem de PP-75, em 14 de julho de 1975, foram obtidos 120 indivíduos e sete espécies (quatro pertencentes a Apidae, duas a Halictidae e uma a Xylocopinae).

A ocorrência de Apoidea no PP, durante o inverno, conforme o quadro descrito a seguir, indica tendências fenológicas mais ou menos definidas, onde o sinal - representa a ausência, \pm a redução drástica e + a presença do taxon considerado. 


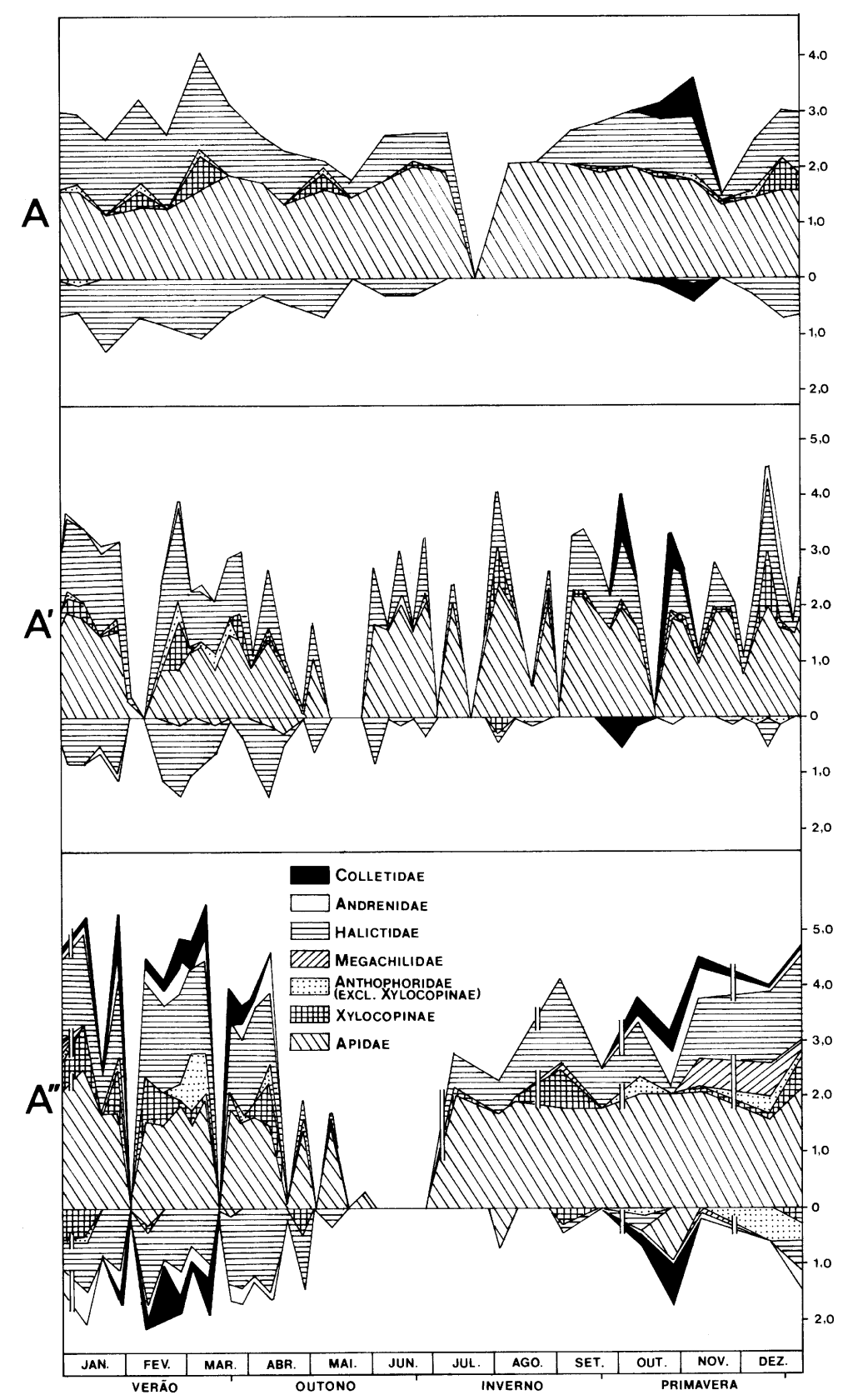

Fig. 22. Flutuação do número de indivíduos por família de abelhas silvestres (Hymenoptera, Apoidea) no Passeio Público, Curitiba, Paraná. A, A', A”: Número de indivíduos coletados em 1992/93, 1986/87 e 1975, respectivamente, em escala logarítmica. A parte superior de cada gráfico refere-se no número de fêmeas e a parte inferior ao número de machos. Fontes: PP-75 (LAROCA, Cure \& Bortoli, 1982); PP-86/87 (TAura, 1990). 
COLLETIDAE

ANDRENIDAE

HALICTIDAE

MEGACHILIDAE

ANTHOPHORIDAE

(excluindo Xylocopinae)

XYLOCOPINAE

APIDAE

$\begin{array}{ccc}\text { PP-92/93 } & \text { PP-86/87 } & \text { PP-75 } \\ - & - & - \\ - & - & - \\ + & + & + \\ - & - & \pm \\ & & \\ - & \pm & - \\ \pm & + & + \\ + & + & +\end{array}$

A família Anthophoridae capturada no inverno, durante o censo de PP-86/87 e Megachilidae em PP-75, encontram-se representadas por apenas um único exemplar fêmea de Exomalopsis villipes e um de Megachile sp. 2, respectivamente.

\section{FLUTUAÇÃO DO NÚMERO DE ESPÉCIES E DE INDIVÍDUOS POR FAMÍLIA DE ABELHAS}

A ocorrência no PP dos variados grupos taxonômicos, é mencionada a seguir, com comentários sobre alguns aspectos do ciclo sazonal de atividade

COLLETIDAE

A presença desta família de abelhas em PP-92/93, é verificada durante os meses de outubro e novembro de 1992, sendo representada apenas por Bicolletes sp. (7 fêmeas e 3 machos). Em PP-86/87 é constituída por Bicolletes sp. (12 fêmeas e 6 machos) e Hylaeus sp. (1 fêmea), sendo que a primeira espécie apresenta atividade entre fins de setembro até início de novembro, enquanto que a segunda foi coletada apenas em 15 de dezembro de 1986. Em PP-75, é representada por Hylaeus rivalis (23 fêmeas e 21 machos) capturada entre janeiro e abril e por Bicolletes sp. (4 fêmeas e 6 machos), com ocorrência entre outubro e novembro de 1975 .

ANDRENIDAE

Encontra-se possivelmente ausente em PP-92/93, pois não foi coletado nenhum representante desta família. Em PP-86/87 é constituída por Anthrenoides meridionalis (4 fêmeas) e Panurginae sp. 1 (1 fêmea e 3 machos), sendo a primeira capturada durante os meses de dezembro de 1986, janeiro e março de 1987, e a segunda em outubro de 1986, janeiro e fevereiro de 1987. Em PP-75, um total de 33 fêmeas e 26 machos 
foram coletados nos meses de janeiro a abril e outubro a dezembro de 1975, os quais são representados por Psaenytia sp., Panurginae sp. 1 e sp. 3, que correspondem a Panurginae sp.1 e A. meridionalis de PP-86/ 87.

\section{HALICTIDAE}

Esta família, assim como a família Apidae, ocorrem em todas as estações do ano, e estão presentes em quase todas as coletas realizadas no PP. Dentre as famílias de Apoidea, Halictidae é a mais rica em espécies, sendo representada em PP-92/93 por 32 espécies e 325 indivíduos (253 fêmeas e 72 machos), em PP-86/87 por 47 espécies e 537 indivíduos (409 fêmeas e 128 machos) e em PP-75 por 45 espécies e 606 indivíduos (417 fêmeas e 189 machos). Nas três amostragens realizadas, observam-se semelhanças quanto ao período de maior atividade deste grupo, o que corresponde aos meses de dezembro a março. Em PP-92/93, o pico máximo verificado foi no dia 8 de março de 1993, com 17 espécies e 65 indivíduos coletados.

Augochlora amphitrite é a espécie predominantemente capturada durante o levantamento de PP-92/93, apresentando-se ativa durante todo o ano, exceto agosto de 1992. O seu período de maior frequência corresponde aos meses de janeiro a março de 1993 e nestes dois primeiros meses é a espécie de Halictidae mais abundantemente coletada.

As espécies Dialictus (Chloralictus) rhytidophorus, Augochlorella michaelis, Augochlorella ephyra, Dialictus (Chloralictus) opacus e Augochlora neivai são, também, as mais abundantemente coletadas neste censo.

\section{MEGACHILIDAE}

Esta família encontra-se ausente nas amostras de PP-92/93 e PP-86/ 87. Em PP-75 foram capturadas 3 espécies, com 8 fêmeas e 1 macho, durante os meses de setembro, novembro e dezembro.

\section{ANTHOPHORIDAE}

É representada em PP-92/93 por 3 espécies: Lophopedia sp. (1 fêmea), Paratetrapedia sp. (1 fêmea) e Thygater analis (4 fêmeas e 1 macho), os quais foram coletados respectivamente em novembro de 1992, maio de 1993 e, dezembro de 1992 a março de 1993. Na amostra de PP86/87 verifica-se a ocorrência de Exomalopsis villipes (1 fêmea) em junho de 1986, Exomalopsis aureosericea (1 fêmea) em outubro de 1986 e Thygater analis (11 fêmeas e 2 machos) entre dezembro de 1986 e abril de 1987. Em PP-75, foram capturadas as espécies E. aureosericea, Melissoptila thoracica e T. analis, totalizando 33 indivíduos presentes 
de janeiro a abril e de outubro a dezembro de 1975 . Observa-se no PP, a ausência de adultos ativos durante o inverno, com exceção de uma fêmea de E. villipes coletada em 30 de junho de 1986.

\section{XYLOCOPINAE}

Nos três períodos de estudo realizados no PP, Xylocopinae apresenta atividade durante todo o ciclo anual, não demonstrando interrupção durante o inverno. Esta subfamília é mencionada à parte, por apresentar tendências fenológicas distintas dos demais representantes da família. Assim, em PP-92/93, observa-se a ocorrência de Ceratina asuncionis (2 fêmeas) em junho de 1992 e fevereiro de 1993, Ceratinula lucidula (1 fêmea) em fevereiro de 1993, Ceratinula sclerops (5 fêmeas) em setembro e dezembro de 1992 e, ainda, em março e maio de 1993, Ceratinula turgida (5 fêmeas) em dezembro de 1992, março e maio de 1993, Xylocopa artifex (1 fêmea) em novembro de 1992, X. augusti (2 fêmeas) em outubro e dezembro de 1992 . O período de atividade máxima, em termos de riqueza de espécies e abundância de indivíduos, compreende os meses de dezembro de 1992 e março de 1993.

Em PP-86/87, Xylocopinae encontra-se constituída por 9 espécies $(C$. asuncionis, Ceratina stilbonota, Ceratina volitans, C. lucidula, $C$. sclerops, C. turgida, Xylocopa frontalis, X. augusti e X. artifex), totalizando 47 indivíduos (45 fêmeas e 2 machos). Apresenta o período de maior frequiência de espécies e de indivíduos em dezembro de 1986 e fevereiro de 1987. Na amostra de PP-75, verifica-se a ocorrência de $C$. asuncionis, $C$. volitans, Ceratinula sp.1 a sp.6, X. augusti e $X$. artifex, com um total de 56 indivíduos (47 fêmeas e 9 machos). Destas o maior número de espécies capturadas é constatada em fevereiro e o de indivíduos, em janeiro de 1975.

\section{APIDAE}

No PP, é a família que possui uma distribuição mais ou menos estável ao longo dos meses, sendo representada em sua maior parte por Meliponinae. Segundo SaKagami \& Laroca (1971), os Meliponinae mostram uma relativa independência em relação às estações do ano, estando presentes mesmo nos meses mais frios. São ativas através do ano e também independentes do período sazonal de floração das plantas (MICHENER, 1979).

Em PP-92/93, observa-se a ocorrência desta família em todos os dias de coleta, com exceção do dia 27 de julho de 1992, em que se verificou somente a atividade de A. mellifera, sendo registradas garoa e a menor média diária de temperatura de campo $\left(11,6^{\circ} \mathrm{C}\right)$ de todo o período anual 
de amostragem. No total foram coletadas sete espécies e 1342 indivíduos.

O período de maior frequência, em número de indivíduos é agosto de 1992, especialmente devido à elevada abundância de Trigona (Trigona) spinipes. Neste mês foi registrada a menor temperatura média mensal de PP-92/93. Ainda, na coleta realizada no dia 24 de agosto de 1992, somente exemplares representantes de Apidae foram capturados, sendo que destes, cento e nove pertencem à $T$. (T.) spinipes, nove à Partamona helleri e dois a Plebeia (Plebeia) emerina.

Nos meses de junho, julho, agosto e setembro de 1992, bem como em abril de 1993, observa-se que dentre os Apoidea, T. (T.) spinipes é a espécie predominantemente capturada. Nos demais meses deste ciclo anual, $P$. (P.) emerina é a mais freqüente.

\section{SUCESSÃO DAS ESPÉCIES DE ABELHAS PREDOMINANTEMENTE CAPTURADAS}

As frequiências mensais (\%) de indivíduos por espécies predominantemente coletadas em PP-92/93, PP-86/87 e PP-75, encontram-se apresentadas na figura $23 \mathrm{e}$ os aspectos gerais comentados a seguir. Os intervalos de confiança foram obtidos seguindo-se o método de Kato, MATSUDA $\&$ Yamashita (1952) ( $c f$. SAKAgami \& Matsuda, 1967 e Laroca, 1972).

JANEIRO

Neste mês, durante a amostragem de PP-92/93, foram coletados um total de 21 espécies e 117 indivíduos, sendo que as espécies predominantemente capturadas $(53,85 \%)$, em ordem decrescente de abundância são $P$. emerina, A. amphitrite, $N$. bipunctata e $T$. spinipes.

A espécie mais abundantemente coletada em PP-86/87 e PP-75 é também $P$. emerina. Considerando-se a ocorrência das espécies de abelhas predominantes, nota-se ainda que $T$. spinipes e A. amphitrite são comuns às três amostragens do $\mathrm{PP}$, embora a sua frequiência seja variável.

\section{FEVEREIRO}

No decorrer deste mês, foram coletados no PP-92/93 22 espécies, distribuídas em 103 indivíduos. Observa-se que $P$. emerina é a espécie mais freqüente, seguida por $A$. amphitrite. Entretanto, A. michaelis e $T$. spinipes são as predominantemente capturadas em PP-86/87 e PP-75, respectivamente, sendo que $P$. emerina é a segunda espécie mais abundante nestas amostras. 
Dentre as espécies predominantes, observa-se que $P$. emerina e $A$. amphitrite são comuns à PP-92/93, PP-86/87 e PP-75.

Verifica-se também que $B$. atratus, uma das espécies predominantemente coletadas somente em PP-75, apresenta a frequiência anual mais elevada nos meses de fevereiro e março, enquanto que em PP-92/93 em janeiro e fevereiro, e em PP-86/87, durante os meses de março e abril.

Em PP-75, ainda, o número total de espécies capturadas durante o referido mês, é o mais representativo dos doze meses de coleta.

MARÇO

Em PP-92/93 e PP-86/87, este é o mês em que o número total de espécies capturadas é o mais elevado do ciclo anual, sendo que na primeira amostragem mencionada, foram coletados 29 espécies e 204 indivíduos, e na segunda, 38 espécies e 193 indivíduos. A diversidade observada neste mês, deve-se especialmente à presença de variadas famílias de abelhas, como também de muitas espécies de Dialictus.

Segundo a ordem decrescente de abundância, as espécies predominantes em PP-92/93, encontram-se distribuídas em: P. emerina, $T$. spinipes, A. amphitrite, T. angustula e N. bipunctata.

Nos três levantamentos realizados no PP, P. emerina é considerada a espécie mais representativa. Também, dentre as espécies predominantemente capturadas, verifica-se a presença comum de $T$. spinipes e $A$. amphitrite.

ABRIL

Foram coletadas no decorrer deste mês, em PP-92/93 19 espécies, totalizando 97 exemplares. Destes indivíduos, 79,38\% representam as espécies predominantes, distribuídos conforme a ordem decrescente de abundância em: T. spinipes, P. emerina, T. angustula, A. amphitrite, $N$. bipunctata e $P$. helleri. Estas duas últimas espécies apresentam a mesma freqüência de captura.

A partir deste mês, observa-se a redução do número de espécies, devido à condições climáticas desfavoráveis, típicas do período outonoinverno.

As espécies predominantes e comuns às três amostras do PP, são $A$. amphitrite, $P$. emerina e $T$. spinipes, sendo que $P$. emerina é a mais representativa em PP-86/87 e PP-75.

MAIO

A amostra de PP-92/93, obtida durante este mês, encontra-se constituída por 15 espécies e 80 indivíduos. Destes, 87,5\% estão incluídas entre as espécies predominantemente capturadas. 


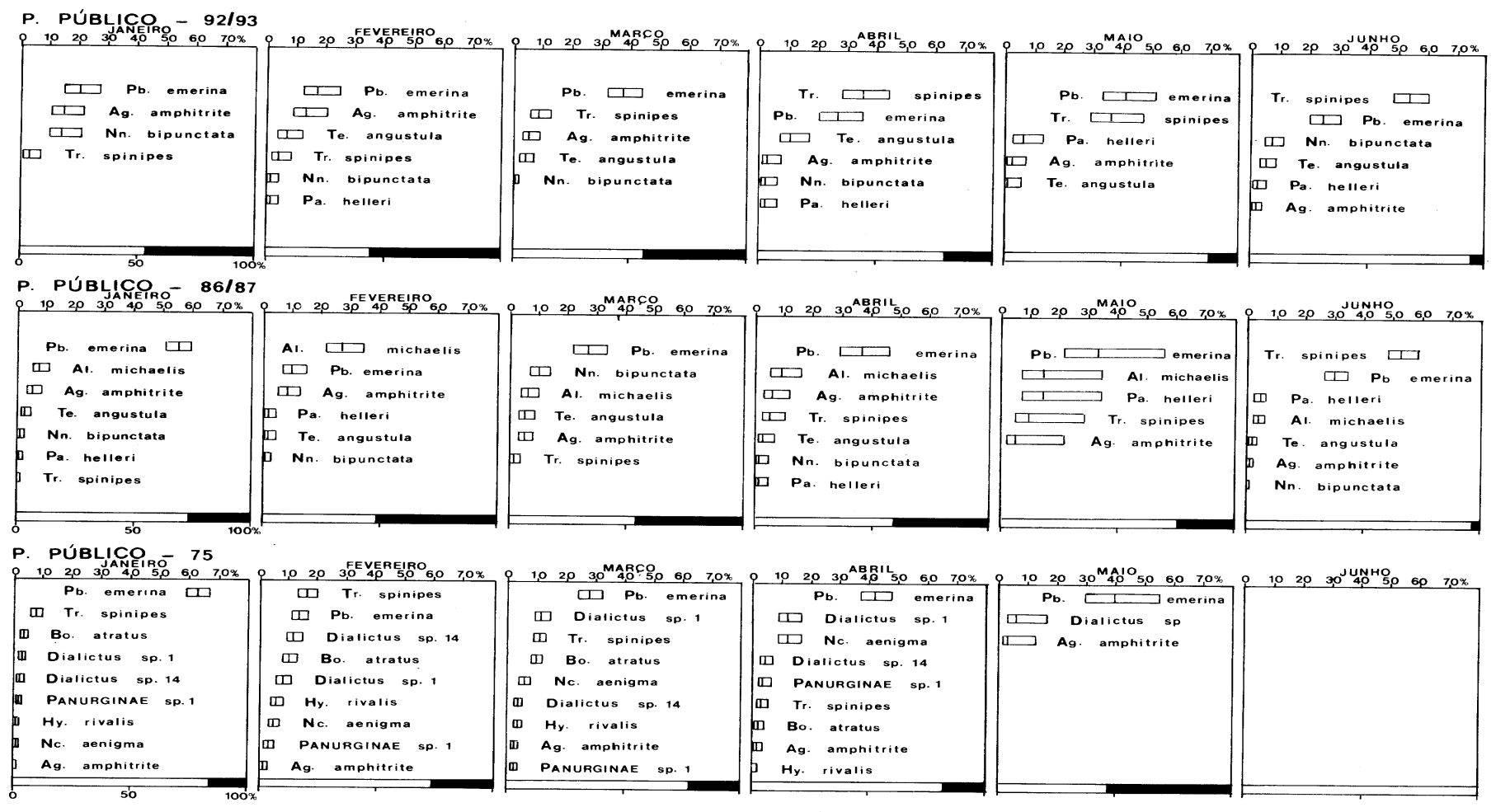


Fig. 23. Sucessão mensal das espécies de abelhas silvestres.....(conclusão)

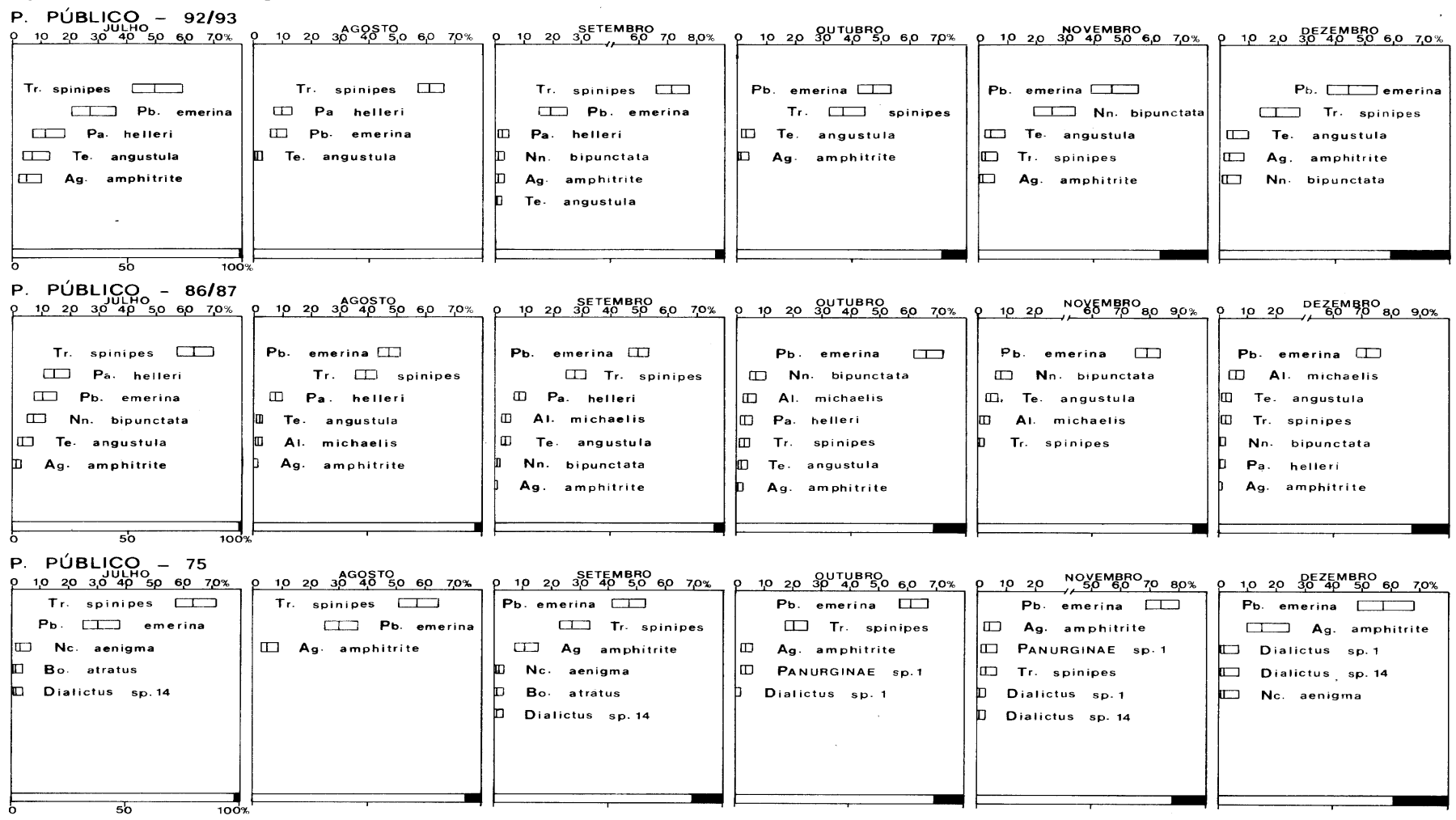

Fig. 23. Sucessão mensal das espécies de abelhas silvestres (Hymenoptera, Apoidea) predominantemente capturadas no Passeio Público, Curitiba, Paraná, em 1992/93, 1986/87 e 1975. Os intervalos de confiança foram obtidos segundo o método de KATO, MATSUDA \& YAMASHITA (1952). A barra horizontal, na base de cada gráfico, apresenta o percentual de indivíduos das espécies predominantes e a secção cheia desta, o percentual de indivíduos das espécies não predominantes. A abreviatura dos gêneros encontram-se conforme a tabela 2. Fonte: PP- 
Em ordem decrescente de abundância relativa, as espécies predominantes em PP-92/93, apresentam-se distribuídas em P. emerina, $T$. spinipes, $P$. helleri, A. amphitrite e $T$. angustula. Observa-se que entre estas, A. amphitrite e $P$. emerina são comuns aos levantamentos efetuados no PP e que a última espécie mencionada é a que apresenta a maior freqüência em PP-92/93, PP-86/87 e PP-75.

JUNHO

Em PP-92/93, no decorrer deste mês, foram verificados 10 espécies em atividade e 184 indivíduos, entre os quais, 94\% pertencem às espécies predominantemente capturadas. A espécie mais representativa é $T$. spinipes, seguida por $P$. emerina, $N$. bipunctata, $T$. angustula, $P$. helleri e A. amphitrite.

No censo de PP-86/87, T. spinipes é também a que apresenta a frequiência mais elevada, e $P$. emerina, a segunda espécie em importância, em termos de abundância relativa.

Em PP-75, entretanto, não se observa captura de exemplares de abelhas, exceto de A. mellifera, não incluída neste estudo.

\section{JULHO}

Foram coletados durante o mês, em PP-92/93, seis espécies e 89 indivíduos, pertencentes às famílias Apidae e Halictidae. A maioria destes, isto é, 98,88\% estão incluídos entre as espécies predominantemente capturadas, sobretudo de Meliponinae.

Segundo a ordem decrescente de abundância, as espécies predominantes em PP-92/93, encontram-se distribuídas em $T$. spinipes, $P$. emerina, P. helleri, T. angustula e A. amphitrite. Ainda, em PP-86/87 e PP-75, T. spinipes é também a mais abundantemente coletada e juntamente com P. emerina, constituem-se nas espécies comuns aos três estudos efetivados no PP.

AGOSTO

No levantamento realizado durante este mês no PP-92/93, foram coletados quatro espécies e 238 indivíduos. Verifica-se neste período, acentuada redução no número de espécies de abelhas em atividade, porém, este é o mês em que constata-se a maior abundância de indivíduos capturados.

Os exemplares coletados pertencem em sua totalidade, em PP-92/93, às espécies predominantes $T$. spinipes, $P$. helleri, $P$. emerina e $T$. angustula, sendo notória a elevada representatividade da primeira espécie citada. Os indivíduos de $T$. spinipes foram capturados, em sua maioria, quando em visita às flores de $R$. indicum, espécie exótica com floração abundante nesta época do ano. 
Nos censos realizados no PP, T. spinipes e $P$. emerina são as espécies comuns.

\section{SETEMBRO}

Neste mês, em PP-92/93, o número de espécies de Apoidea em atividade começa a aumentar. Assim, foram coletados 13 espécies e 206 indivíduos, pertencentes à Apidae, Halictidae e Xylocopinae.

Os indivíduos predominantemente capturados em PP-92/93 (95,63\%) encontram-se distribuídos em ordem decrescente de abundância, entre as espécies $T$. spinipes, $P$. emerina, $P$. helleri, $N$. bipunctata, A. amphitrite e T. angustula.

Em PP-86/87 e PP-75, P. emerina é a espécie que apresenta a maior frequiência, enquanto que em PP-92/93, é a segunda espécie mais abundante. Além desta espécie, também T. spinipes e A. amphitrite são comuns às três épocas de estudo no PP.

\section{OUTUBRO}

Verificam-se no decorrer deste mês, em PP-92/93, a ocorrência de 15 espécies e 190 indivíduos. Destes exemplares 89,47\% representam as espécies predominantemente capturadas, cuja abundância relativa constatada, em ordem decrescente é a seguinte: P. emerina, T. spinipes, $T$. angustula e A. amphitrite.

Em PP-86/87, P. emerina é também a mais freqüente, assim como em PP-75. As espécies predominantes em PP-92/93, PP-86/87 e PP-75, e portanto, comuns às três amostras, são A. amphitrite, P. emerina e $T$. spinipes.

\section{NOVEMBRO}

Foram capturados neste mês, em PP-92/93, 16 espécies e 100 indivíduos, entre os quais $78 \%$ encontram-se entre os exemplares pertencentes às espécies predominantemente capturadas. Assim como em PP-96/ 87 e PP-75, P. emerina é a espécie com a maior freqüência, embora nestes dois últimos levantamentos mencionados, tenha sido constatada a elevada frequiência desta em relação às outras espécies.

Em ordem decrescente de abundância, as espécies predominantemente coletadas em PP-92/93, são P. emerina, $N$. bipunctata, $T$. angustula, $T$. spinipes e A. amphitrite.

Nos levantamentos realizados em PP-92/93, PP-86/87 e PP-75, observa-se que as únicas espécies comuns são $P$. emerina e $T$. spinipes.

\section{DEZEMBRO}

Em PP-92/93, foram capturadas 20 espécies, totalizando 92 indivíduo. Destes últimos, 73,91\% encontram-se incluídos entre as espécies predominantemente capturadas. 
Em termos de abundância relativa, em ordem decrescente de ocorrência, em PP-92/93, as espécies predominantes são P. emerina, $T$. spinipes, $T$. angustula, A amphitrite e $N$. bipunctata.

No decorrer deste mês, observa-se elevada freqüência de $P$. emerina, a mais abundantemente coletada nas amostragens de PP-92/93, PP-86/ 87 e PP-75. Também, constata-se a presença comum de A. amphitrite, nestas três épocas de levantamento.

\section{SUCESSÃO DAS ESPÉCIES DE PLANTAS PREDOMINANTEMENTE} VISITADAS

A seqüência fenológica das espécies de plantas predominantemente visitadas, por fêmeas e machos das famílias de abelhas silvestres, em PP-92/93, PP-86/87 e PP-75, encontram-se indicadas nas Figuras 24 e 25 , respectivamente, consideradas segundo o método de KATO, MATSUDA \& Yamashita (1952) ( $c f$. SaKagami \& Matsumura, 1967 e Laroca, 1972).

Em PP-92/93 foram capturados exemplares de abelhas sobre 69 espécies de plantas, entre as quais apenas nove são predominantemente visitadas. Entre estas, a espécie mais freqüentemente visitada é $R$. indicum, seguida por A. mulleri-friderici, Chlorophytum sp., C. selloi, V. breviflora, D. wallichii, T. sellowiana, Impatiens sp. e Calladium sp. Todavia, as duas últimas espécies mencionadas apresentam a mesma proporção de visitas.

As espécies vegetais predominantemente visitadas em PP-86/87, dentre as 85 espécies e em ordem decrescente de abelhas capturadas, são $R$. indicum, Impatiens sp, K. uvaria, L. japonicum, B. eriospatha, D. wallichii, V. breviflora, Chlorophytum sp., C. selloi, C. rosea e $L$. lucidum.

Verifica-se em PP-75, uma composição florística bastante diferenciada das duas amostras citadas anteriormente. Assim, de um total de 64 espécies de plantas visitadas, apresentam-se como as predominantemente procuradas, da maior a menor frequiência de abelhas capturadas, as espécies $P$. punctatum, $R$. simssi, B. eriospatha, M. platyclada, T. pilosa, L. japonicum, E. splendens, Spondia sp., Spiraea sp., $L$. muscari x variegata, Musa sp., A. henryi e C. crocosmiflora.

Dentre as espécies predominantes em PP-75, P. punctatum, R. simssi, M. platyclada, T. pilosa, Spondia sp., L. muscari x variegata, Musa sp., A. henryi e $C$. crocosmiflora encontram-se ausentes em PP-86/87 e PP-92/93. Todavia, B. eriospatha, L. japonicum e E. splendens, embora presentes em PP-92/93, não se configuram entre as predominantemente visitadas. 

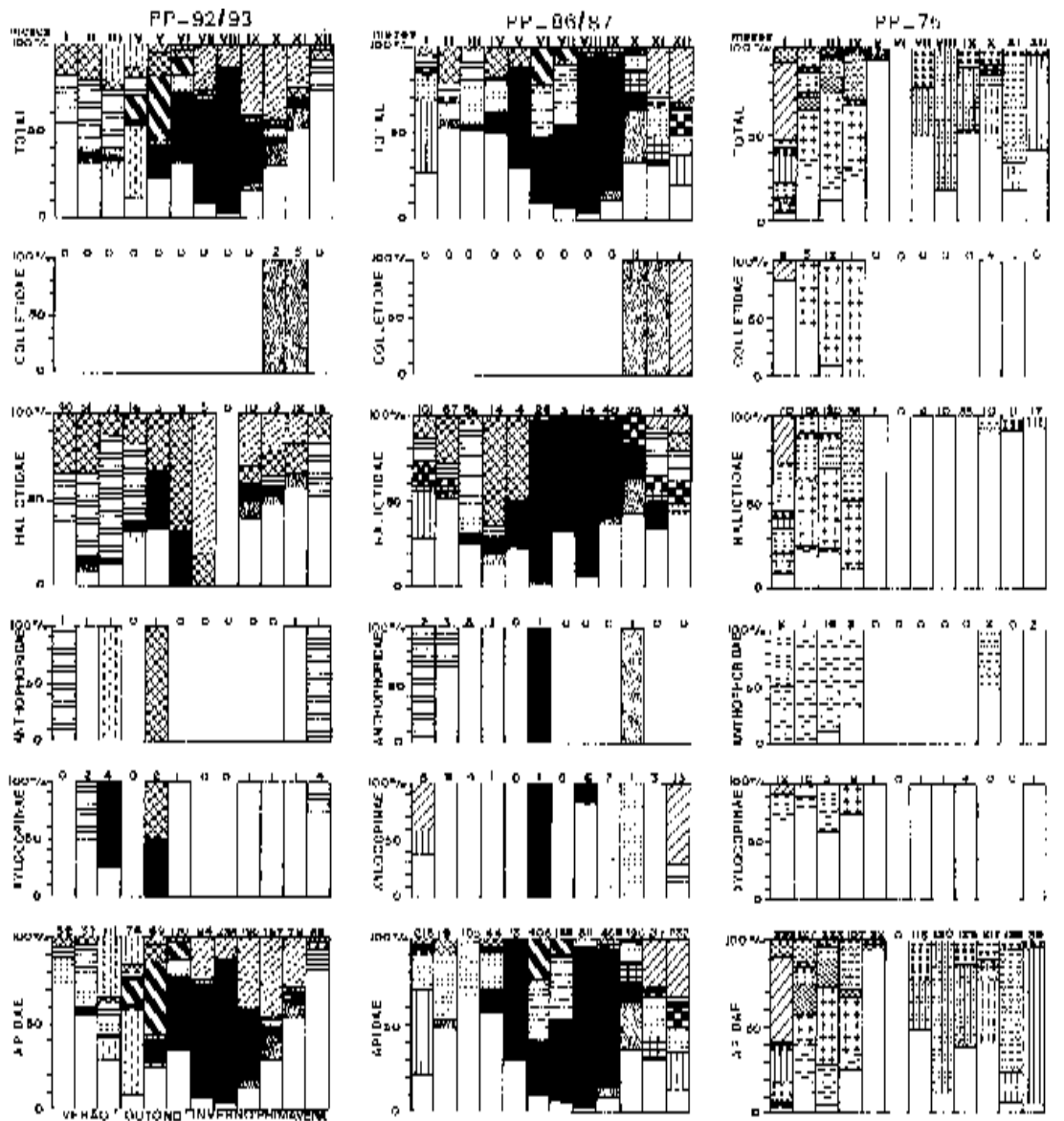

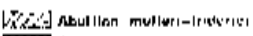
BA Alpines hanryl $2 Z$ kisile arlimpenthn

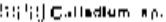

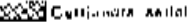
-7 Chluruphilure ipe

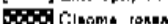

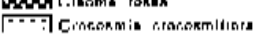

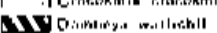

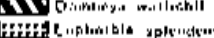

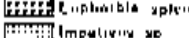

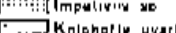

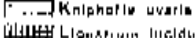

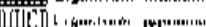

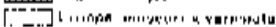
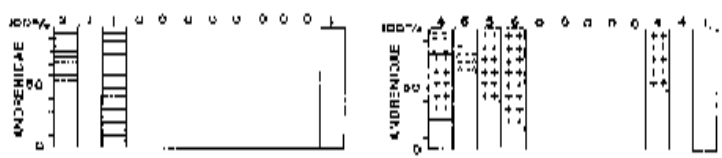

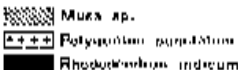

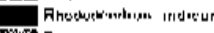

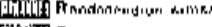

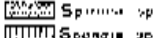

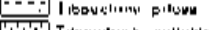

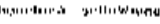

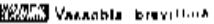

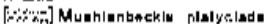

Fig. 24. Espécies de plantas predominantemente visitadas por fêmeas das famílias de abelhas silvestres (Hymenoptera, Apoidea) em cada mês, no Passeio Público, Curitiba, Paraná, em 1992/93, 1986/87 e 1975. O número de indivíduos coletados sobre as flores é indicado sobre os gráficos. A família Anthophoridae não inclui Xylocopinae. Fontes: PP-75 (Laroca, Cure \& Bortoli, 1982); PP-86/87 (Taura, 1990). 

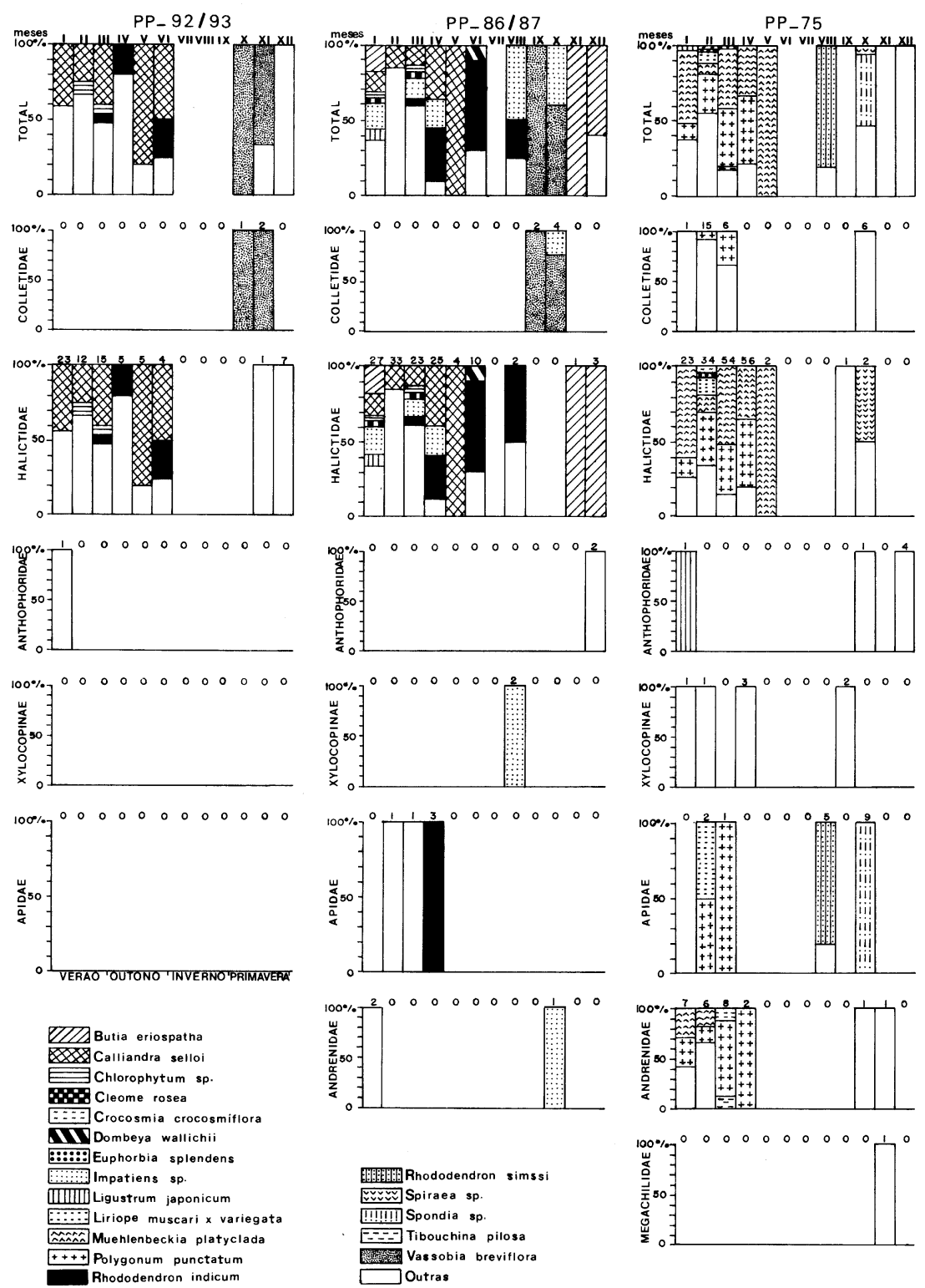

NNDin Liriope muscari $\times$ variegata Mñenlenbeckia platyclada Rhododendron indicum
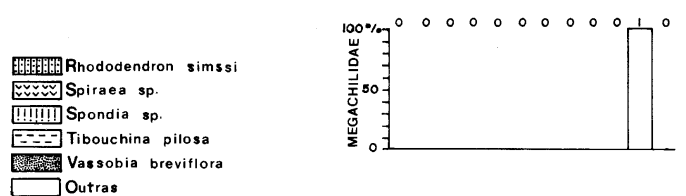

Fig. 25. Espécies de plantas predominantemente visitadas por machos das famílias de abelhas silvestres (Hymenoptera, Apoidea) em cada mês, no Passeio Público, Curitiba, Paraná, em 1992/93, 1986/87 e 1975. O número de indivíduos coletados sobre as flores é indicado sobre os gráficos. A família Anthophoridae não inclui Xylocopinae. Fontes: PP-75 (Laroca, Cure \& Bortoli, 1982); PP-86/87 (Taura, 1990). 
Tabela 8. Número de espécies de plantas (Pl.) visitadas por abelhas silvestres (Hymenoptera, Apoidea) e o número de exemplares de abelhas (Ab.) capturados nas flores, por família de planta, no Passeio Público, Curitiba, Paraná, em 1992/93, 1986/87 e 1975.

\begin{tabular}{|c|c|c|c|c|c|c|c|c|}
\hline \multirow[t]{2}{*}{ FAMÍLIA } & \multicolumn{2}{|c|}{ PP-92/93 } & \multicolumn{2}{|c|}{ PP-86/87 } & \multicolumn{2}{|c|}{ PP-75 } & \multicolumn{2}{|c|}{ TOTAL } \\
\hline & Pl. & $\mathrm{Ab}$. & Pl. & $\mathrm{Ab}$. & Pl. & $\mathrm{Ab}$. & $\mathrm{Pl}$. & Ab. \\
\hline Asteraceae & 3 & 13 & 5 & 17 & 6 & 96 & 12 & 126 \\
\hline Ericaceae & 1 & 445 & 1 & 1181 & 4 & 251 & 5 & 1877 \\
\hline Liliaceae & 5 & 174 & 5 & 330 & 1 & 79 & 6 & 583 \\
\hline Polygonaceae & & & 1 & 18 & 2 & 555 & 3 & 573 \\
\hline Palmae & 1 & 30 & 1 & 174 & 1 & 218 & 1 & 422 \\
\hline Oleaceae & 3 & 38 & 3 & 244 & 1 & 118 & 3 & 400 \\
\hline Leguminosae - & 8 & 164 & 10 & 165 & 8 & 45 & 22 & 374 \\
\hline Malvaceae & 2 & 251 & 2 & 40 & 3 & 59 & 5 & 350 \\
\hline Balsaminaceae & 1 & 53 & 1 & 258 & & & 1 & 311 \\
\hline Solanaceae & 4 & 93 & 4 & 142 & 2 & 33 & 6 & 268 \\
\hline Melastomataceae & 2 & 64 & 2 & 52 & 4 & 133 & 5 & 249 \\
\hline Sterculiaceae & 1 & 59 & 1 & 114 & & & 1 & 173 \\
\hline Anacardiaceae & 1 & 30 & 1 & 21 & 1 & 116 & 2 & 167 \\
\hline Euphorbiaceae & 1 & 3 & 3 & 16 & 2 & 120 & 4 & 139 \\
\hline Acanthaceae & 1 & 14 & 1 & 1 & 4 & 122 & 6 & 137 \\
\hline Rosaceae & 3 & 6 & 1 & 3 & 1 & 103 & 4 & 112 \\
\hline Iridaceae & 1 & 3 & 1 & 5 & 3 & 80 & 5 & 88 \\
\hline Zingiberaceae & & & 1 & 2 & 3 & 80 & 3 & 82 \\
\hline Apocynaceae & 2 & 48 & 1 & 16 & 10 & 2 & 2 & 74 \\
\hline Musaceae & 1 & 6 & & & 1 & 65 & 2 & 71 \\
\hline Capparidaceae & 1 & 1 & 1 & 69 & & & 1 & 70 \\
\hline Araceae & 1 & 53 & 1 & 16 & & & 1 & 69 \\
\hline Sapindaceae & 1 & 3 & 1 & 43 & 1 & 12 & 1 & 58 \\
\hline Lythraceae & 1 & 11 & 2 & 41 & 2 & 5 & 4 & 57 \\
\hline Labiatae & 2 & 4 & 2 & 38 & 1 & 3 & 3 & 45 \\
\hline Scrophulariaceae & 1 & 2 & & & 1 & 41 & 2 & 43 \\
\hline Celastraceae & 1 & 3 & 1 & 39 & & & 1 & 42 \\
\hline Verbenaceae & 1 & 2 & 1 & 14 & 2 & 20 & 3 & 36 \\
\hline Bignoniaceae & 2 & 6 & 3 & 23 & & & 3 & 29 \\
\hline Cactaceae & & & & & 1 & 28 & 1 & 28 \\
\hline Apiaceae -" & & & & & 2 & 27 & 2 & 27 \\
\hline Brassicaceae & 1 & 26 & & & & & 1 & 26 \\
\hline
\end{tabular}


Tabela 8 (conclusão)

\begin{tabular}{|c|c|c|c|c|c|c|c|c|}
\hline \multirow{2}{*}{ FAMÍLIA } & \multicolumn{2}{|c|}{ PP-92/93 } & \multicolumn{2}{|c|}{ PP-86/87 } & \multicolumn{2}{|c|}{ PP-75 } & \multicolumn{2}{|c|}{ TOTAL } \\
\hline & Pl. & $\mathrm{Ab}$. & Pl. & Ab. & $\mathrm{Pl}$. & Ab. & Pl. & $\mathrm{Ab}$. \\
\hline Myrtaceae & 2 & 9 & 5 & 15 & & & 5 & 24 \\
\hline Loranthaceae & & & 1 & 21 & & & 1 & 21 \\
\hline Convolvulaceae & 1 & 18 & 1 & 2 & & & 1 & 20 \\
\hline Portulacaceae & & & 1 & 19 & & & 1 & 19 \\
\hline Aquifoliaceae & & & & & 1 & 17 & 1 & 17 \\
\hline Bromeliaceae & 2 & 9 & 2 & 7 & & & 2 & 16 \\
\hline Pittosporaceae & 1 & 2 & 1 & 12 & & & 1 & 14 \\
\hline Magnoliaceae & 1 & 9 & 1 & 3 & & & 1 & 12 \\
\hline Thymelaeaceae & 1 & 2 & 1 & 10 & & & 1 & 12 \\
\hline Caryophyllaceae & & & 1 & 11 & & & 1 & 11 \\
\hline Commelinaceae & & & 1 & 3 & 2 & 8 & 3 & 11 \\
\hline Rubiaceae & & & 1 & 10 & & & 1 & 10 \\
\hline Urticaceae & 1 & 7 & 1 & 2 & & & 1 & 9 \\
\hline Theaceae & 1 & 1 & 1 & 5 & & & 1 & 6 \\
\hline Amaryllidaceae & 1 & 4 & 1 & 1 & & & 1 & 5 \\
\hline Aceraceae & & & & & 1 & 4 & 1 & 4 \\
\hline Marantaceae & 1 & 4 & & & & & 1 & 4 \\
\hline Bombacaceae & 1 & 1 & 1 & 2 & & & 1 & 3 \\
\hline Violaceae & 1 & 1 & 1 & 2 & & & 1 & 3 \\
\hline Amaranthaceae & & & & & 1 & 2 & 1 & 2 \\
\hline Nyctaginaceae & & & 1 & 2 & & & 1 & 2 \\
\hline Rhamnaceae & & & 1 & 2 & & & 1 & 2 \\
\hline Tiliaceae & & & 1 & 2 & & & 1 & 2 \\
\hline Cupressaceae & & & 1 & 1 & & & 1 & 1 \\
\hline Flacourtiaceae & 1 & 1 & & & & & 1 & 1 \\
\hline Lauraceae & & & 1 & 1 & & & 1 & 1 \\
\hline Plantaginaceae & & & & & 1 & 1 & 1 & 1 \\
\hline Proteaceae & 1 & 1 & & & & & 1 & 1 \\
\hline Rutaceae & & & 1 & 1 & & & 1 & 1 \\
\hline TOTAL & 69 & 1674 & 85 & 3216 & 64 & 2451 & $157^{*}$ & 7341 \\
\hline
\end{tabular}

- Leguminosae = inclui Caesalpiniaceae, Fabaceae e Mimosaceae

- Apiaceae = Umbelliferae

* Indica o número total dos três censos, considerando-se as espécies comuns. 
Tabela 9. Sucessão mensal de espécies de plantas predominantemente visitadas no Passeio Público, Curitiba, Paraná, em 1992/93, 1986/87 e 1975, ordenadas conforme a freqüência decrescente de abelhas silvestres (Hymenoptera, Apoidea) capturadas nestas plantas.

\begin{tabular}{|c|c|c|c|}
\hline & PP-92/93 & PP-86/87 & PP-75 \\
\hline Janeiro & $\begin{array}{l}\text { Calliandra selloi } \\
\text { Chlorophytum } \mathrm{sp} . \\
\text { Impatiens } \mathrm{sp}\end{array}$ & $\begin{array}{l}\text { Ligustrum japonicum } \\
\text { Impatiens sp. } \\
\text { Chlorophytum } \mathrm{sp} . \\
\text { Cleome rosea } \\
\text { Butia eriospatha } \\
\text { Calliandra selloi }\end{array}$ & $\begin{array}{l}\text { Butia eriospatha } \\
\text { Ligustrum japonicum } \\
\text { Alpinea henryi } \\
\text { Liriope muscari-variegata } \\
\text { Crocosmia crocosmiflora } \\
\text { Muehlenbeckia platyclada } \\
\text { Polygonum punctatum } \\
\text { Euphorbia splendens } \\
\text { Tibouchina pilosa } \\
\text { Musa sp. }\end{array}$ \\
\hline Fevereiro & $\begin{array}{l}\text { Chlorophytum sp. } \\
\text { Calliandra selloi } \\
\text { Impatiens } \mathrm{sp} \cdot \\
\text { Rhododendron } \\
\text { indicum. } \\
\text { Vassobia breviflora }\end{array}$ & $\begin{array}{l}\text { Calliandra selloi } \\
\text { Impatiens } \mathrm{sp} . \\
\text { Chlorophytum } \mathrm{sp} . \\
\text { Cleome rosea } \\
\text { Vassobia breviflora. } \\
\text { Rhododendron } \\
\text { indicum }\end{array}$ & $\begin{array}{l}\text { Polygonum punctatum } \\
\text { Tibouchina pilosa } \\
\text { Liriope muscari } x \text { variegata } \\
\text { Musa sp. } \\
\text { Alpinea henryi } \\
\text { Crocosmia crocosmiflora } \\
\text { Euphorbia splendens } \\
\text { Muehlenbeckia platyclada }\end{array}$ \\
\hline Março & $\begin{array}{l}\text { Chlorophytum sp. } \\
\text { Calladium sp. } \\
\text { Calliandra selloi. } \\
\text { Tibouchina } \\
\text { sellowiana. } \\
\text { Impatiens sp. } \\
\text { Rhododendron } \\
\text { indicum }\end{array}$ & $\begin{array}{l}\text { Impatiens sp. } \\
\text { Chlorophytum } \mathrm{sp} . \\
\text { Calliandra selloi } \\
\text { Rhododendron } \\
\text { indicum }\end{array}$ & $\begin{array}{l}\text { Polygonum punctatum } \\
\text { Tibouchina pilosa } \\
\text { Muehlenbeckia platyclada } \\
\text { Musa sp. } \\
\text { Crocosmia crocosmiflora } \\
\text { Alpinea henryi. } \\
\text { Euphorbia splendens. } \\
\text { Liriope muscari } x \text { variegata }\end{array}$ \\
\hline Abril & $\begin{array}{l}\text { Tibouchina sellowian } \\
\text { Calladium sp. } \\
\text { Dombeya wallichii. } \\
\text { Chlorophytum } \mathrm{sp} . \\
\text { Calliandra selloi } \\
\text { Rhododendron } \\
\text { indicum }\end{array}$ & $\begin{array}{l}\text { CGalliandra selloi } \\
\text { Rhododendron indicum } \\
\text { Impatiens sp. } \\
\text { Chlorophytum sp. } \\
\text { Vassobia breviflora }\end{array}$ & $\begin{array}{l}\text { Polygonum punctatum } \\
\text { Muelhenbeckia platyclada } \\
\text { Tibouchina pilosa } \\
\text { Musa sp. } \\
\text { Euphorbia splendens } \\
\text { Muelhenbeckia platyclada } \\
\text { Euphorbia splendens }\end{array}$ \\
\hline Maio & $\begin{array}{l}\text { Dombeya wallichii } \\
\text { Calliandra selloi } \\
\text { Rhododendron } \\
\text { indicum } \\
\text { Abutilon mulleri- } \\
\text { friderici } \\
\text { Impatiens sp. } \\
\text { Tibouchina sellowianc }\end{array}$ & $\begin{array}{l}\text { Rhododendron indicum } \\
\text { Calliandra selloi }\end{array}$ & $\begin{array}{l}\text { Muelhenbeckia platyclada } \\
\text { Euphorbia splendens }\end{array}$ \\
\hline
\end{tabular}


Tabela 9 (conclusão)

\begin{tabular}{|c|c|c|c|}
\hline & PP-92/93 & PP-86/87 & PP-75 \\
\hline Junho & $\begin{array}{l}\text { Rhododendron indicum } \\
\text { Dombeya wallichii. } \\
\text { Impatiens } \text { sp. · } \\
\text { Calliandra selloi } \\
\text { Abutilon mulleri-friderici }\end{array}$ & $\begin{array}{l}\text { Rhododendron indicum } \\
\text { Kniphofia uvaria } \\
\text { Dombeya wallichii } \\
\text { Impatiens } \mathrm{sp}\end{array}$ & \\
\hline Julho & $\begin{array}{l}\text { Chlorophytum } \mathrm{sp} . \\
\text { Calliandra selloi } \\
\text { Impatiens } \mathrm{sp} \cdot \\
\text { Rhododendron } \\
\text { indicum. } \\
\text { Vassobia breviflora }\end{array}$ & $\begin{array}{l}\text { Rhododendron indicum } \\
\text { Impatiens sp. } \\
\text { Dombeya wallichii } \\
\text { Kniphofia uvaria }\end{array}$ & $\begin{array}{l}\text { Rhododendron simssi } \\
\text { Euphorbia splendens }\end{array}$ \\
\hline Agosto & $\begin{array}{l}\text { Rhododendron indicum } \\
\text { Abutilon mulleri-friderici }\end{array}$ & $\begin{array}{l}\text { Rhododendron indicum } \\
\text { Impatiens sp. } \\
\text { Kniphofia uvaria }\end{array}$ & Rhododendron simssi \\
\hline Setembro & $\begin{array}{l}\text { Abutilon mulleri-friderici } \\
\text { Rhododendron indicum } \\
\text { Vassobia breviflora } \\
\text { Impatien sp. } \\
\text { Calliandra selloi }\end{array}$ & $\begin{array}{l}\text { Rhododendron indicum } \\
\text { Vassobia breviflora } \\
\text { Impatiens sp. } \\
\text { Kniphofia uvaria } \\
\text { Cleome rosea }\end{array}$ & $\begin{array}{l}\text { Rhododendron simssi } \\
\text { Euphorbia splendens } \\
\text { Spiraea } \mathrm{sp} .\end{array}$ \\
\hline Outubro & $\begin{array}{l}\text { Abutilon mulleri-friderici } \\
\text { Vassobia breviflora } \\
\text { Impatiens sp. } \\
\text { Calliandra selloi. } \\
\text { Rhododendron indicum. } \\
\text { Chlorophytum sp. }\end{array}$ & $\begin{array}{l}\text { Vassobia breviflora } \\
\text { Rhododendron indicum } \\
\text { Impatiens sp. · } \\
\text { Ligustrum lucidum. } \\
\text { Cleome rosea } \\
\text { Chlorophytum sp. } \\
\text { Kniphofia uvaria }\end{array}$ & $\begin{array}{l}\text { Spondia sp. } \\
\text { Euphorbia splendens } \\
\text { Spiraea } \mathrm{sp} . \\
\text { Rhododendron indicum } \\
\text { Polygonum punctatum }\end{array}$ \\
\hline Novembro & $\begin{array}{l}\text { Abutilon mulleri-friderici } \\
\text { Vassobia breviflora } \\
\text { Calliandra selloi } \\
\text { Chlorophytum sp. } \\
\text { Rhododendron indicum }\end{array}$ & $\begin{array}{l}\text { Butia eriospatha } \\
\text { Impatiens sp. } \\
\text { Ligustrum lucidum } \\
\text { Chlorophytum } \mathrm{sp} . \\
\text { Cleome rosea } \\
\text { Rhododendron indicum } \\
\text { Vassobia breviflora }\end{array}$ & $\begin{array}{l}\text { Spiraea } \mathrm{sp.} \\
\text { Spondia sp. } \\
\text { Euphorbia splendens }\end{array}$ \\
\hline Dezembro & $\begin{array}{l}{ }^{\circ} \text { Chlorophytum } \mathrm{sp} . \\
\text { Calliandra selloi } \\
\text { Abutilon mulleri-friderici }\end{array}$ & $\begin{array}{l}\text { Butia eriospatha } \\
\text { Ligustrum japonicum } \\
\text { Cleome rosea } \\
\text { Impatiens sp. } \\
\text { Chlorophytum sp. } \\
\text { Calliandra selloi }\end{array}$ & $\begin{array}{l}\text { Ligustrum japonicum } \\
\text { Euphorbia splendens }\end{array}$ \\
\hline
\end{tabular}

- indica freqüências iguais.

Fontes: PP-75 (Laroca, Cure \& Bortoli, 1982); pp-86/87 (Taura, 1990). 
Em ordem decrescente de abundância de abelhas (fêmeas e machos) coletadas mensalmente, a sucessão das espécies de plantas predominantes nas três amostragens realizadas no PP, apresenta-se conforme a Tabela 9 .

\section{COMENTÁRIOS FINAIS E CONCLUSÕES}

O homem têm alterado sensivelmente o ambiente em que vive, por meio de atividades como desmatamentos, queimadas, práticas agrícolas, urbanização e industrialização.

Em ambientes urbanos, algumas espécies de abelhas podem ser favorecidas, em certas circunstâncias, como por exemplo pela existência de recursos vegetais oriundos de plantas cultivadas e de locais propícios para nidificação, tornando-se assim, relativamente abundantes em locais restritos.

O Passeio Público (PP) é uma pequena "área verde", localizada praticamente no centro de uma cidade, em que se verifica uma urbanização crescente e portanto, exposta a conseqüências decorrentes de atividades humanas como poluição do ar, ruídos, pavimentação, tráfego intenso, presença de visitantes, jardinagem contínua e introdução de espécies vegetais.

A associação de abelhas (Hymenoptera, Apoidea) do PP, possivelmente é influenciada pela localização do mesmo, com limitações em receber novos imigrantes, acentuados por perturbações decorrentes da urbanização e atividades humanas. Assim, nota-se neste local, uma simplificação cada vez maior na composição apifaunística, verificandose decréscimos quanto ao número de espécies capturadas nas três épocas de estudo, isto é, em PP-92/93, PP-86/87 e PP-75. Também, quando comparado com as demais áreas do Planalto de Curitiba, a comunidade de abelhas do PP é a mais reduzida.

Considerando-se as três amostras obtidas no PP, constata-se a predominância de Halictidae em número de espécies, sendo a mesma situação também verificada nas outras áreas do Planalto de Curitiba. A elevada diversidade é observada nesta família tanto ao nível genérico como específico, enquanto que o maior número de espécies é verificada em Dialictus e Augochloropsis.

No PP, as famílias com menor representatividade em termos de número de espécies são Colletidae, Andrenidae e Megachilidae. Esta última apresenta a menor diversidade na amostragem de PP-75, estando 
ausente na de PP-86/87 e PP-92/93, indicando possivelmente a extinção desta do local. Nesta área, verifica-se também a redução gradativa do número de espécies de Colletidae e Andrenidae nos censos de PP-86/87 e PP-92/93, e a ausência de Andrenidae em PP-92/93.

Em número de indivíduos por família de abelhas silvestres, observa-se a predominância de Apidae, especialmente Meliponinae, com elevada frequiência de indivíduos capturados nas flores da maioria das famílias vegetais presentes no local. Entretanto, nas demais localidades do Planalto de Curitiba, o maior número de indivíduos capturados pertence a Halictidae.

No PP, tal situação é devida em parte, à organização das populações de Meliponinae em colônias, com elevado número de indivíduos e hábitos poliléticos, com eficiência de coleta de recursos alimentares em flores de variadas espécies vegetais ao longo do ano, sem interrupção de atividade de vôo durante o inverno. As espécies desta subfamília são também favorecidas por atividades antrópicas, com locais propícios para nidificação em ambientes artificiais, como construções, "paredões" de concreto e o trabalho de preservação das árvores que estavam sendo atacadas por cupins, com a posterior ocupação das cavidades parcialmente preenchidas por cimento pelos ninhos de abelhas desta subfamília. Podem ainda, estar sendo beneficiados pela retirada constante de colônias de Apis mellifera pelos funcionários do PP (devido aos riscos pela sua agressividade para as populações humanas e animais) e assim as cavidades que seriam ocupadas por esta espécie ficam disponíveis para nidificação por outras.

Em relação às espécies predominantemente capturadas, evidenciamse algumas modificações entre as três épocas de estudos realizados no PP. Assim, em PP-92/93 e PP-86/87, a representatividade baseia-se quase que exclusivamente por Apidae, com exceção de Augochlora amphitrite e Augochlorella michaelis, ambos pertencentes à Halictidae, na primeira e segunda amostras citadas, respectivamente.

Em PP-75, nota-se a ocorrência de espécies de Apidae, Halictidae, Colletidae e Andrenidae.

A espécie mais abundantemente capturada em PP-92/93, é $T$. spinipes, enquanto que $P$. emerina consta como a mais freqüente nos levantamentos de PP-86/87 e PP-75.

Verifica-se também a ocorrência de Partamona helleri nas amostras de PP-92/93 e PP-86/87, ausente em PP-75. No PP, observa-se ainda a presença de uma colônia de Lestrimelitta limao, não incluída nas amostragens de PP-92/93, PP-86/87 e PP-75. 
Algumas espécies como Bombus atratus, Neocorynura aenigma, Hylaeus rivalis, Dialictus (Chloralictus) sp.1 e sp. 14, Panurginae sp.1, são consideradas predominantes apenas na amostra de PP-75. No levantamento de PP-92/93, verifica-se a ausência de $H$. rivalis e Panurginae sp.1. A redução na abundância ou mesmo desaparecimento destas abelhas, deve-se possivelmente entre outros fatores, também à retirada de plantas como por exemplo Polygonum punctatum e Muehlenbeckia platyclada, espécies predominantemente visitadas em PP-75 e diminuição da área com solo exposto, devido ao aumento de asfalto.

A variação no número de famílias, assim como de espécies que compõem a flora local e que são visitadas por abelhas silvestres, evidencia modificações na cobertura vegetal pela prática de jardinagem, com renovação contínua de espécies, herbáceas e arbustivas, com a finalidade de se manter a área sempre florida.

Ericaceae é a família que apresenta a maior frequiência de visitas de indivíduos de abelhas silvestres, em PP-92/93 e PP-86/87, em sua maioria representantes de Apidae. No entanto, em termos de número de espécies de abelhas, a família de planta preferencialmente procurada é Liliaceae. Em PP-75, Polygonaceae é a família mais visitada, tanto por indivíduos como por espécies de abelhas. Entretanto, ambas as espécies representantes desta última família de planta mencionada, Muehlenbeckia platycladum e Polygonum punctatum, encontram-se ausentes em PP92/93 e em PP-86/87.

Em PP-92/93 e PP-86/87, Rhododendron indicum é a mais procurada dentre as espécies de plantas predominantemente visitadas, enquanto que em PP-75, a espécie mais requisitada pelas abelhas é $P$. punctatum.

A comparação entre os três levantamentos do PP, indica variação na preferência de espécies de plantas freqüentadas pelas abelhas, e mesmo espécies como Butia eriospatha, Euphorbia splendens, Ligustrum japonicum, Tibouchina sellowiana e Vassobia breviflora, comuns às três épocas de estudo, apresentam-se como predominantemente visitadas em apenas uma ou no máximo duas das amostras. Isto se deve à prática de jardinagem, com constantes podas de ramos e galhos, cultivo maior ou menor de determinadas espécies durante certo período de tempo e substituição constante de plantas do local.

As espécies de abelhas poliléticas são possivelmente as mais favorecidas na área de estudo, com recursos florais diversificados disponíveis ao longo do ciclo anual. 
Em termos de fenologia, observa-se no PP que Halictidae, Xylocopinae e Apidae apresentam atividades de adultos em todas as estações do ano, enquanto que Colletidae e Andrenidae interrompem a atividade de vôo durante o inverno, constituindo-se em dois grupos fenologicamente distintos. As famílias Anthophoridae e Megachilidae, apesar de terem sido coletadas no inverno, encontram-se representadas por apenas um indivíduo cada, sendo um exemplar de Exomalopsis villipes e um de Megachile sp. 2, respectivamente.

As espécies de Apoidea apresentam, no PP-92/93, atividade mais elevada durante os meses mais quentes do ano, ou seja, durante o verão e a primavera, épocas em que se verifica também a maior diversidade de plantas floridas, e acentuada redução durante os meses mais frios. A mesma tendência é constatada também em PP-86/87 e PP-75, a qual encontra-se coerente com o padrão descrito por SAKAGAMI, LAROCA \& Moure (1967) para São José dos Pinhais e Laroca (1972) para Boa Vista, Curitiba, ambos no Estado do Paraná, que se caracteriza pela diminuição do número de espécies em atividade durante o período de inverno.

As oscilações observadas nas atividades de abelhas, tanto em relação ao número de espécies quanto de indivíduos, são também influenciadas por condições climáticas desfavoráveis no período de coleta. Também, nos meses mais frios do ano, compreendidos entre junho e agosto, quando ocorre redução de atividade de vôo de abelhas, em dias ensolarados e propícios, podem ser capturados muitos indivíduos e um número razoável de espécies, geralmente pertencentes à Apidae.

A realização de levantamentos em um mesmo local, durante épocas distintas, possibilita o conhecimento mais preciso sobre a estrutura da comunidade de abelhas, tendências fenológicas, relações com as flores, bem como de espécies que sobrevivem ao longo do tempo e fatores responsáveis pelas modificações, preferencialmente em biótopos urbanos, os quais se encontram sujeitos à mudanças imprevisíveis. Conseqüentemente, torna-se importante e necessária a realização de estudos similares em locais variados, pois, estes são extremamente reduzidos até o presente momento.

\section{BIBLIOGRAFIA}

Almeida, M. C. \& S. Laroca. 1988. Trigona spinipes (Apidae, Meliponinae): Taxonomia, bionomia e relações tróficas em áreas restritas. Acta Biol. Par., Curitiba, 17 : 67-108. 
Armbruster, W. S. \& D. A. Guinn. 1989. The solitary bee fauna (Hymenoptera: Apoidea) of interior and arctic Alaska : flower associations, habitat use, and phenology. J. Kans. Entomol. Soc. $62(4): 468-483$.

BAKer, H. G. \& P. D. Hurd, Jr. 1968. Intrafloral ecology. Ann. Rev. Entomol. $13: 385-414$.

Bárbola, I. DE F. 1993. A Comunidade de Apoidea (Hymenoptera) da Reserva Passa Dois (Lapa, Paraná) : Diversidade, Fenologia e Relações tróficas. Tese de Mestrado. Univ. Fed. do Paraná. 103 pp.

BATRA, S. W. T. 1993. India's buzzy biodiversity of bees. Current Science 65 (3) : 277 - 280.

BAZILIO, S. 1997. Melissocenose de uma área restrita de Floresta de Araucária do Distrito do guará (Guarapuava, PR). Tese de Mestrado. Univ. Fed. do Paraná. 103 pp.

Bortoli, C. de \& S. Laroca. 1990. Estudo biocenótico em Apoidea (Hymenoptera) de uma área restrita em São José dos Pinhais (PR, Sul do Brasil), com nota comparativas. Dusenia 15 : 1-112.

CAmargo, J. M. F. de \& M. Mazucato. 1984. Inventário da apifauna e flora apícola de Ribeirão Preto, SP, Brazil. Dusenia 14 (2) : 55-87.

CAmpos, M. J. O. 1989. Estudo das interações entre a comunidade de Apoidea, na procura de recursos alimentares, e a vegetação de cerrado da reserva de Corumbataí, $S$. P. Tese de Doutorado. Univ. Fed. de São Carlos, S. P., Brazil. 114 pp.

Carvalho, A. M. C. \& L. R. Bego. 1996. Studies on Apoidea fauna of cerrado vegetation at the Panga Ecological Reserve, Uberlândia, MG, Brazil. Revta bras. Ent. 40 (2) : 147-156.

Celery, W. 1988. Wild bees (Hymenoptera, Apoidea) of the Bedkowska Valley (Krakow-Czestochowa Upland). Part I. Colletidae, Halictidae. Acta Biológica Cracoviensia, Zoologia 30 : 1-17.

Celery, W. 1991. Wild bees (Hymenoptera, Apoidea) of the Bedkowicw Valley (Krakow-Cze stochova Upland). Part 2. Andrenidae, Mellitidae, Megachilidae, Anthophoridae, Apidae. Acta Biológica Cracoviensia, Series : Zoologia 33 : 19-37.

Constantinescu, A. 1976. Ord. Hymenoptera, Apoidea (Fam. Colletidae, Halictidae, Mellitidae, Megachilidae et Apidae) in L'entomofaune du Nord de la Dobrogea, la zone Mãcin - Tulcea - Niculitel. Travaux du Muséum d'Histoire Neturelle "Grigore Antipa” 17 : 153158. 
CREPET, W. L. 1983. The role of insect pollination in the evolution of the angiosperms. Pp. 31-50. In L. Real (ed.), Pollination Biology. Orlando, Flórida, Academic Press.

CURE, J. R. 1983. Estudo ecológico de comunidade de abelhas silvestres (Hymenoptera, Apoidea) do Parque da Cidade , comparado ao de outras áreas de Curitiba, Paraná. Tese de Mestrado. Univ. Fed. do Paraná. 100 pp.

Cure, J. R. ; M. Thiengo; F. A. Silveira \& L. B. Rocha. 1992. Levantamento da fauna de abelhas silvestres na "Zona da Mata" de Minas Gerais. III. Mata Secundária na região de Viçosa (Hymenoptera, Apoidea). Revta bras. Zool. 9 (3/4) : 223-239.

DoRn, M. 1977. Ergebnisse faunistisch - ökologischer untersuchungen an solitären Apoidea (Hymenoptera) im Botanischen Garten der Martin - Luther - Universität in Halle (Saale). Hercynia N. F. , Leipzig 14 (2) : 196-211.

DRESSLER, R. L. 1967. Why do euglossine bees visit orchid flowers? Atas do Simpósio sobre a Biota Amazônica. 5 : 171-180.

Faegri, K. \& L. van der PiJl. 1979. The Principles of Pollination Ecology. Oxford, Pergamon Press. 244 pp.

FEINSINGER, P. 1983. Coevolution and pollination. In D. J. FUTUYMA \& M. SLATKIN (eds.), Coevolution, pp. 282 - 310. Sunderland, Massachusetts, Sinauer Associates.

Ferreira, J. C. V. 1996. O Paraná e seus Municípios. Maringá, PR., Memória Brasileira. 728 pp.

GINSBERG, H. S. 1981. Historical development of bee foraging patterns in central New York State. Psyche. 88 (3/4) : 337-346.

Ginsberg, H. S. 1983. Foraging ecology of bees in an old field. Ecology. 64 (1) : 165-175.

Haeseler, von V. 1972. Anthropogene biotope (Kahlschlag, Kiesgrube, stadtgärten) als refugien für insekten, untersucht am beispiel der Hymenoptera Aculeata. Zool. Jb. Syst. Bd. 99 (2) : 133-212.

Heinrich, B. 1975. Energetics of pollination. Ann. Rev. Ecology and Systematics 6 : 139-170.

Heithaus, E. R. 1979 a. Community structure of neotropical flower visiting bee and wasps : diversity and phenology. Ecology 60 (1) : 190 202.

Heithaus, E. R. 1979 b. Flower visitation records and resource overlap of bees and wasps in northwest Costa Rica. Brenesia 16 : 9-52. 
Heithaus, E. R. 1979 c. Flower feeding specialization in wild bee and wasp communities in seasonal neotropical habitats. Oecologia 42 : 179-194.

HoldRIDGe, L. R. 1967. Life Zone Ecology. Tropical Science Center, San Jose, Costa Rica. 206 pp.

HunZiKer, A. 1984. Estudios sobre Solanaceae. XIX. Sinopsis de Vassobia. Kurtziana 17 : 91-118.

INOUYE, D. W. 1978. Resource partitioning in bumblebees : experimental studies of foraging behaviour. Ecology 59 : 672-678.

Instituto Brasileiro de Geografia e Estatística. 1996. Anuário Estatístico do Brasil, Rio de Janeiro, vol. 56.

JACOB-RemacLE, A. \& J. P. Jacob. 1990. Intérêt faunistique des sablières de Lorraine belge : l'exemple des Hymenopteres Apoïdes solitaires. Notes Fauniques de Gembloux 21 : 13-22.

Johnson, L. K. S. P. HubBel. 1974. Aggression and competition among stingless bees : Field studies. Ecology 55 : 120-127.

Kato, M.; T. Matsuda \& Z. Yamashita. 1952. Associative ecology of insects found in paddy field cultivated by various planting forms. Sci. Rep. Tohoku Univ., IV (Biol.) 19 : 291 - 301.

KERR, W.E. 1985. Número máximo e mínimo de colônias de Meliponideos que devem ser colocados em um local. Boletim Capel 40 : 7-8.

KERR, W. E. 1987. Determinação do sexo nas abelhas. XVI. Informações adicionais sobre os genes XO, XA e XB. Rev. Brasil. Biol. 47(1/ 2): 111-113.

KERR, W. E.; S. F. SAKAGAMI; R. ZUCCHI; V. PORTUGAL ARAUJO \& J. M. F. de CAMARGO. 1967. Observações sobre a arquitetura dos ninhos e comportamento de algumas espécies de abelhas sem ferrão das vizinhanças de Manaus, Amazonas (Hymenoptera, Apoidea). Atas do Simpósio sobre a Biota Amazônica 5: 255 309.

KerR, W. E. \& R. Vencovski. 1982. Melhoramento genético em abelhas. I. Efeito do número de colônias sobre o melhoramento. Rev. Brasil. Genet. 2 : 279-285.

Kevan, P. G. \& H. G. BAKer. 1983. Insects as flower visitors and pollinators. Ann. Rev. Entomol. 28 : 407-453.

Knoll, A. H. 1986. Patterns of change in plant communities through geological time. In J. DIAMOND and T. J. CASE, eds. Community Ecology, pp. 126-141. New York, Harper \& How. 
Knoll, F. R. N. 1985. Abundância relativa das abelhas no campus da

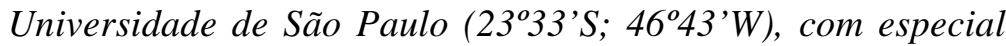
referência à Tetragonisca angustula Latreille. Dissertação de Mestrado, Univ. Fed. de São Paulo. 78 pp.

KNoll, F. R. N. 1990. Abundância relativa, sazonalidade e preferências florais de Apidae (Hymenoptera) em uma área urbana (233' S; 46 $43^{\circ} W$ ). Tese de Doutorado. USP. 127 pp.

KREBS, C. J. 1972. Ecology: The Experimental Analysis of Distribution and Abundance. New York, Harper \& Row Publishers. 694 pp.

Laroca, S. 1972. Estudo Feno-ecológico em Apoidea do Litoral e Primeiro Planalto Paranaenses. Tese de Mestrado. Univ. Fed. Parana. 61 pp.

Laroca, S. 1983. Biocoenotics of Wild Bees (Hymenoptera, Apoidea) at three neartic sites. With comparative notes on some Neotropical Assemblages. Ph. D. Thesis. Kansas University, USA, $194 \mathrm{pp}$.

Laroca, S. 1995. Ecologia : Principios e Métodos. Petrópolis, Vozes. $197 \mathrm{pp}$.

Laroca, S. \& M. C. de Almeida. 1985. Adaptação dos palpos labiais de Niltonia virgilii (Hymenoptera, Apoidea, Colletidae) para a coleta de néctar, em Jacaranda pubérula (Bignoniaceae), com descrição do macho. Revta bras. Ent. 29 (2) : 289-297.

Laroca, S. \& M. C. de Almeida. 1994. O relicto de cerrado de Jaguariaíva (Paraná, Brasil): I. Padrões biogeográficos, melissocenoses e flora melissófila. Acta Biol. Par., Curitiba, 23 : 89-122.

Laroca, S. \& S. LaUer. 1973. Adaptação comportamental de Scaura latitarsis para coleta de pólen (Hymenoptera, Apoidea). Acta Biol. Paranaense, Curitiba, 2 : 147-152.

Laroca, S. \& A. I. Orth. 1984. Pilhagem de um ninho de Plebeia catamarcensis meridionalis por Lestrimelitta limao (Apidae, Meliponinae) em Itapiranga, SC, Sul do Brasil. Dusenia 14 (3) :123-127.

Laroca, S. \& M. L. Winston. 1978. Interaction between Apis and Bombus (Hymenoptera: Apidae) on the flowers of tall thistle; honeybees gather pollen from bodies of bumblebees. J. Kans. Entomol. Soc. 51 (2) : 274-275.

Laroca, S.; V. O. Becker \& F. C. V. Zanella. 1989. Diversidade, abundância relativa e fenologia em Sphingidae (Lepdoptera) na Serra do Mar (Quatro Barras, PR.), Sul do Brasil. Acta Biol. Par., Curitiba, $18: 13-53$. 
Laroca, S. ; J. R. Cure \& C. de Bortoli. 1982. A associação de abelhas silvestres (Hymenoptera, Apoidea) de uma área restrita no interior da cidade de Curitiba (Brasil) : uma abordagem biocenótica. Dusenia 13 (3) : 93-117.

LAROCA, S. ; C. D. Michener \& R. M. HofMeister. 1989. Long mouthparts among "short-tongued"bees and fine structure of the labium in Niltonia (Hymenoptera, Colletidae). J. Kans. Entomol. Soc. 62 (3) : 400-410.

LinsLey, E. G. 1958. The ecology of solitary bees. Hilgardia 27 (19) : 543-599.

Linsley, E. G. \& M. A. Cazier. 1970. Some competitive relationships among matinal and late afternoon foraging activities of caupolicanine bees in southastern Arizona (Hymenoptera, Colletidae). J. Kans. Entomol. Soc. 43 : 251-261.

MaAck, R. 1981. Geografia Física do Estado do Paraná. Curitiba, PR., Pap. Max Roesner Ltda. 350 pp.

MACKAY, P. A. G. KNERER. 1979. Seasonal ocurrence and abundance in a community of wild bees from an old field habitat in Southern Ontario. Can. Entomol. 3 (3) : 367-376.

MackenZie, K. E. \& M. L. Winston. 1984. Diversity and abundance of native bee pollinators on berry crops and natural vegetation in the lower Fraser Valley, British Columbia (Canada). Can. Entomol. 116 (7) : 956-974.

Marchal,J.-L. \& J. Leclerq. 1979. Les Hymenopteres Aculeates Solitaires du Carre de Gembloux (UTM : FS 10). Notes Fauniques de Gembloux 3 : 1-32.

Martins, R. 1995. Terra e Gente do Paraná. Curitiba, Coleção Farol do Saber. 340 pp.

Matsumura, T. \& M. MunaKata. 1969. Relative abundance, phenology and flower preference of andrenid bees at Hakodateyama, Northern Japan (Hymenoptera, Apoidea). Jour. Fac. Sci. Hokkaido Univ. Ser. VI Zool., 17 (1) : 106-126.

Matsuura, M. ; S. F. SaKagami \& H. Fukuda. 1974. A wild bee survey in Kibi (Wakayama Pref.), Southern Japan. Jour. Fac. Sci. Hokkaido Univ. Ser. VI Zool., 19 (2) : 422-437.

Michener, C. D. 1965. A classification of the bees of the Australian and South Pacific regions. Bull. Amer. Mus. Nat. Hist. 130 : 1-362.

Michener, C. D. 1969. Comparative social behavior of bees. Ann. Rev. Entomol. 14 : 299-342. 
Michener, C. D. 1974. The social behavior of the bees. A comparative study. Cambridge, Massachusetts, Harvard University Press. 404 pp.

Michener, C. D. 1979. Biogeography of the bees. Ann. Missouri Bot. Gard. 66 (3) : 277-347.

MoldenKe, A. R. 1976. Evolutionary history and diversity of the bee faunas of Chile and Pacific North America. Wasmann J. Biol. 34 (2) : 147-178.

Morse, D. H. 1977. Resource partitioning in bumble bees : the role of behavioral factors. Science 197 : 678-680.

Moscone, E. A. 1986. Sobre el gineceo de Vassobia (Solanaceae). Bol. Soc. Argent. Bot. 24 (3-4) : 319-331.

MunAKATA, M. 1971. Relative abundance, phenology and flower preference of andrenid bees at Akagawa near Hakodate, Northern Japan (Hymenoptera, Apoidea). Journal of Hokkaido University of Education (Section II B) 22 (1) : 26-39.

Nogueira-Neto, P. 1970. A criação de abelhas indígenas sem ferrão (Meliponinae). $2^{\mathrm{a}}$ ed., São Paulo, Edit. Chácaras e Quintais. 364 pp.

Nogueira-Neto, P. 1997. Vida e criação de abelhas indígenas sem ferrão. São Paulo, Nogueirapis. 445 pp.

Odum, E. P. 1985. Ecologia. Rio de Janeiro, Brasil, Discos CBS. 434 pp.

Orth, A. I. 1983. Estudo ecológico de abelhas silvestres (Hymenoptera, Apoidea) em Caçador, SC, com ênfase em polinizadores potenciais da macieira (Pyrus malus L.) (Rosaceae). Tese de Mestrado. Univ. Fed. Paraná. 135 pp.

Ortolan, S. M. L. S. 1989. Biocenótica em Apoidea (Hymenoptera) de áreas de macieira ( $\underline{\text { Pyrus }} \underline{\text { malus }}$ ) em Lages - Santa Catarina com notas comparativas e experimento preliminar de polinização com Plebeia emerina L. Tese de Mestrado. Univ. Fed. Paraná. 170 pp.

OsychnyUK, A. Z. 1959. Bdjolini (Apoidea) pravoberejnogo stepu Ukaini. Vidavn. Nauk Ukrain. RSR. Kieve. 92 pp.

PaXton, R. 1995. Conserving wild bees. Bee World 76 (2) : 53-55.

Pearson, J. F. W. 1933. Studies on the ecological relations of bees in the Chicago region. Ecological Monographs 3 (3) : 373-441.

Pedro, S. R. M. \& J. M. F. de Camargo. 1991. Interactions on floral resources between the africanized honey bee Apis mellifera L. and the native bee community (Hymenoptera: Apoidea) in a natural "cerrado" ecosystem in southeast Brazil. Apidologie 22 : 397415 . 
Pesenko, Y. A. 1978. On the fauna and ecology of Apoidea (Hymenoptera) of the Lower Don. VII. Phenology, seasonal and diurnal abundance dynamics. Entomol. Rev. 51 (4) : 523-529.

Poole, R. W. 1974. An Introduction to Quantitative Ecology. New York, McGraw-Hill. 532 pp.

Preston, F. W. 1948. The commones and rarity os species. Ecology 29 :254-283.

Price, P. W. 1975. Insect Ecology. New York, John Wiley \& Sons. 514 pp.

PYKE, G. H. 1982. Local geographic distributions of bumblebees near Crested Butte, Colorado : Competition and Community Structure. Ecology 63 (2) : 555-573.

RoubIK, D. W. 1978. Competitive interactions between neotropical pollinators and africanized honey bees. Science 201: 1030-1032.

RouBIK, D. W. 1980. Foraging behavior of competing africanized honey bees and stingless bees. Ecology 61 (4) : 836-845.

Saint-Hilaire, A. 1978. Viagem a Curitiba e Província de Santa Catarina. Belo Horizonte, Itatiaia. 209 pp.

SaKagami, S. F. \& H. Fukuda. 1973. Wild bee survey at the campus of Hokkaido University. J. Fac. Sci. Hokkaido Univ. Ser. VI Zool. 19 (1) : 190-250.

SAKAGAMI, S. F. \& S. LAROCA. 1963. Additional observations on the habits of the cleptobiotic stingless bees, the genus Lestrimelitta Friese (Hymenoptera, Apoidea). J. Fac. Sci. Hokkaido Univ., Ser. VI Zool. 15 (2): 319-339.

SaKagami, S. F. \& S. Laroca. 1971 a. Relative abundance, phenology and flower visits of apid bees in eastern Paraná, Southern Brazil (Hymenoptera, Apidae). Kontyû 39 (3): 217-230.

SAKAGAMI, S. F. \& S. LAROCA. 1971 b. Observations on the bionomics of some neotropical xylocopine bees, with comparative and biofaunistic notes (Hymenoptera, Anthophoridae). J. Fac. Sci. Hokkaido Univ. Ser. VI Zool. 18 (1) : 57-127.

SaKagami, S. F. \& T. Matsumura. 1967. Relative abundance, phenology and flower preference of andrenid bees in Sapporo, North Japan (Hymenoptera, Apoidea). Japan J. Ecol. 17 (6): 237-250.

SaKagami, S. F. \& M. J. Toda. 1986. Some artic and subartic solitary bees collected at Inuvik and Tuktoyaktuk, NWT, Canada (Hymenoptera : Apoidea). Can. Entomol. 118 ( 5) : 395-405. 
Sakagami, S. F. ; S. Laroca \& J. S. Moure. 1967. Wild bee biocoenotics in São José dos Pinhais (PR), South Brazil. Preliminary report. $J$. Fac. Sci. Hokkaido Univ. Ser. VI Zool. 16 (2) : 253-291.

Schaffer, W. M.; D. B. Jensen; D. E. Hobbs; J. Gurevitch; J. R. Todd $\&$ M. V. SCHAFFER. 1979. Competition, foraging energetics, and the cost of sociality in three species of bees. Ecology 60 ( 5) : 976987.

Schaffer, W. M.; D. W. Zeh; S. L. Buchmann; S. Kleinhans; M. V. SCHAFFER \& J. ANTRIM. 1983. Competition for nectar between introduced honey bees and native north american bees and ants. Ecology 64 ( 3) : 564-577.

SchwarTz, D. 1993. A comunidade de abelhas silvestres (Hymenoptera, Apoidea) da Ilha das Cobras (Paraná, Brasil) : aspectos ecológicos e biogeográficos. Tese de Mestrado. Univ. Fed. Paraná. 77 pp.

Silveira, F. A. 1989. Abelhas silvestres (Hymenoptera : Apoidea) e suas fontes de alimento no cerrado da Estação Florestal de Experimentação de Paraopeba - Minas Gerais. Tese de Mestrado. Univ. Fed. de Viçosa. 50 pp.

Silveira, F. A. \& M. J. O. CAmpos. 1995. A melissofauna de Corumbataí (SP) e Paraopeba (MG) e uma análise da biogeografia das abelhas do cerrado brasileiro (Hymenoptera, Apoidea). Revta bras. Ent. 39 (2) : 371-401.

Silveira, F. A. ; L. B. da Rocha; J. R. Cure \& M. J. F. de Oliveira. 1993. Abelhas silvestres (Hymenoptera, Apoidea) da Zona da Mata de Minas Gerais. III. Diversidade, abundância e fontes de alimento em uma pastagem abandonada em Ponte Nova. Revta bras. Ent. 37 (3) : 595-610.

Smith, L. B.; R. J. Downs \& R. M. Klein. 1966. Solanaceas. In: P. R. Reitz (ed.). Flora Ilustrada Catarinense. Itajaí, Santa Catarina. $321 \mathrm{pp}$.

Southwood, T. R. E. 1971. Ecological methods, with particular reference to the study of insect populations. London, Chapman and Hall. $391 \mathrm{pp}$.

Stanley, R. G. \& H. F. Linskens. 1974. Pollen: Biology, Biochemistry, Management. Berlin, Springer-Verlag. 307 pp.

Steiner, K. E. \& V. B. Whitehead. 1990. Pollinator adaptation to oilsecreting flowers - Rediviva and Diascia. Evolution 44(6): 17011707. 
Tascharntke, T. 1984. Bienen (Hymenoptera : Apoidea) des Schnaakenmoors in Hamburg. Entomol. Mitt. Zool. Mus. Hamburg BD. 8 (122) : 7-20.

TAURA, H. M. 1990. A comunidade de abelhas silvestres (Hymenoptera, Apoidea) do Passeio Público, Curitiba, Paraná, Sul do Brasil : uma abordagem comparativa. Tese de Mestrado. Univ. Fed. Paraná. 131 pp.

Taura, H. M. \& S. Laroca. 1991. Abelhas altamente sociais (Apidae) de uma área restrita em Curitiba (Brasil) : Distribuição dos ninhos e abundância relativa. Acta Biol. Par., Curitiba, 20 (1,2,3,4) : 85101.

Tepedino, V. J. \& N. L. Stanton. 1981. Diversity and competition in beeplant communities on short-grass prairie. Oikos 36(1) : 35-44.

THORP, R. W. 1979. Structural, behavioral and physiological adaptations of bees (Apoidea) for collecting pollen. Ann. Missouri Bot. Gard. $66: 788-812$.

Thorp, R. W. \& D. L. BRIGgs. 1980. Bees collecting pollen from other bees (Hymenoptera, Apoidea). J. Kans. Entomol. Soc. 53 (1) : $166-170$.

TisHLER, W. 1973. Ecology of arthropod fauna in man-made habitats : the problem of synanthropy. Zool. Anz., Leipzig, 109 (3/4) : 157-161.

Torres, F. ; S. F. Gayubo \& E. Asencio. 1989. Efecto de la presion urbana sobre abejas y avispas (Hymenoptera, Aculeata) en Salamanca. V. Superfamilia Apoidea. Instituto Nacional de Investigaciones Agrarias. Madrid, España. 49 pp.

Uehira, Y. ; Y. Akahira \& S. F. Sakagami. 1979. A wild bee survey in Kiritappu Highmoor, eastern Hokkaido. Low Temp. Sci., B. 37 : 47-57.

Usui, M. ; Y. Nishijima; H. Fukuda \& S. F. Sakagami. 1976. A wild bee survey in Obihiro, eastern Hokkaido. Res. Bull. Obihiro Univ. 10 (1) : 225-251.

PIJL, L. VAN DER. 1960. Ecological aspects of flower evolution. I. Phyletic evolution. Evolution 14 (4) : 403-416.

PIJL, L. VAN DER. 1961. Ecological aspects of flower evolution. II. Zoophilous flower classes. Evolution 15 (1) : 44-59.

Vogel, S. \& C. D. Michener. 1985. Long bees legs and oil-producing floral spurs, and a new Rediviva (Hymenoptera, Melittidae; Scrophulariaceae). J. Kans. Entomol. Soc. 58 (2) : 359-364.

Whiting, P. W. 1943. Multiple alleles in complementray sex determination in Habrobracon. Genetics 28 : 365-382. 
Williams, I. H. ; S. A. Corbet \& J. L. Osborne. 1991. Beekeeping, wild bees and pollination in the European Community. Bee World 72 (4) : 170-180.

WILson, E. O. 1972. The Insects Societies. Cambridge, Harvard Univ. Press. 548 pp.

Wilson, E. O. 1994. Diversidade da vida. São Paulo, Companhia das Letras. 447 pp.

Yamauchi, K. ; K. Okumura \& S. F. Sakagami. 1976. Biofaunistic survey of wild bees in Hida-Hagiwara (Gifu Prefecture) central Japan. Science Report of the Faculty of Education, of Gifu University (Natural Science) 5 (5) : 413-423.

ZANELLA, F. C. V. 1991. Estrutura da comunidade de abelhas silvestres (Hymenoptera, Apoidea) da Ilha do Mel, Planície Litorânea Paranaense, Sul do Brasil, com notas comparativas. Tese de Mestrado. Univ. Fed. Paraná. 88 pp.

Recebido em: 20.12.2000. 